\author{
OAK RIDGE \\ NATIONAL LABORATORY
}

MANAGED BY UT-BATTELLE

FOR THE DEPARTMENT OF ENERGY
ORNL/CF-04/06

\section{Results From ORNL Characterization of German Reference Fuel From \\ EUO 2358-2365 \\ Composite}

\author{
J. D. Hunn
}

April 2004

This report was prepared as an account of work sponsored by an agency of the United States Government. Neither the United States Government nor any agency thereof, or any of their employees, makes any warranty, expressed or implied, or assumes any legal liability or responsibility for any third party's use, or the results of such use, of any information, apparatus, product or process disclosed in this report, or represents that its use by such third party would not infringe privately owned rights. 


\section{DOCUMENT AVAILABILITY}

Reports produced after January 1, 1996, are generally available free via the U.S. Department of Energy (DOE) Information Bridge.

Web site http://www.osti.gov/bridge

Reports produced before January 1, 1996, may be purchased by members of the public from the following source.

National Technical Information Service

5285 Port Royal Road

Springfield, VA 22161

Telephone 703-605-6000 (1-800-553-6847)

TDD 703-487-4639

Fax 703-605-6900

E-mail info@ntis.fedworld.gov

Web site http://www.ntis.gov/support/ordernowabout.htm

Reports are available to DOE employees, DOE contractors, Energy Technology Data Exchange (ETDE) representatives, and International Nuclear Information System (INIS)

representatives from the following source.

Office of Scientific and Technical Information

P.O. Box 62

Oak Ridge, TN 37831

Telephone 865-576-8401

Fax 865-576-5728

E-mail reports@adonis.osti.gov

Web site http://www.osti.gov/contact.html

This report was prepared as an account of work sponsored by an agency of the United States Government. Neither the United States Government nor any agency thereof, nor any of their employees, makes any warranty, express or implied, or assumes any legal liability or responsibility for the accuracy, completeness, or usefulness of any information, apparatus, product, or process disclosed, or represents that its use would not infringe privately owned rights. Reference herein to any specific commercial product, process, or service by trade name, trademark, manufacturer, or otherwise, does not necessarily constitute or imply its endorsement, recommendation, or favoring by the United States Government or any agency thereof. The views and opinions of authors expressed herein do not necessarily state or reflect those of the United States Government or any agency thereof. 
ORNL/CF-04/06

Revision 0

\title{
Results from ORNL Characterization of German Reference Fuel from the EUO 2358-2365 Composite
}

\author{
John D. Hunn \\ Oak Ridge National Laboratory
}

This document is a compilation of the characterization data obtained on a sample of TRISOcoated $500 \mu \mathrm{m} \mathrm{UO}_{2}$ produced by the Germans and obtained by the AGR program for use as a reference material. This sample came from the EUO 2358-2365 composite studied by General Atomics (GA) and referenced in GA document \#910852 "Acceptance Test report for German Fuel Particles." The ORNL designation for the material characterized was AGR-06. 


\section{Table of Contents}

$1 \quad$ Breaking Off Coating Fragments __ 3

$2 \quad$ Size and Shape Measurements __ 13

2.1 Size and shape of kernels ___ 13

2.2 Size and shape of coated particles ___ 15

2.3 Size and shape after removing $\mathrm{OPyC}$

$3 \quad$ Measurement of Coating Thicknesses _ 22

3.1 Kernel diameter _ 23

3.2 Buffer thickness __ 24

3.3 IPyC thickness _ 26

3.4 SiC thickness__ 27

3.5 OPyC thickness___ 28

3.6 Total particle radius___ 30

4 Density Measurement _ 31

4.1 Kernel density____ 31

4.2 Buffer and IPyC density ___ 31

4.3 SiC density _ 32

4.4 OPyC density ___ 33

4.5 Particle Density___ 37

5 Optical Anisotropy Measurements _ 38

$6 \quad$ TEM Analysis of PyC Layer __ 41

$7 \quad$ SEM Analysis__ 44

7.1 SEM of kernels ___ 44

7.2 SEM of coated particles _ 50

$8 \quad$ Summary and Comparison to HOBEG and GA Data _ 57

9 Appendix A: 2-MGEM Data Report __ 59 


\title{
1 Breaking Off Coating Fragments
}

\author{
J.D. Hunn, D.L. Barker, and N. Hashimoto
}

Several measurements required that the particle coatings be broken away from the kernel. This was done by placing several particles at a time into a stainless steel cylindrical dye and applying light pressure with a stainless steel cylindrical ram. The particles were fractured between the two flat surfaces of the cylinders. In most cases, the coating layers separated cleanly at the kernel/buffer interface. However, pieces could also be found that had separated at the silicon carbide/outer pyrocarbon (SiC/OPyC) or the buffer/inner pyrocarbon (IPyC) interface. It is believed that the clean buffer/IPyC separation is due to a special layer between the buffer and IPyC. This special layer can be seen in the polished cross section images in section 7.2.

Figure 1-1 through Figure 1-5 show a coating fragment that separated at the kernel/buffer interface in SE (secondary electron) and BSE (backscattered electron) imaging modes. Figure 1-1 shows the smooth inner surface of the buffer where the buffer separated cleanly from the kernel. Figure 1-5 shows the $\mathrm{SiC}$ fracture surface at high magnification. The fracture was mostly intragranular fracture along cleavage planes, although some facets were observed indicating intergranular fracture occurred as well.

Figure 1-6 through Figure 1-9 show a coating fragment that separated at the buffer/IPyC interface. The inner surface of the IPyC was rough and there may be some pieces of buffer still attached in places. 
ORNL/CF-04/06

Revision 0
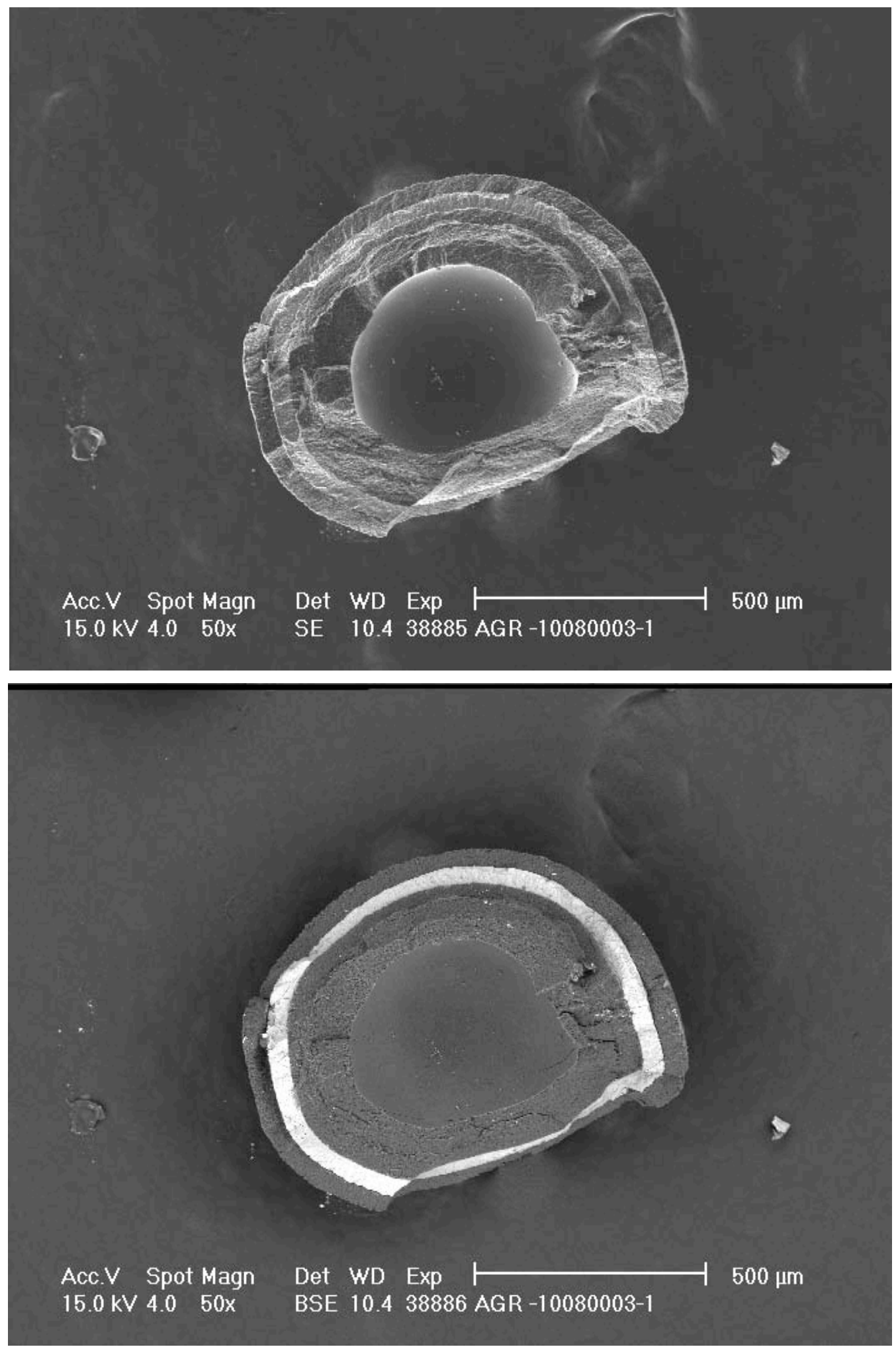

Figure 1-1: Buffer/IPyC/SiC/OPyC coating removed from kernel 
ORNL/CF-04/06

Revision 0
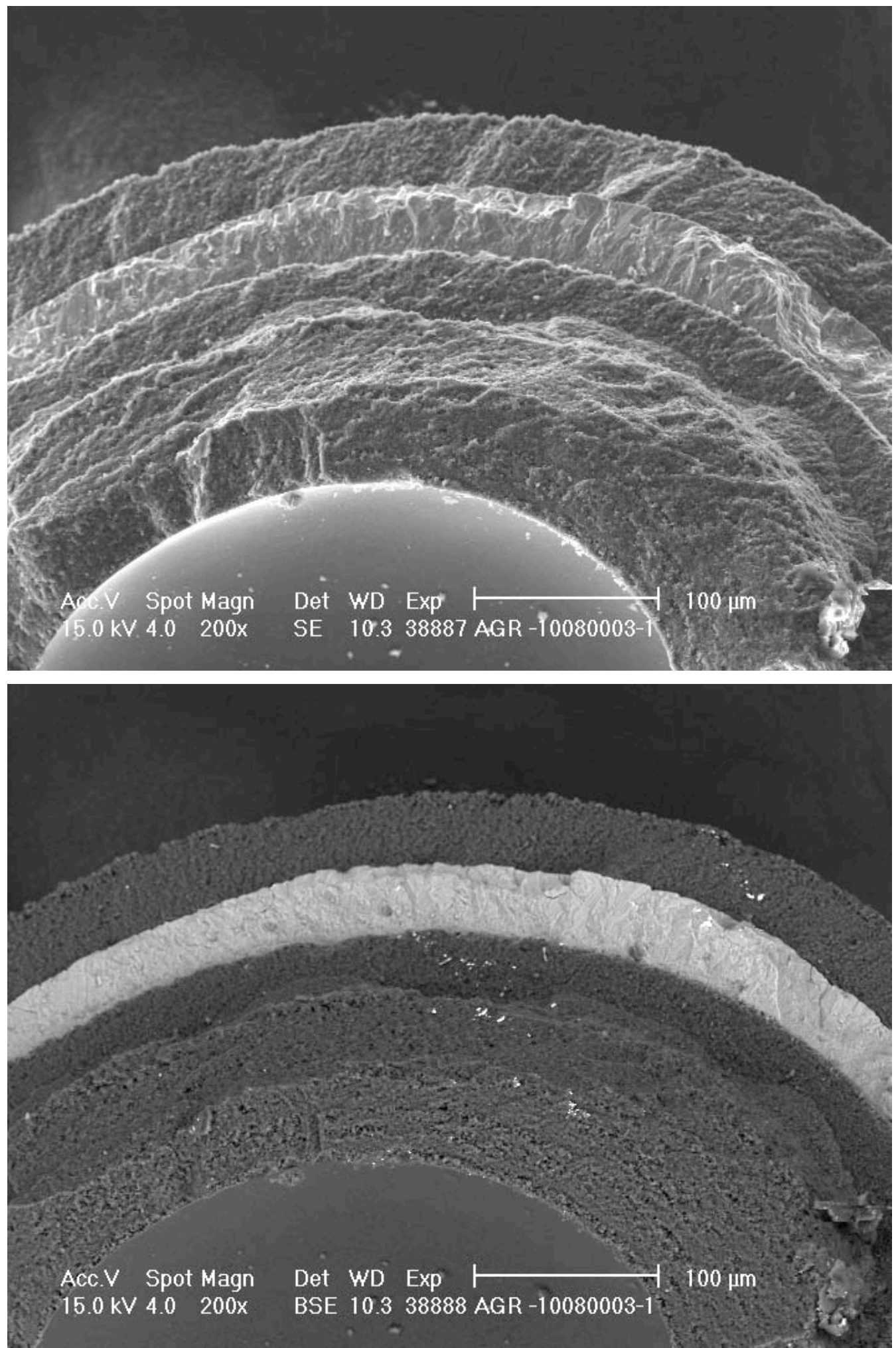

Figure 1-2: Buffer/IPyC/SiC/OPyC coating removed from kernel 
ORNL/CF-04/06

Revision 0
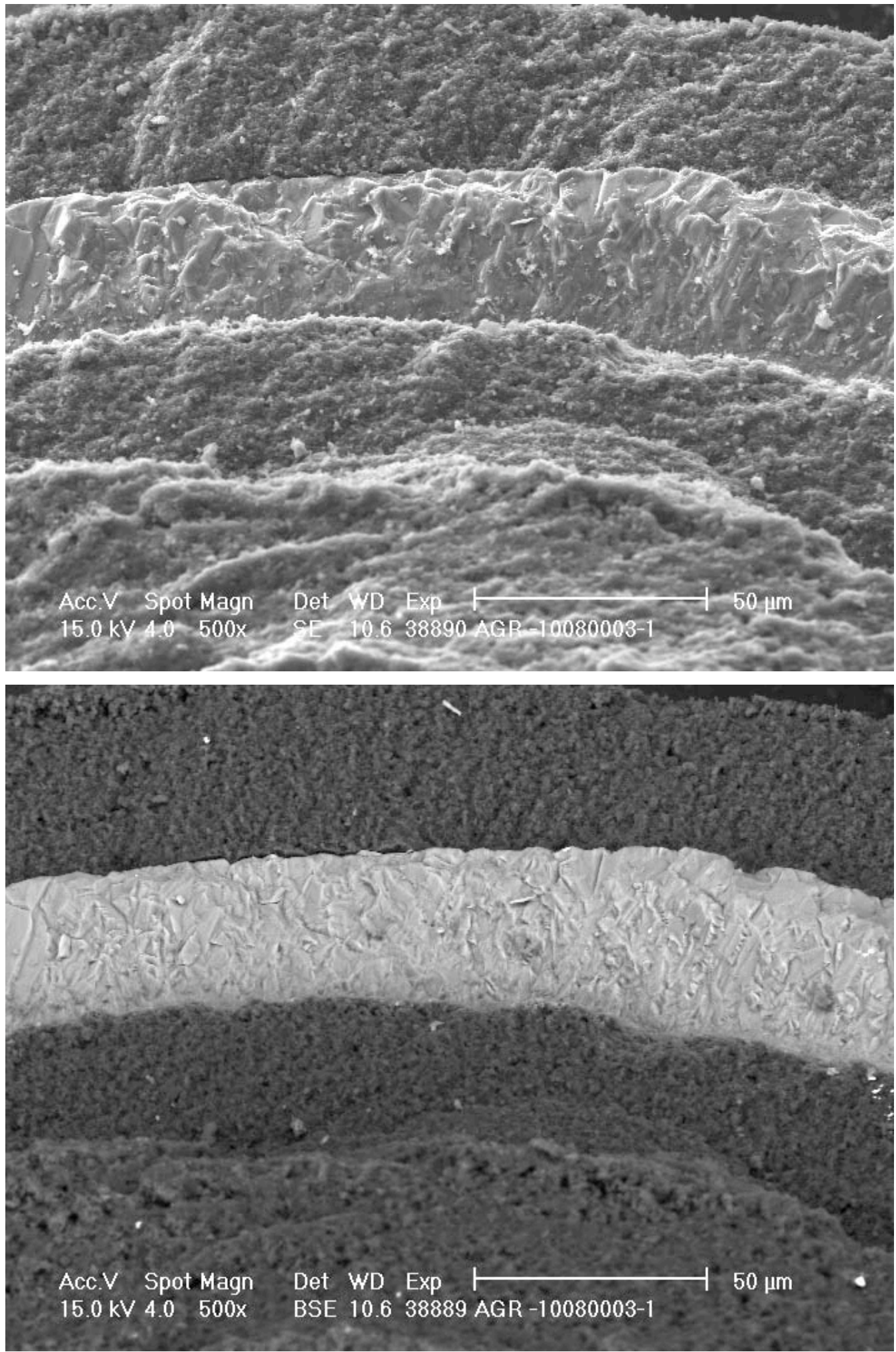

Figure 1-3: Buffer/IPyC/SiC/OPyC coating removed from kernel 
ORNL/CF-04/06

Revision 0
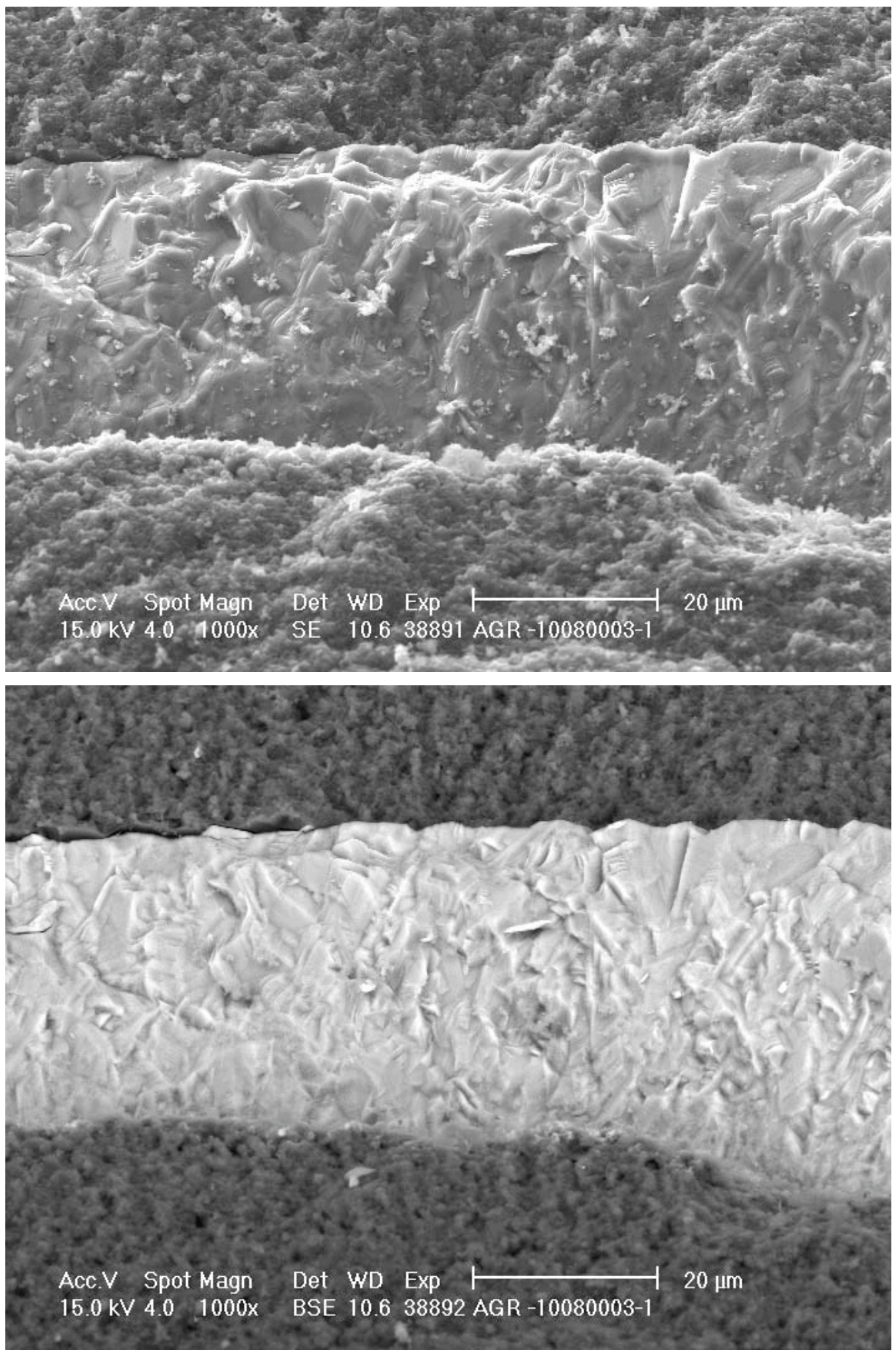

Figure 1-4: IPyC/SiC/OPyC fracture surface 
ORNL/CF-04/06

Revision 0
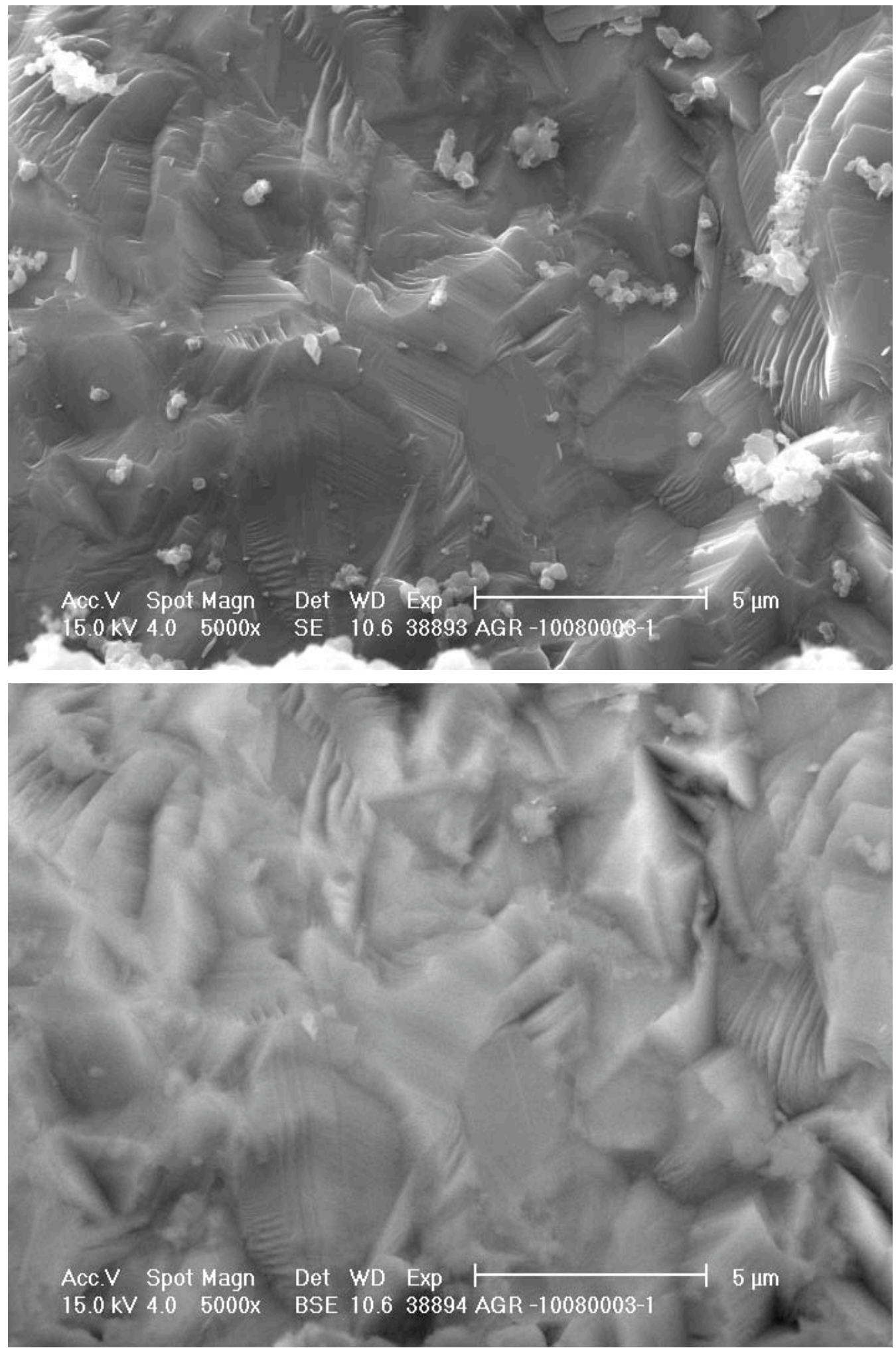

Figure 1-5: $\mathrm{SiC}$ fracture surface 
ORNL/CF-04/06

Revision 0
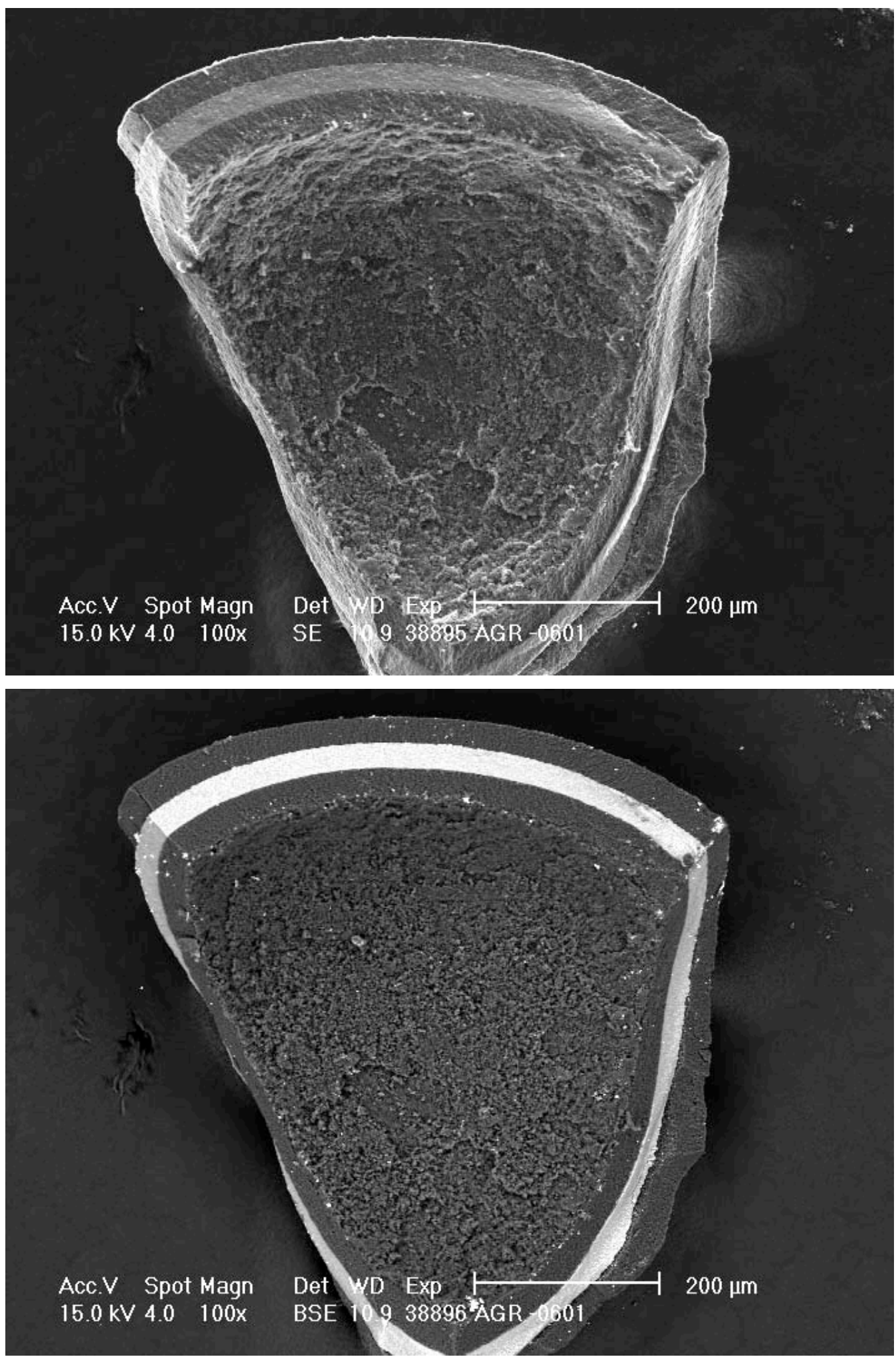

Figure 1-6: $\mathrm{IPyC} / \mathrm{SiC} / \mathrm{OPyC}$ coating removed from buffer 
ORNL/CF-04/06

Revision 0
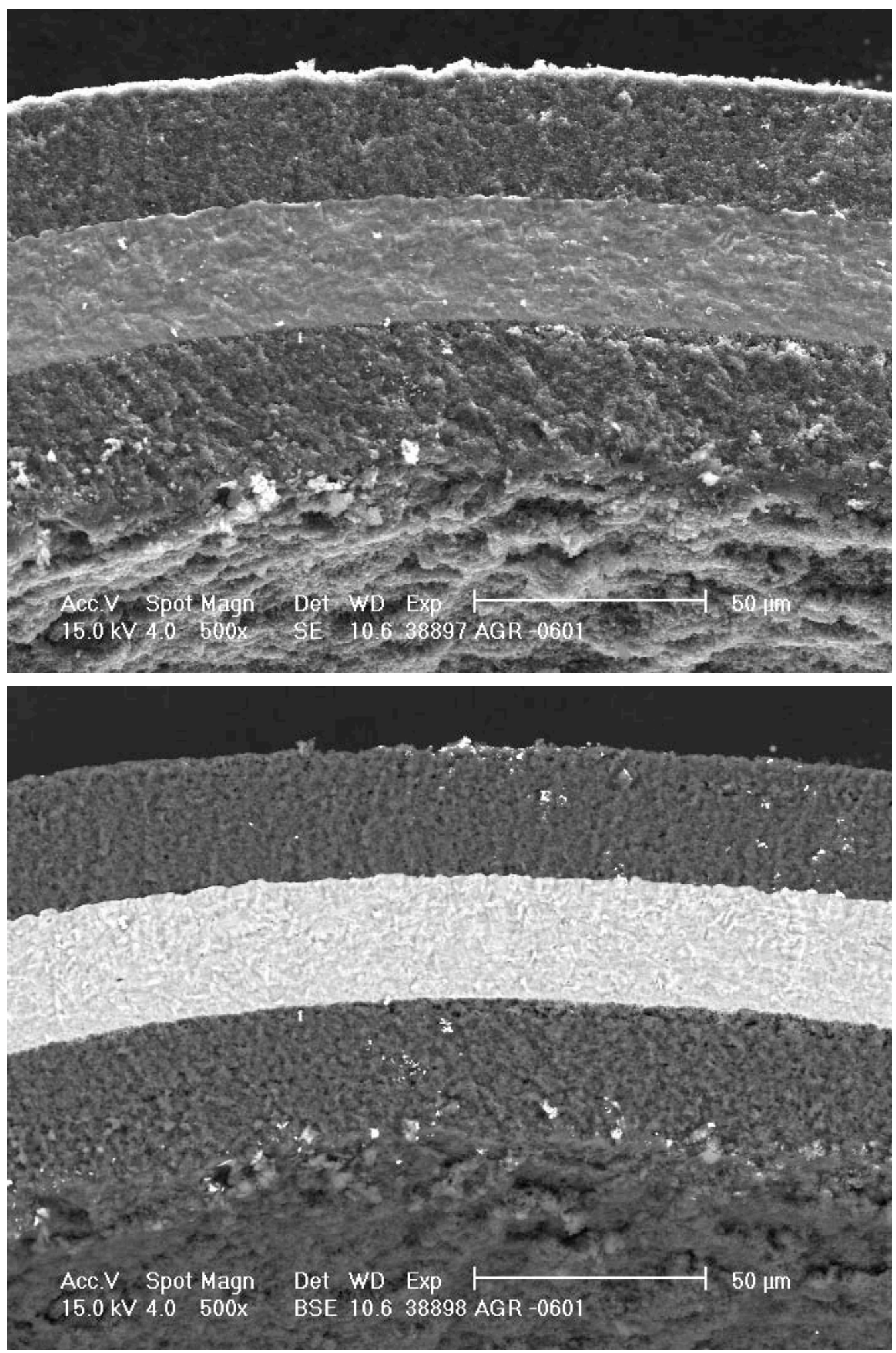

Figure 1-7: $\mathrm{IPyC} / \mathrm{SiC} / \mathrm{OPyC}$ coating removed from buffer 
ORNL/CF-04/06

Revision 0
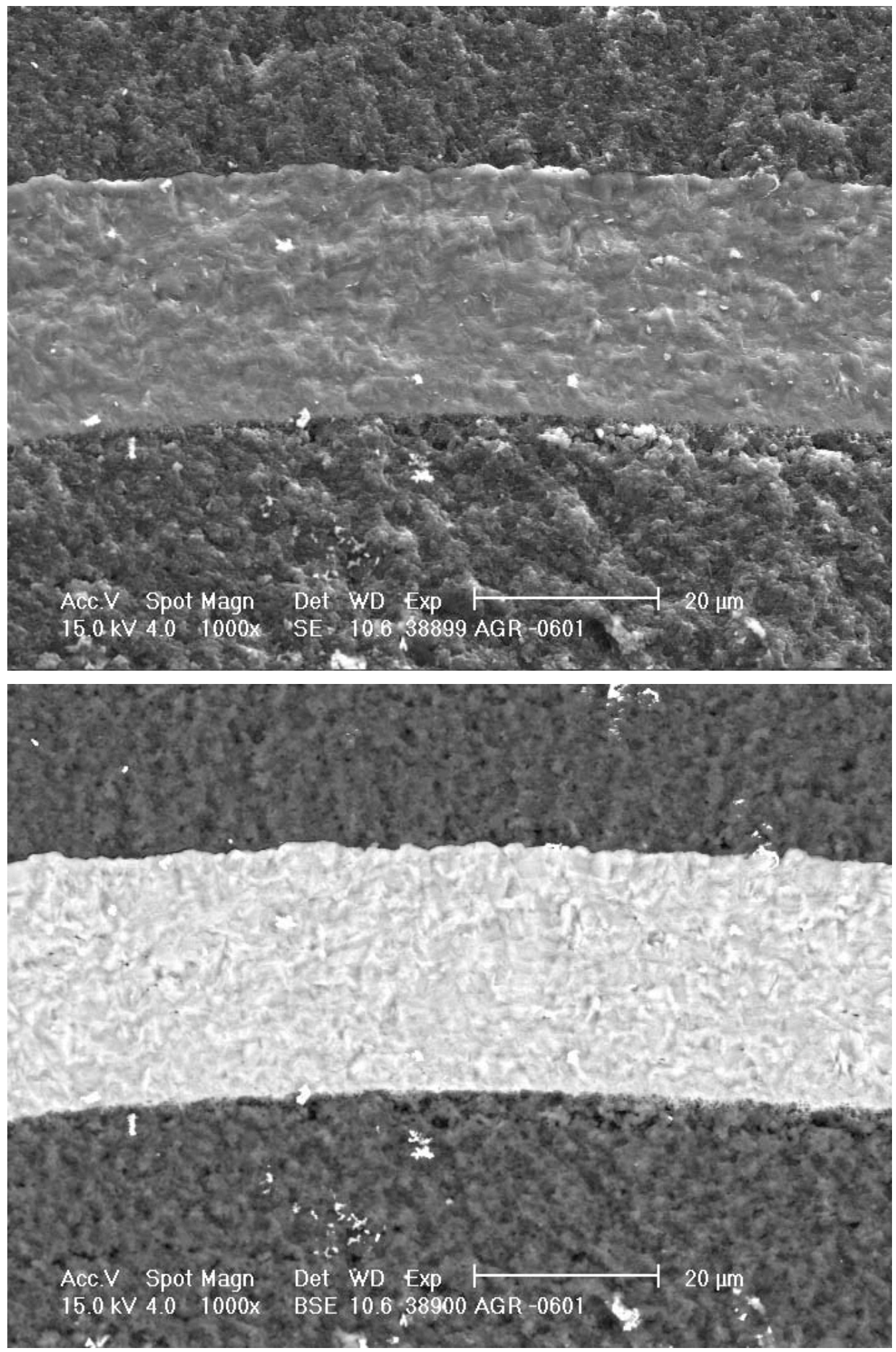

Figure 1-8: IPyC/SiC/OPyC fracture surface 
ORNL/CF-04/06

Revision 0
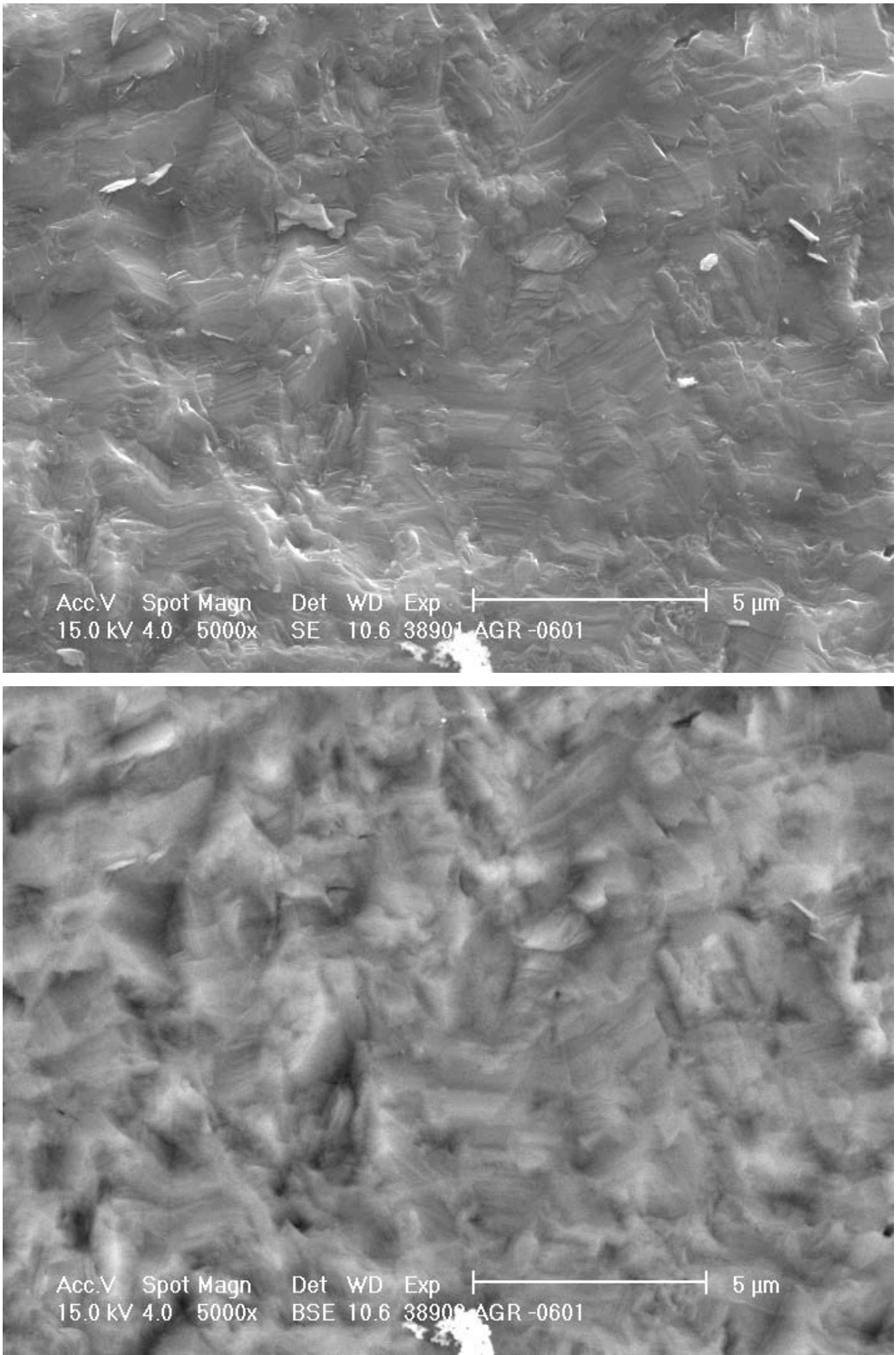

Figure 1-9: SiC fracture surface 


\title{
2 Size and Shape Measurements
}

\author{
J.D. Hunn, A.K. Kercher, and J.R. Price
}

\subsection{Size and shape of kernels}

Shadow images for a random orientation of 6704 kernels (about $4.7 \mathrm{~g}$ ) extracted from AGR06 were obtained. Image analysis software was used to find the center of each kernel and identify 360 points around the perimeter. The uncertainty for this measurement was $\pm 1 \mu \mathrm{m}$. This data was then compiled to report sphericity (maximum radius/minimum radius), mean diameter, standard deviation in diameter, maximum diameter, and minimum diameter for each kernel measured. The summary data from each kernel in the sample was then compiled to obtain the average, standard deviation, maximum, and minimum of the individual kernel quantities (sphericity, mean diameter, standard deviation in diameter, maximum diameter, and minimum diameter).

Figure 2-1 contains the summary data and shows the distributions of the kernel sphericity and mean kernel diameter. Note that with this technique we actually measured the radius of the kernel. In the table we simply multiplied the radius by two in order to report the numbers in terms of diameter. This was done because these values are usually specified and reported in terms of diameter. The error introduced by making this conversion was small because the kernel cross sections were fairly symmetrical.

The measured kernels had an average mean diameter of $506 \mu \mathrm{m}$ with a standard deviation in the distribution of $8 \mu \mathrm{m}$. The distribution was close to Gaussian. Based on variable sampling statistics, we expect the average mean diameter of the German kernels to be $504-508 \mu \mathrm{m}$ with 95\% confidence. Less than $1 \%$ of the kernels measured had mean diameters outside the range $485-525 \mu \mathrm{m}$. The largest kernel measured had a mean diameter of $565 \mu \mathrm{m}$. The smallest kernel had a mean diameter of $472 \mu \mathrm{m}$.

The average sphericity of the kernels was 1.05 with a standard deviation of 0.02 . Note that the sphericity distribution was also close to Gaussian with a tail toward higher sphericity. More than $52 \%$ of the kernels measured had a sphericity greater than 1.05. Sphericities above 1.05 were usually associated with kernels with oval cross sections. 
ORNL/CF-04/06

Revision 0

\begin{tabular}{|c|c|c|c|c|c|}
\hline & Sphericity & Mean Diameter & St. Dev. In Diameter & Maximum Diameter & Minimum Diameter \\
\hline Average & 1.05 & 506 & 6 & 517 & 492 \\
\hline Standard Deviation & 0.02 & 8 & 3 & 7 & 11 \\
\hline Maximum & 1.16 & 565 & 17 & 571 & 555 \\
\hline Minimum & 1.01 & 472 & 1 & 488 & 447 \\
\hline
\end{tabular}

\begin{tabular}{|c|c|}
\hline Sphericity & Frequency \\
\hline 1 & 0 \\
\hline 1.01 & 2 \\
\hline 1.02 & 203 \\
\hline 1.03 & 779 \\
\hline 1.04 & 1069 \\
\hline 1.05 & 1143 \\
\hline 1.06 & 1163 \\
\hline 1.07 & 995 \\
\hline 1.08 & 610 \\
\hline 1.09 & 377 \\
\hline 1.1 & 208 \\
\hline 1.11 & 79 \\
\hline 1.12 & 35 \\
\hline 1.13 & 19 \\
\hline 1.14 & 9 \\
\hline 1.15 & 2 \\
\hline 1.16 & 3 \\
\hline More & 0 \\
\hline Mean Diameter & Frequency \\
\hline 470 & 0 \\
\hline 475 & 3 \\
\hline 480 & 3 \\
\hline 485 & 11 \\
\hline 490 & 88 \\
\hline 495 & 414 \\
\hline 500 & 1036 \\
\hline 505 & 1584 \\
\hline 510 & 1728 \\
\hline 515 & 1108 \\
\hline 520 & 513 \\
\hline 525 & 162 \\
\hline 530 & 34 \\
\hline 535 & 8 \\
\hline 540 & 3 \\
\hline 545 & 0 \\
\hline 550 & 0 \\
\hline 555 & 0 \\
\hline 560 & 0 \\
\hline 565 & 1 \\
\hline More & 0 \\
\hline
\end{tabular}
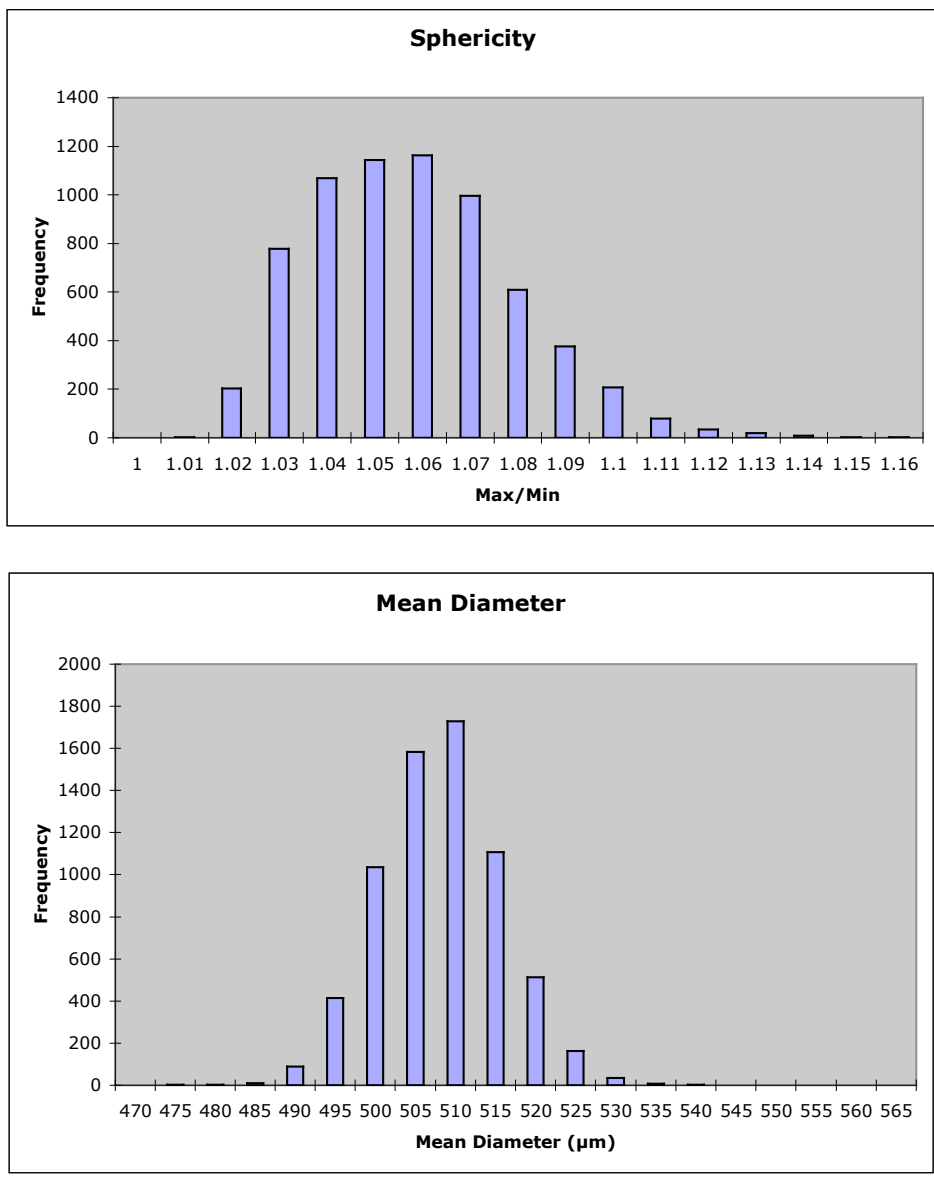

Figure 2-1: Size and shape summary for kernels extracted from German reference fuel. Reported diameters are actually two times measured radii. Diameters are in $\mu \mathrm{m}$. 
ORNL/CF-04/06

Revision 0

\subsection{Size and shape of coated particles}

Shadow images were obtained for a random orientation of 1118 coated particles (about $1.5 \mathrm{~g}$ ) riffled from AGR-06. Image analysis as described above was used to measure the size and shape of the particles. Figure 2-2 contains the compiled data and shows the distributions of the particle sphericity and mean particle radius. In reporting the data for the particle size and shape, we left the results in terms of the measured radius, rather than multiplying by two to estimate the diameter. The faceting of the coated particles was such that it was more appropriate to report the data in terms of radius.

The measured particles had an average mean radius of $461 \mu \mathrm{m}$ with a standard deviation in the distribution of $12 \mu \mathrm{m}$. The distribution was close to Gaussian. Based on variable sampling statistics, we expect the average mean radius of the German particles to be $460-462 \mu \mathrm{m}$ with $95 \%$ confidence. Less than $1 \%$ of the particles measured had mean radius outside the range 445 $485 \mu \mathrm{m}$. The largest particle measured had a mean radius of $501 \mu \mathrm{m}$. The smallest particle had a mean radius of $425 \mu \mathrm{m}$. The minimum mean radius of $425 \mu \mathrm{m}$ suggested that no particles measured are missing more than $80 \%$ of their $100 \mu \mathrm{m}$ thick buffer layer uniformly around the particle. However, the more aspherical particles exhibited local radii of as low as $391 \mu \mathrm{m}$, which could indicate that more than $80 \%$ of the buffer is missing at that location.

The average sphericity of the particles was 1.09 with a standard deviation of 0.02 . Note that the sphericity distribution was also close to Gaussian with a tail toward higher sphericity. More than $59 \%$ of the particles measured had a sphericity greater than 1.085 . Less than $1 \%$ above 1.085 is the preliminary AGR fuel specification for particle aspect ratio (sphericity). Higher sphericities were associated with faceted particles. Figure 2-3 shows some particles with high aspect ratios. The yellow circle in each figure is a best circle fit to the perimeter of each particle.

Figure 2-4 and Figure 2-5 show results from the two separately riffled batches that made up the 1118 particles summarized in Figure 2-2. It is interesting to compare these results to give insight into the riffling and sampling statistics. There was no significant difference between the average mean radius and average sphericity for the two riffled batches. The 847 particles in the sub-lot shown in Figure 2-4 was sufficient to give a near Gaussian distribution. Increasing the number of analyzed particles to 1118 did not significantly change the results. There were not enough particles in the 271 particle sub-lot of Figure 2-5 to give a normal distribution. However, the mean values and standard deviations were not adversely effected by the non-normal distribution. 
ORNL/CF-04/06

Revision 0

\begin{tabular}{c|ccccc} 
& Sphericity & Mean Radius & St. Dev. In Radius & Maximum Radius & Minimum Radius \\
\hline Average & 1.09 & 461 & 9 & 479 & 441 \\
Standard Deviation & 0.02 & 12 & 3 & 13 & 524 \\
Maximum & 1.18 & 501 & 18 & 486 \\
Minimum & 1.03 & 425 & 3 & 391
\end{tabular}

\begin{tabular}{cc}
\hline Sphericity & Frequency \\
\hline 1 & 0 \\
1.01 & 0 \\
1.02 & 0 \\
1.03 & 2 \\
1.04 & 11 \\
1.05 & 40 \\
1.06 & 85 \\
1.07 & 151 \\
1.08 & 168 \\
1.09 & 196 \\
1.1 & 147 \\
1.11 & 119 \\
1.12 & 84 \\
1.13 & 44 \\
1.14 & 36 \\
1.15 & 23 \\
1.16 & 7 \\
1.17 & 2 \\
1.18 & 3 \\
More & 0 \\
\hline
\end{tabular}

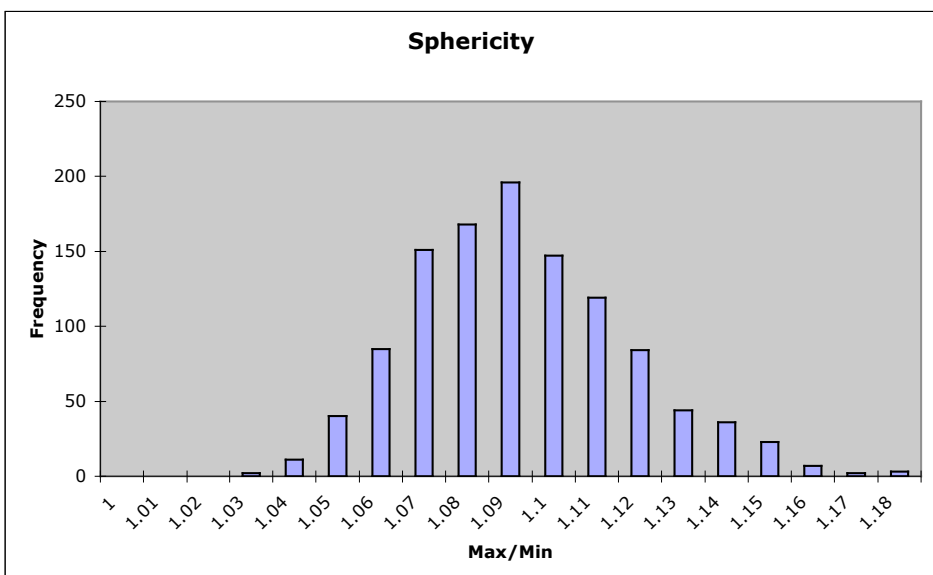

\begin{tabular}{cc}
\hline Mean Radius & Frequency \\
\hline 425 & 0 \\
430 & 2 \\
435 & 6 \\
440 & 19 \\
445 & 54 \\
450 & 113 \\
455 & 156 \\
460 & 180 \\
465 & 172 \\
470 & 158 \\
475 & 118 \\
480 & 59 \\
485 & 46 \\
490 & 24 \\
495 & 9 \\
500 & 1 \\
505 & 1 \\
More & 0 \\
\hline
\end{tabular}

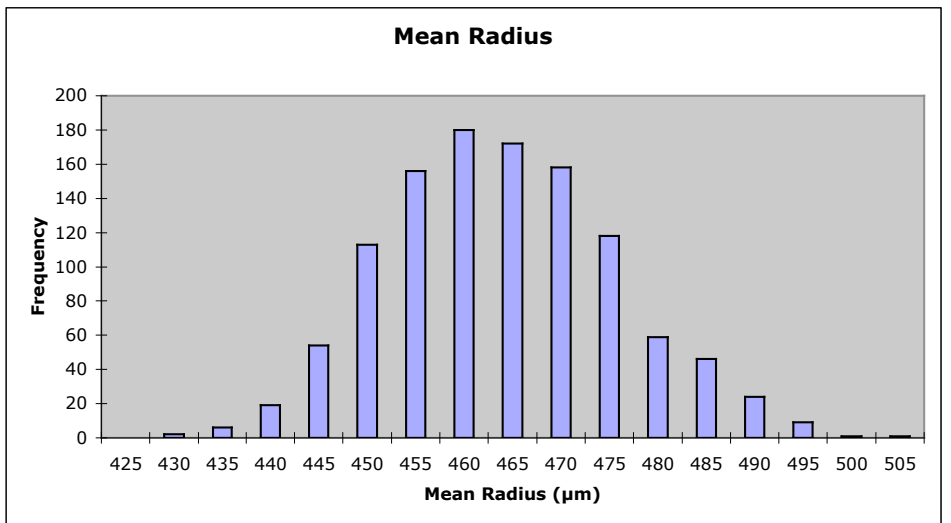

Figure 2-2: Size and shape summary for 1118 coated particles. Radii are in $\mu \mathrm{m}$. 

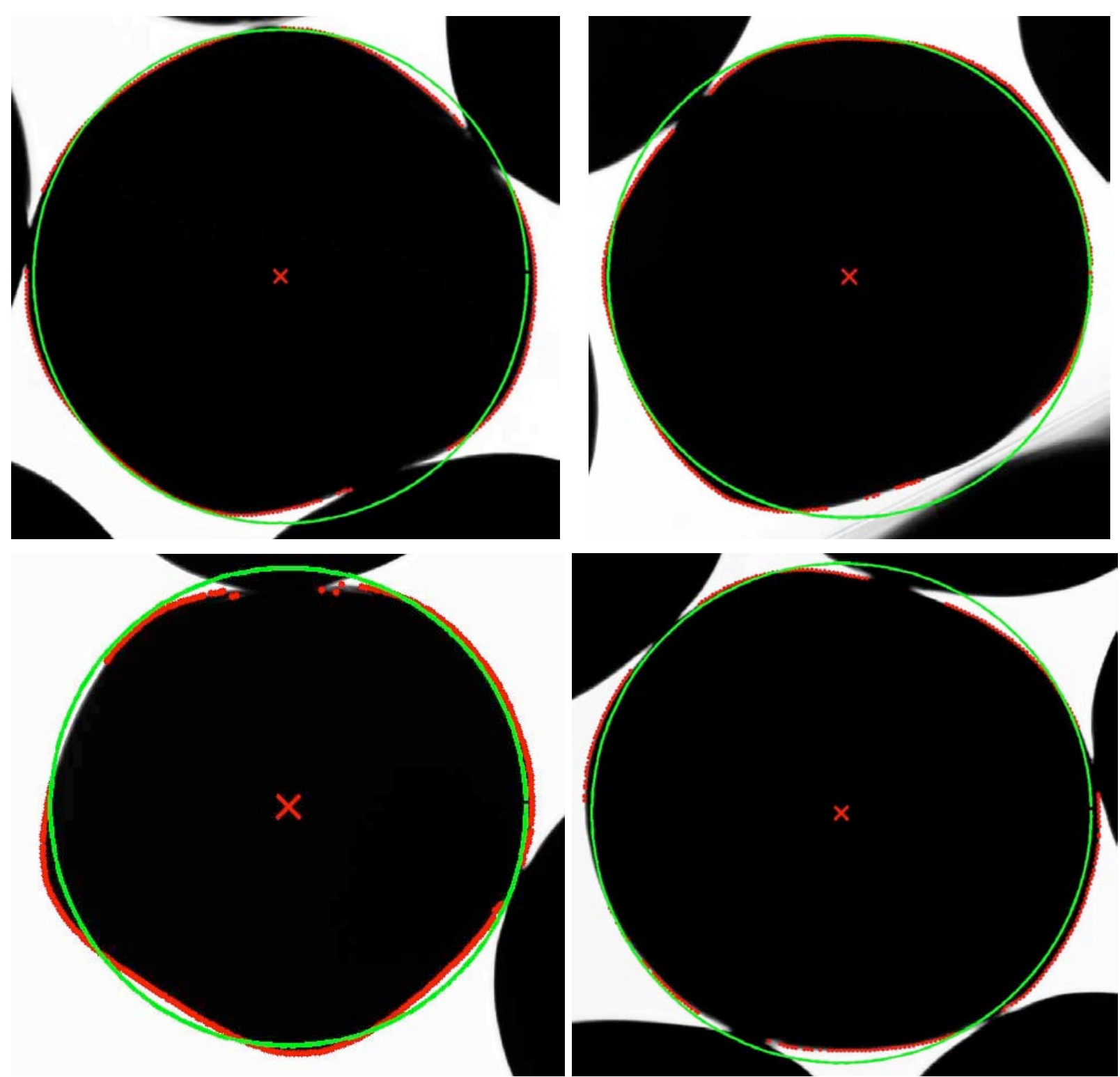

Figure 2-3: Coated particles with high aspect ratio. 
ORNL/CF-04/06

Revision 0

\begin{tabular}{c|ccccc} 
& Sphericity & Mean Radius & St. Dev. In Radius & Maximum Radius & Minimum Radius \\
\hline Average & 1.09 & 462 & 9 & 479 & 441 \\
Standard Deviation & 0.02 & 12 & 3 & 12 & 520 \\
Maximum & 1.17 & 501 & 18 & 486 \\
Minimum & 1.03 & 425 & 3 & 391
\end{tabular}

\begin{tabular}{cc}
\hline Sphericity & Frequency \\
\hline 1 & 0 \\
1.01 & 0 \\
1.02 & 0 \\
1.03 & 1 \\
1.04 & 9 \\
1.05 & 34 \\
1.06 & 68 \\
1.07 & 110 \\
1.08 & 126 \\
1.09 & 149 \\
1.1 & 120 \\
1.11 & 89 \\
1.12 & 59 \\
1.13 & 30 \\
1.14 & 25 \\
1.15 & 18 \\
1.16 & 6 \\
1.17 & 2 \\
1.18 & 1 \\
More & 0 \\
\hline
\end{tabular}

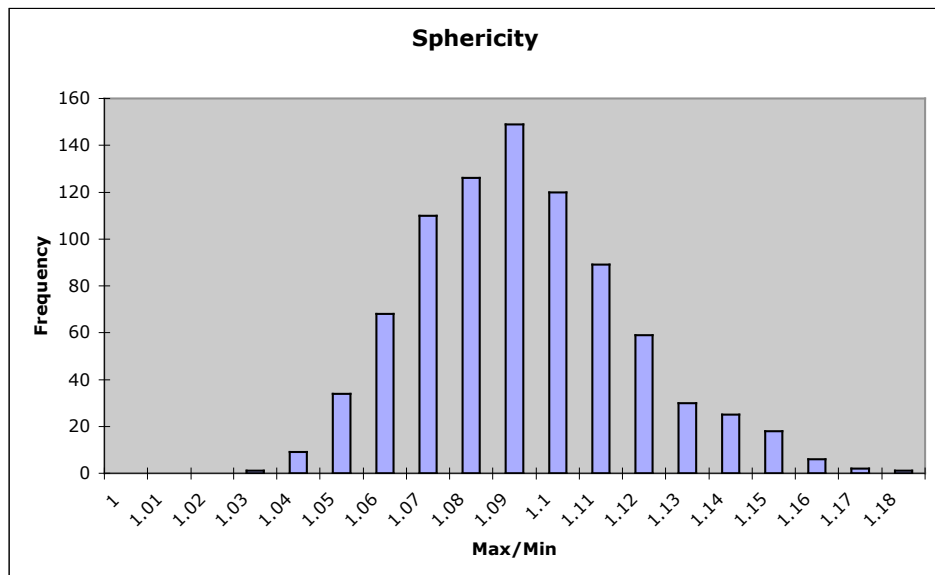

\begin{tabular}{cc}
\hline Mean Radius & Frequency \\
\hline 425 & 0 \\
430 & 2 \\
435 & 5 \\
440 & 13 \\
445 & 36 \\
450 & 74 \\
455 & 121 \\
460 & 144 \\
465 & 132 \\
470 & 121 \\
475 & 91 \\
480 & 45 \\
485 & 36 \\
490 & 19 \\
495 & 6 \\
500 & 1 \\
505 & 1 \\
More & 0 \\
\hline
\end{tabular}

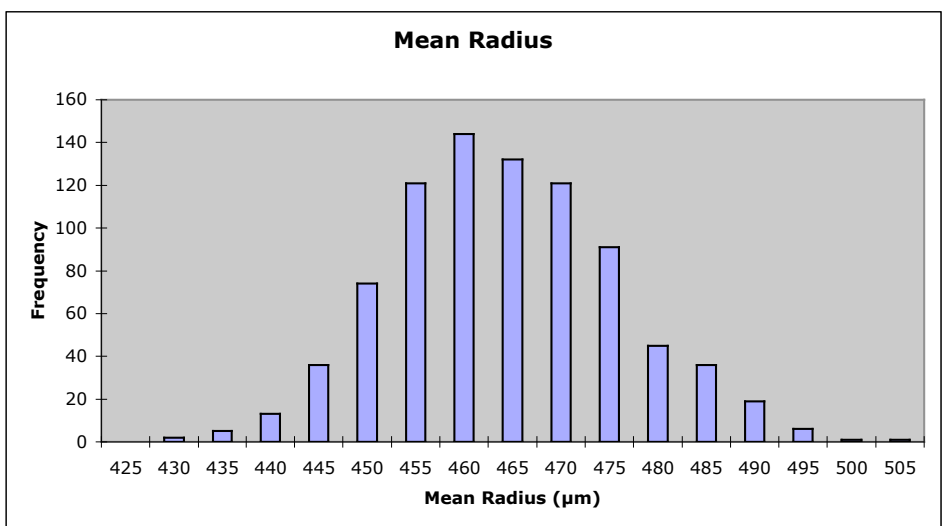

Figure 2-4: Size and shape summary for 847 coated particles. Radii are in $\mu \mathrm{m}$. 
ORNL/CF-04/06

Revision 0

\begin{tabular}{|c|c|c|c|c|c|}
\hline & Sphericity & Mean Radius & St. Dev. In Radius & Maximum Radius & Minimum Radius \\
\hline Average & 1.09 & 460 & 9 & 478 & 439 \\
\hline Standard Deviation & 0.03 & 12 & 3 & 13 & 13 \\
\hline Maximum & 1.18 & 491 & 18 & 524 & 471 \\
\hline Minimum & 1.03 & 435 & 3 & 447 & 405 \\
\hline
\end{tabular}

\begin{tabular}{cc}
\hline Sphericity & Frequency \\
\hline 1 & 0 \\
1.01 & 0 \\
1.02 & 0 \\
1.03 & 1 \\
1.04 & 2 \\
1.05 & 6 \\
1.06 & 17 \\
1.07 & 41 \\
1.08 & 42 \\
1.09 & 47 \\
1.1 & 27 \\
1.11 & 30 \\
1.12 & 25 \\
1.13 & 14 \\
1.14 & 11 \\
1.15 & 5 \\
1.16 & 1 \\
1.17 & 0 \\
1.18 & 2 \\
More & 0 \\
\hline &
\end{tabular}
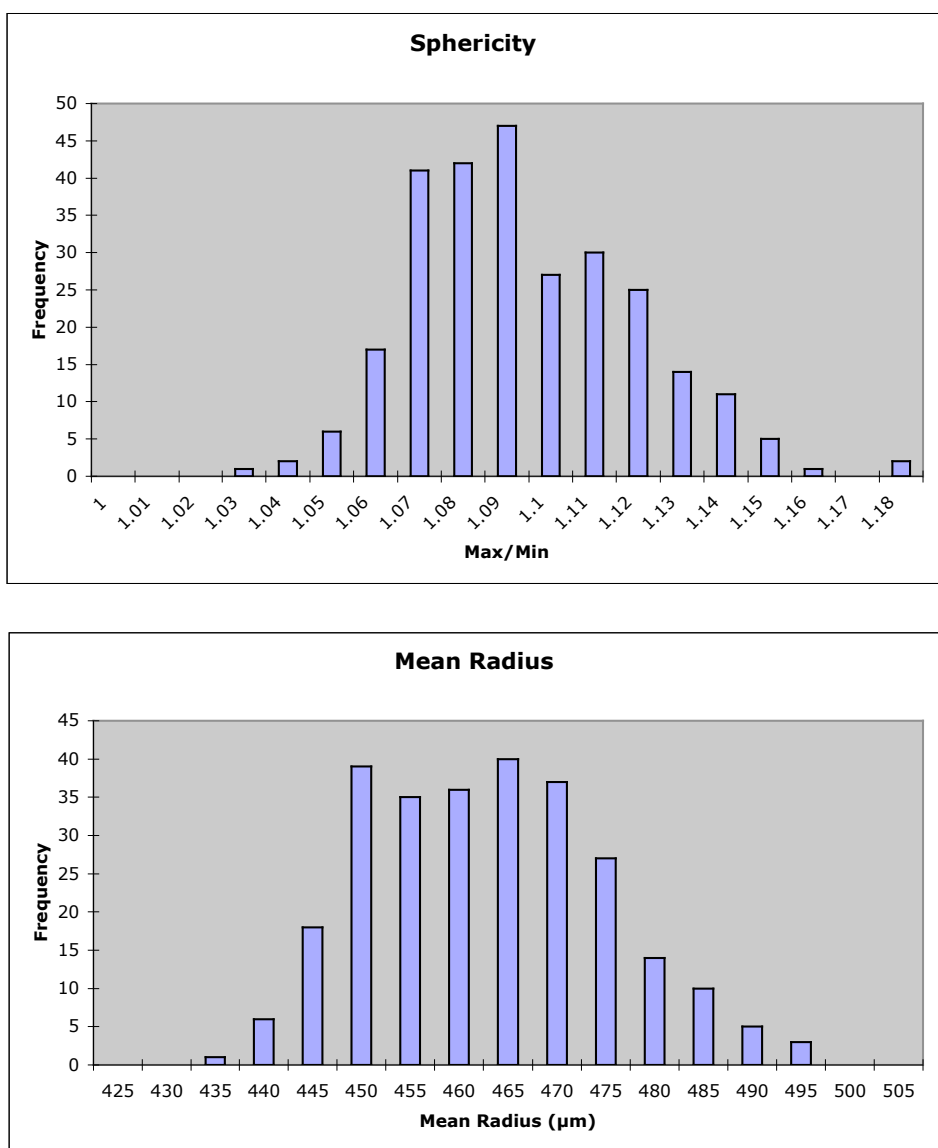

Figure 2-5: Size and shape summary for 271 particles. Radii are in $\mu \mathrm{m}$. 


\subsection{Size and shape after removing OPyC}

The same sample of particles described in section 2.2 was remeasured after removing the OPyC layer by heating in air at $800^{\circ} \mathrm{C}$ for 4 hours. The $\mathrm{OPyC}$ was removed as part of the porosimetry measurement of the $\mathrm{OPyC}$ density described in section 4.4. Figure 2-6 shows the data summary for 1283 particles measured. The measured particles had an average mean radius of $426 \mu \mathrm{m}$ with a standard deviation in the distribution of $12 \mu \mathrm{m}$. The distribution was close to Gaussian. The difference in the average mean radius before and after OPyC removal was $35 \mu \mathrm{m}$. Direct measurement of the $\mathrm{OPyC}$ thickness as described in section 3.5 yielded an average mean thickness of $36 \mu \mathrm{m}$. The sample of particles before and after removal of the OPyC exhibited the same standard deviation in mean radius. This was expected for an OPyC layer with a standard deviation in thickness of a few microns. Note that the number of particles measured in Figure 2-2 was 1118. These numbers were different because the technique used did not measure every particle in the sample. Some particle projections were cutoff at the edges of the images and not analyzed.

The average sphericity of the particles was 1.07 with a standard deviation of 0.02 . The lower

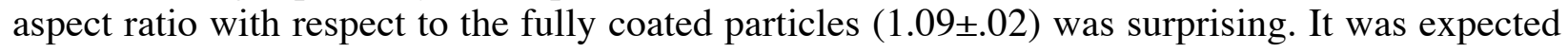
that removal of a fairly uniform $\mathrm{OPyC}$ layer would result in an increase in the aspect ratio (subtracting a constant from the numerator and denominator of a ratio greater than one increases the ratio). The increase in aspect ratio may indicate that the OPyC layer was not uniform in thickness around the layer, but rather varied by $7-8 \mu \mathrm{m}$ in some particles. Note that the fact that the definition of sphericity based on an aspect ratio dependent on the radius is a weak point in the way sphericity is currently defined. 
ORNL/CF-04/06

Revision 0

\begin{tabular}{|c|c|c|c|c|c|}
\hline & Sphericity & Mean Radius & St. Dev. In Radius & Maximum Radius & Minimum Radius \\
\hline Average & 1.07 & 426 & 7 & 440 & 410 \\
\hline Standard Deviation & 0.02 & 12 & 2 & 12 & 12 \\
\hline Maximum & 1.15 & 462 & 15 & 495 & 450 \\
\hline Minimum & 1.02 & 366 & 2 & 383 & 349 \\
\hline
\end{tabular}

\begin{tabular}{cc}
\hline Sphericity & Frequency \\
\hline 1 & 0 \\
1.01 & 0 \\
1.02 & 0 \\
1.03 & 4 \\
1.04 & 33 \\
1.05 & 119 \\
1.06 & 241 \\
1.07 & 262 \\
1.08 & 186 \\
1.09 & 186 \\
1.1 & 127 \\
1.11 & 62 \\
1.12 & 32 \\
1.13 & 16 \\
1.14 & 9 \\
1.15 & 6 \\
More & 0 \\
\hline
\end{tabular}

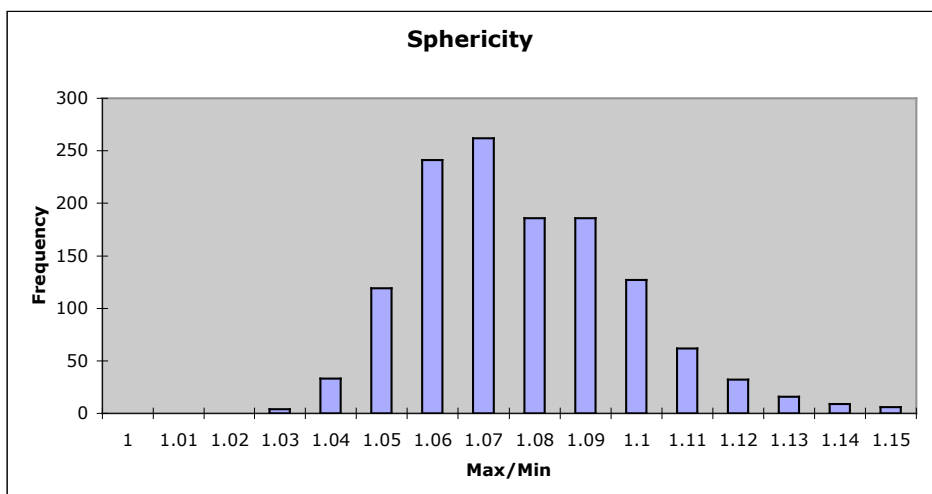

\begin{tabular}{cc}
\hline Mean Radius & Frequency \\
\hline 365 & 0 \\
370 & 1 \\
375 & 0 \\
380 & 0 \\
385 & 0 \\
390 & 0 \\
395 & 0 \\
400 & 9 \\
405 & 33 \\
410 & 60 \\
415 & 124 \\
420 & 182 \\
425 & 218 \\
430 & 212 \\
435 & 171 \\
440 & 119 \\
445 & 86 \\
450 & 39 \\
455 & 23 \\
460 & 5 \\
465 & 1 \\
More & 0 \\
\hline
\end{tabular}

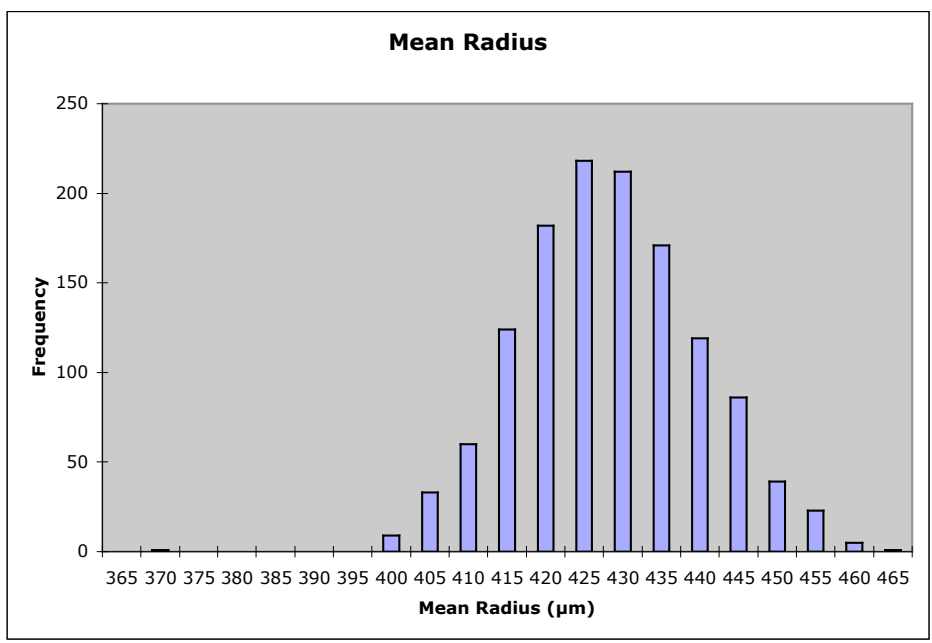

Figure 2-6: Size and shape summary for 1283 particles with the OPyC removed. Radii are in $\mu \mathrm{m}$. 


\title{
3 Measurement of Coating Thicknesses
}

\author{
J.D. Hunn, A.K. Kercher, and J.R. Price
}

Coating thicknesses were measured on 186 particles by mounting particles in a clear epoxy and grinding and polishing the particles to close to, but not beyond, the midpoint. The polished cross sections were imaged with bright field reflected mode with a computer-automated optical microscope and the images were computer analyzed to extract the thickness info for each layer. The deviation of the measured layer thickness from the actual layer thickness due to the polished cross section not being exactly at a midplane was corrected by measuring the outer diameter of the particle and applying a geometric correction. 


\subsection{Kernel diameter}

The cross section measurement provides a secondary measurement of the kernel diameter. This measurement introduces more uncertainty than the shadow image technique in section 2 because of some uncertainty in the kernel buffer interface created during grinding. Figure 3-1 shows the data summary for the kernel radius. The average mean radius was $257 \mu \mathrm{m}$. The average sphericity was 1.04 . The mean kernel size measured by this technique was slightly higher than what was measured by shadow imaging $(253 \mu \mathrm{m})$, probably due to the added uncertainty in identifying the kernel edge.

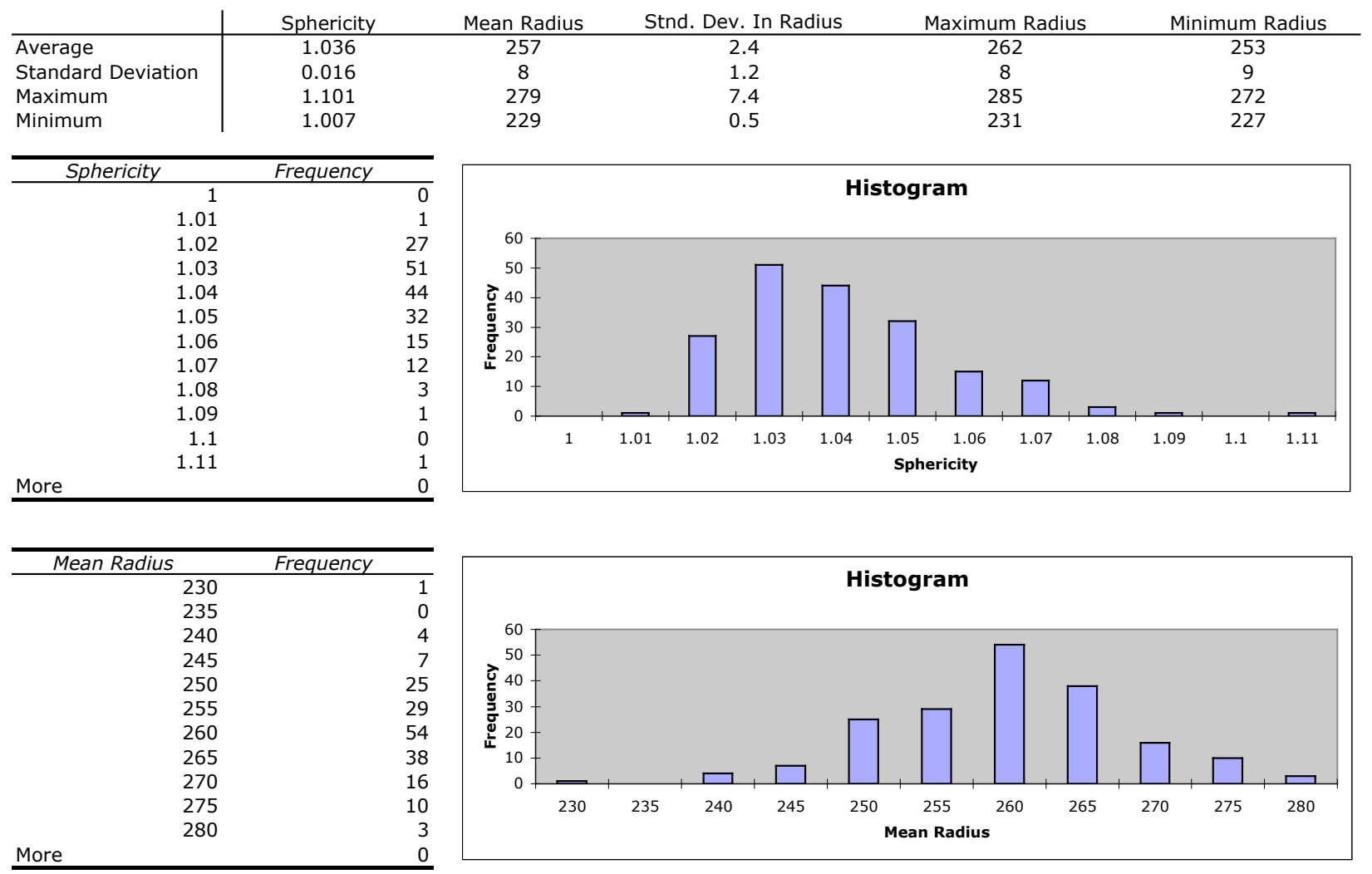

Figure 3-1: Data summary for kernel radius from cross section measurement. Radii are in $\mu \mathrm{m}$. 


\subsection{Buffer thickness}

Figure 3-2 shows the data summary for the measurements made on the buffer. The average mean buffer thickness was $94 \mu \mathrm{m}$ with a standard deviation in the distribution of $11 \mu \mathrm{m}$. The thickness distribution was close to Gaussian. Based on variable sampling statistics, we expect the average mean buffer thickness of the German kernels to be $92-96 \mu \mathrm{m}$ with $95 \%$ confidence. The thickest point measured in a buffer layer was $131 \mu \mathrm{m}$. The thinnest point measured in a buffer layer was $63 \mu \mathrm{m}$. Figure 3-3 shows an example of a buffer with a high standard deviation in thickness. This resulted in a faceted particle. The non-uniform buffer layer also resulted in more thickness deviation in the outer layers. Where the buffer layer was thinner, the other layers also tended to be thinner. The strong dependence on particle shape and coating uniformity on the buffer uniformity suggest that some optimization of the buffer coating step would be valuable. It would be interesting to study the correlation between irregularity in the buffer thickness and coating bed fluidization conditions.

\begin{tabular}{|c|c|}
\hline & Mean Thickness \\
\hline $\begin{array}{l}\text { Average } \\
\text { Standard Deviation } \\
\text { Maximum } \\
\text { Minimum }\end{array}$ & $\begin{array}{c}94 \\
11 \\
121 \\
72\end{array}$ \\
\hline Mean Thickness & Frequency \\
\hline 70 & 0 \\
\hline 75 & 4 \\
\hline 80 & 15 \\
\hline 85 & 21 \\
\hline 90 & 34 \\
\hline 95 & 31 \\
\hline 100 & 26 \\
\hline 105 & 23 \\
\hline 110 & 17 \\
\hline 115 & 8 \\
\hline 120 & 7 \\
\hline 125 & 1 \\
\hline More & 0 \\
\hline
\end{tabular}

Stnd. Dev. In Thickness Maximum Thickness Minimum Thickness

$\begin{array}{ccc}5.0 & 105 & 83 \\ 1.3 & 12 & 10 \\ 9.1 & 131 & 108 \\ 2.5 & 83 & 63\end{array}$

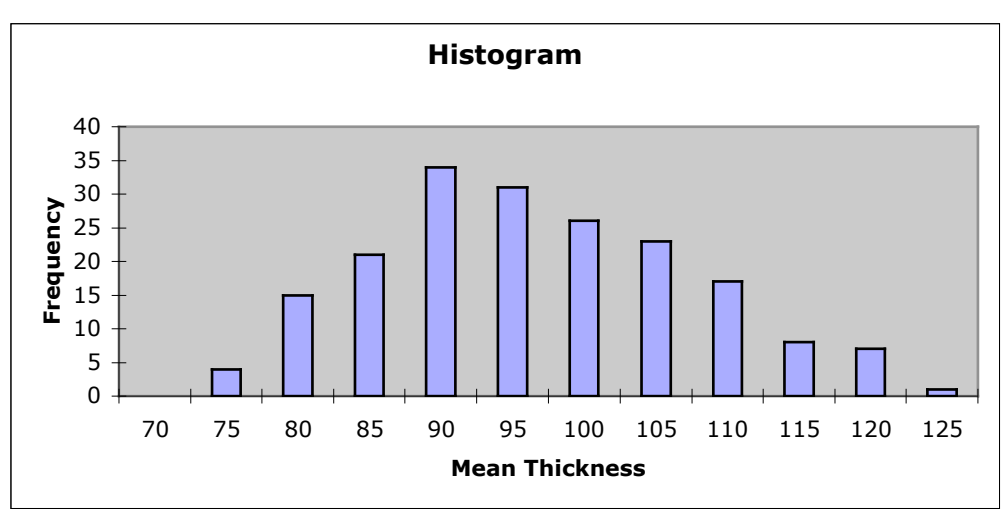

Figure 3-2: Data summary for buffer thickness. Thicknesses are in $\mu \mathrm{m}$. 
ORNL/CF-04/06

Revision 0

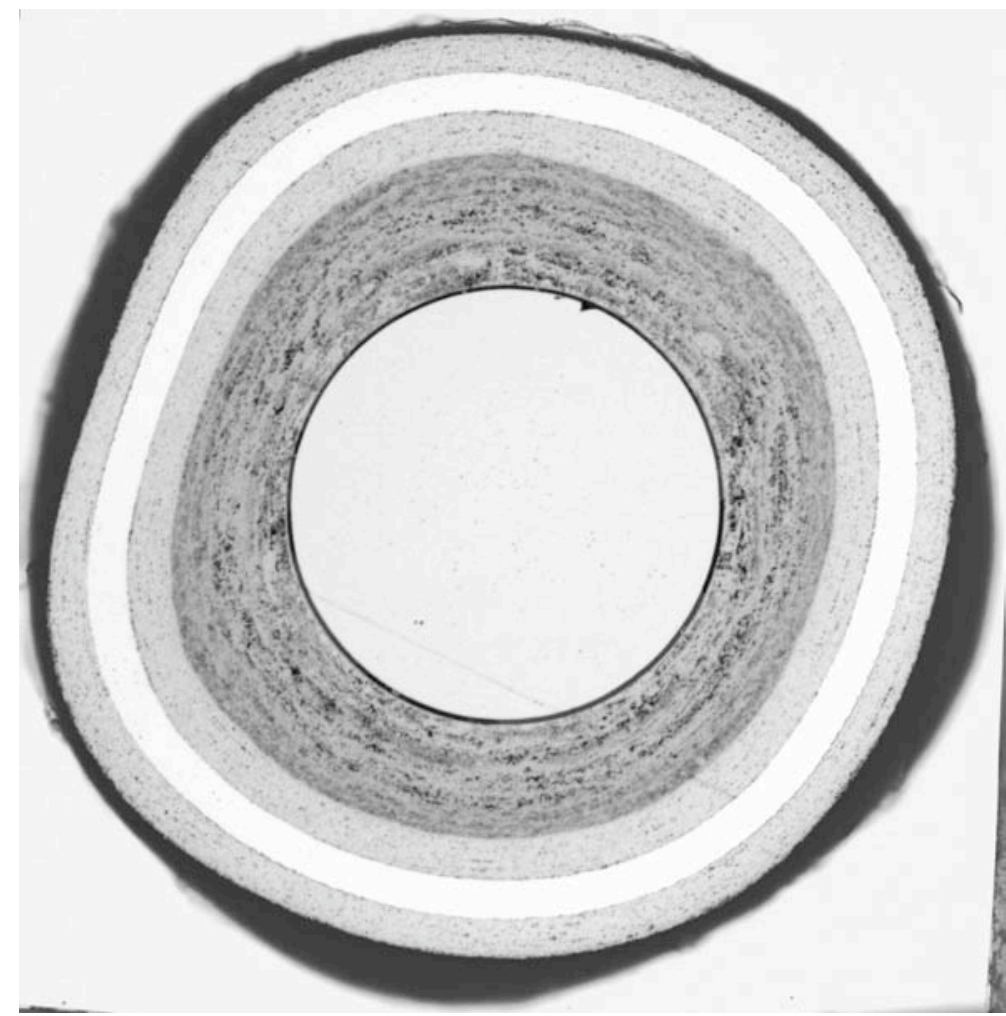

Figure 3-3: Particle with non-uniform buffer layer. 


\subsection{IPyC thickness}

Figure 3-4 shows the data summary for the measurements made on the IPyC. The average mean IPyC thickness was $39 \mu \mathrm{m}$ with a standard deviation in the distribution of $3 \mu \mathrm{m}$. The thickness distribution was close to Gaussian. Based on variable sampling statistics, we expect the average mean IPyC thickness of the German kernels to be $38-40 \mu \mathrm{m}$ with $95 \%$ confidence. The thickest point measured in an IPyC layer was $56 \mu \mathrm{m}$. The thinnest point measured in an IPyC layer was $21 \mu \mathrm{m}$.

\begin{tabular}{|c|c|}
\hline & Mean Thickness \\
\hline Average & 39 \\
\hline Standard Deviation & 3 \\
\hline Maximum & 46 \\
\hline Minimum & 33 \\
\hline Mean Thickness & Frequency \\
\hline 32 & 0 \\
\hline 33 & 2 \\
\hline 34 & 2 \\
\hline 35 & 6 \\
\hline 36 & 6 \\
\hline 37 & 16 \\
\hline 38 & 23 \\
\hline 39 & 21 \\
\hline 40 & 30 \\
\hline 41 & 28 \\
\hline 42 & 25 \\
\hline 43 & 14 \\
\hline 44 & 8 \\
\hline 45 & 4 \\
\hline 46 & 1 \\
\hline 47 & 1 \\
\hline More & 0 \\
\hline
\end{tabular}

Stnd. Dev. In Thickness Maximum Thickness Minimum Thickness

$\begin{array}{ccc}2.5 & 46 & 33 \\ 0.5 & 3 & 3 \\ 4.7 & 56 & 40 \\ 1.4 & 37 & 21\end{array}$

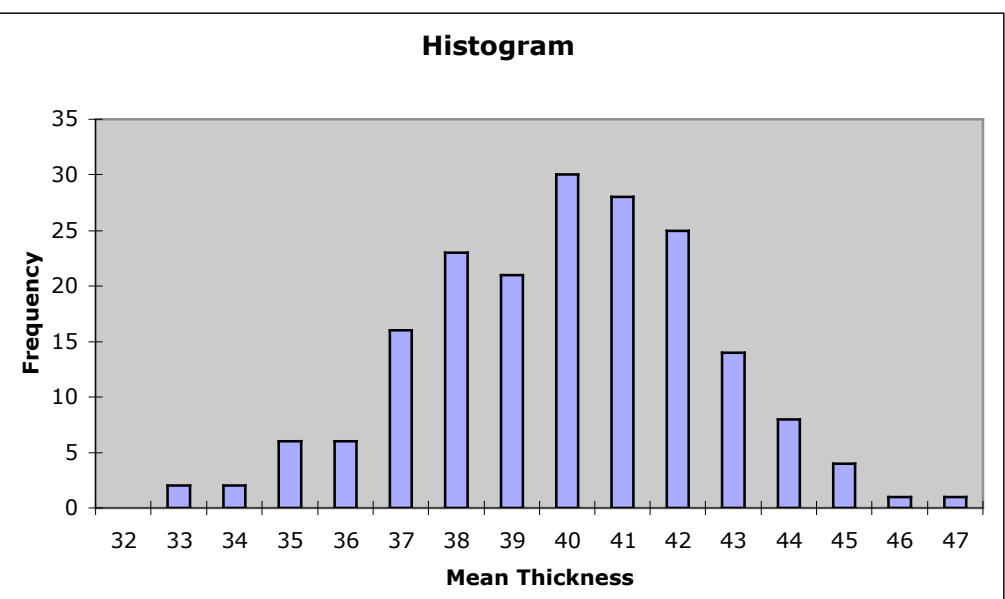

Figure 3-4: Data summary for IPyC thickness. Thicknesses are in $\mu \mathrm{m}$. 


\subsection{SiC thickness}

Figure 3-5 shows the data summary for the measurements made on the SiC. The average mean SiC thickness was $33.9 \mu \mathrm{m}$ with a standard deviation in the distribution of $1.4 \mu \mathrm{m}$. The thickness distribution was close to Gaussian. Based on variable sampling statistics, we expect the average mean SiC thickness of the German kernels to be 33-35 $\mu \mathrm{m}$ with $95 \%$ confidence. The thickest point measured in a SiC layer was $43 \mu \mathrm{m}$. The thinnest point measured in a SiC layer was $24 \mu \mathrm{m}$. The maximum standard deviation in thickness around a SiC layer was only $2.5 \mu \mathrm{m}$. This indicated that the $\mathrm{SiC}$ layers were very uniform in thickness on each particle. The largest local deviations in $\mathrm{SiC}$ thickness that were observed were associated with large deviations in the buffer thickness.

\begin{tabular}{|c|c|}
\hline & Mean Thickness \\
\hline Average & 33.9 \\
\hline Standard Deviation & 1.4 \\
\hline Maximum & 36.6 \\
\hline Minimum & 28.9 \\
\hline Mean Thickness & Frequency \\
\hline 27 & 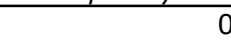 \\
\hline $2 \varepsilon$ & 0 \\
\hline 25 & 1 \\
\hline 30 & 2 \\
\hline 3. & 3 \\
\hline 32 & 13 \\
\hline 33 & 30 \\
\hline $3<$ & 38 \\
\hline 35 & 57 \\
\hline 36 & 34 \\
\hline 37 & 8 \\
\hline More & 0 \\
\hline
\end{tabular}

Stnd. Dev. In Thickness

Maximum Thickness

Minimum Thickness

$1.3 \quad 37.1 \quad 31.0$

0.3

2.5

1.7

1.7

42.9

34.8

0.7

24.2

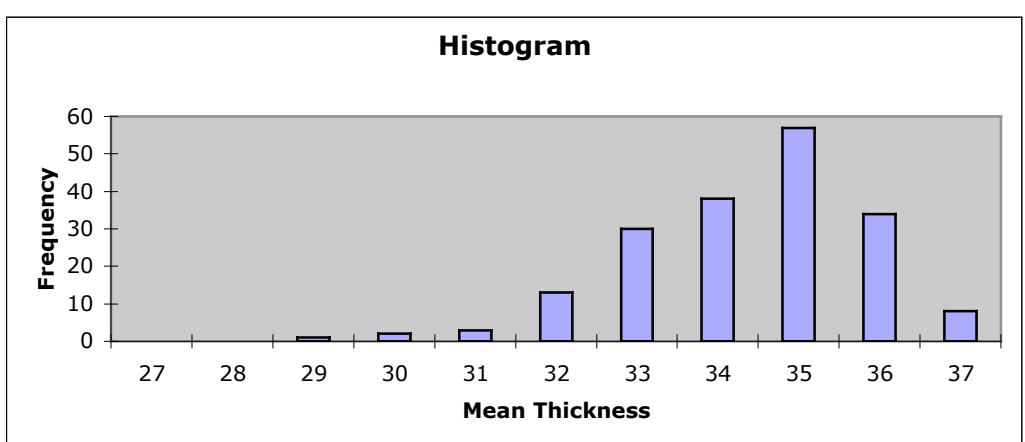

Figure 3-5: Data summary for $\mathrm{SiC}$ thickness. Thicknesses are in $\mu \mathrm{m}$. 


\subsection{OPyC thickness}

Figure 3-6 shows the data summary for the measurements made on the OPyC. The average mean OPyC thickness was $36 \mu \mathrm{m}$ with a standard deviation in the distribution of $2 \mu \mathrm{m}$. The thickness distribution was close to Gaussian. Based on variable sampling statistics, we expect the average mean OPyC thickness of the German kernels to be 35-37 $\mu \mathrm{m}$ with $95 \%$ confidence. The thickest point measured in an OPyC layer was $51 \mu \mathrm{m}$. The thinnest point measured in an OPyC layer was $26 \mu \mathrm{m}$. Figure 3-7 and Figure 3-8 show that the thickest and thinnest regions observed in the $\mathrm{OPyC}$ layers were associated with faceted regions in the particle.

\begin{tabular}{|c|c|}
\hline & Mean Thickness \\
\hline Average & 36 \\
\hline Standard Deviation & 2 \\
\hline Maximum & 45 \\
\hline Minimum & 32 \\
\hline Mean Thickness & Frequency \\
\hline 32 & 2 \\
\hline 33 & 7 \\
\hline 34 & 14 \\
\hline 35 & 25 \\
\hline 36 & 36 \\
\hline 37 & 42 \\
\hline 38 & 37 \\
\hline 39 & 11 \\
\hline 40 & 4 \\
\hline 41 & 6 \\
\hline 42 & 2 \\
\hline 43 & 0 \\
\hline 44 & 0 \\
\hline 45 & 1 \\
\hline More & 0 \\
\hline
\end{tabular}

\begin{tabular}{ccc} 
Stnd. Dev. In Thickness & Maximum Thickness & Minimum Thickness \\
\hline 2.6 & 42 & 30 \\
0.5 & 2 & 2 \\
4.3 & 51 & 37 \\
1.4 & 36 & 26
\end{tabular}

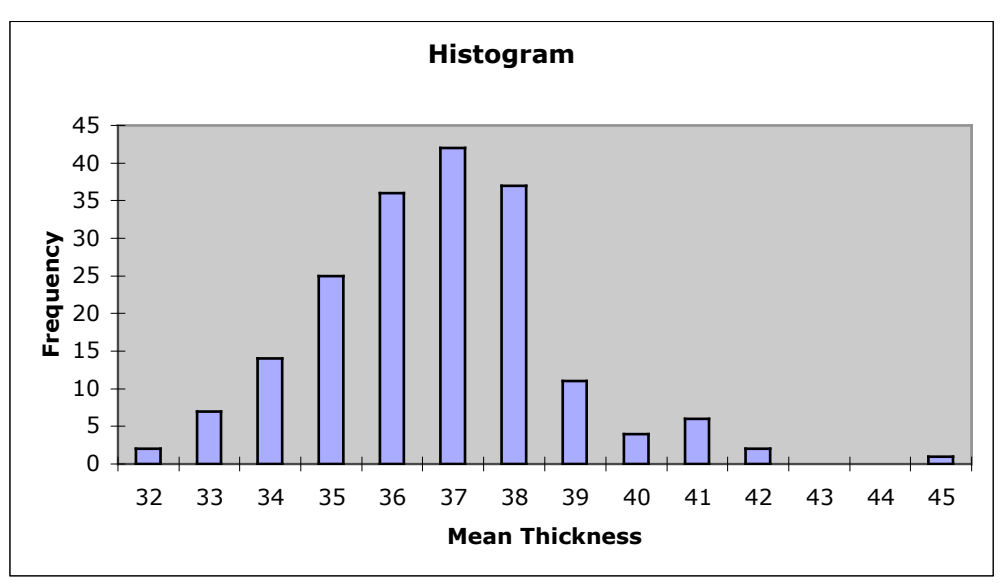

Figure 3-6: Data summary for OPyC thickness. Thicknesses are in $\mu \mathrm{m}$. 
ORNL/CF-04/06

Revision 0

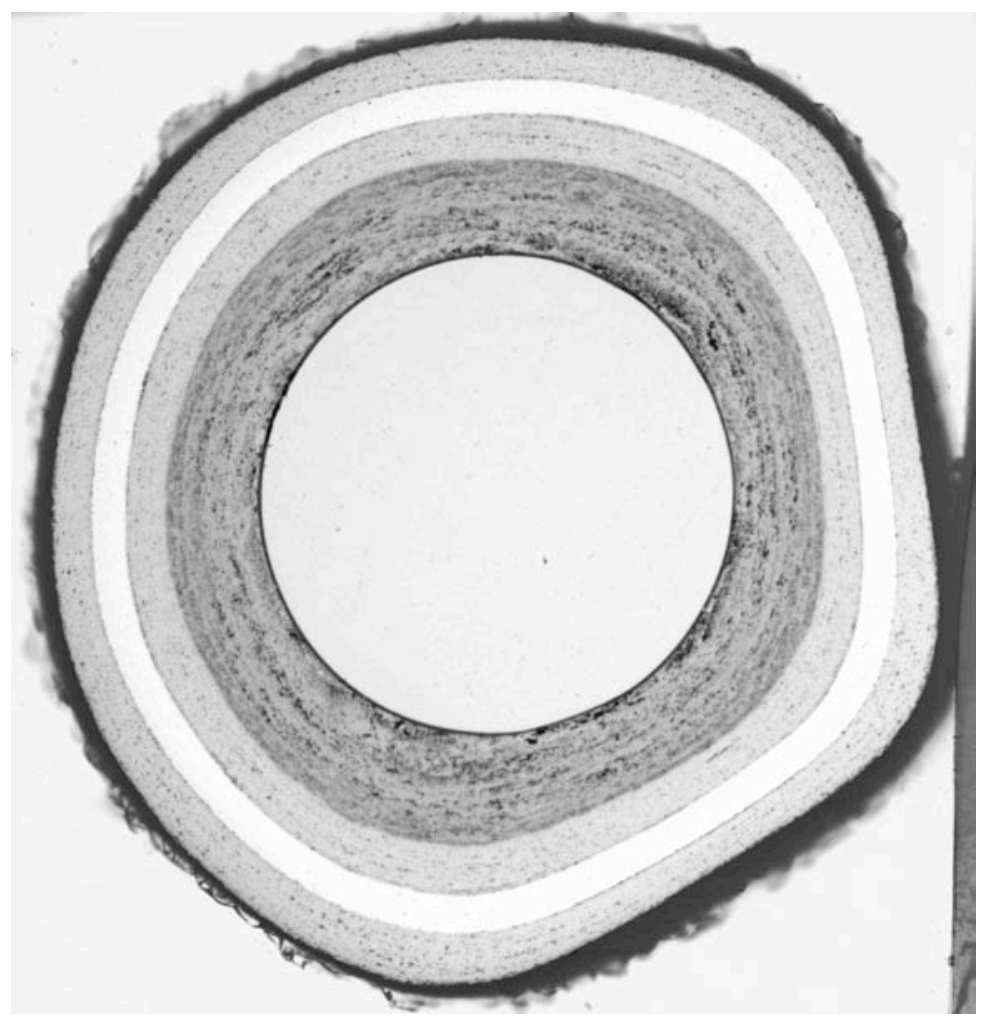

Figure 3-7: Particle showing thickest local OPyC region.

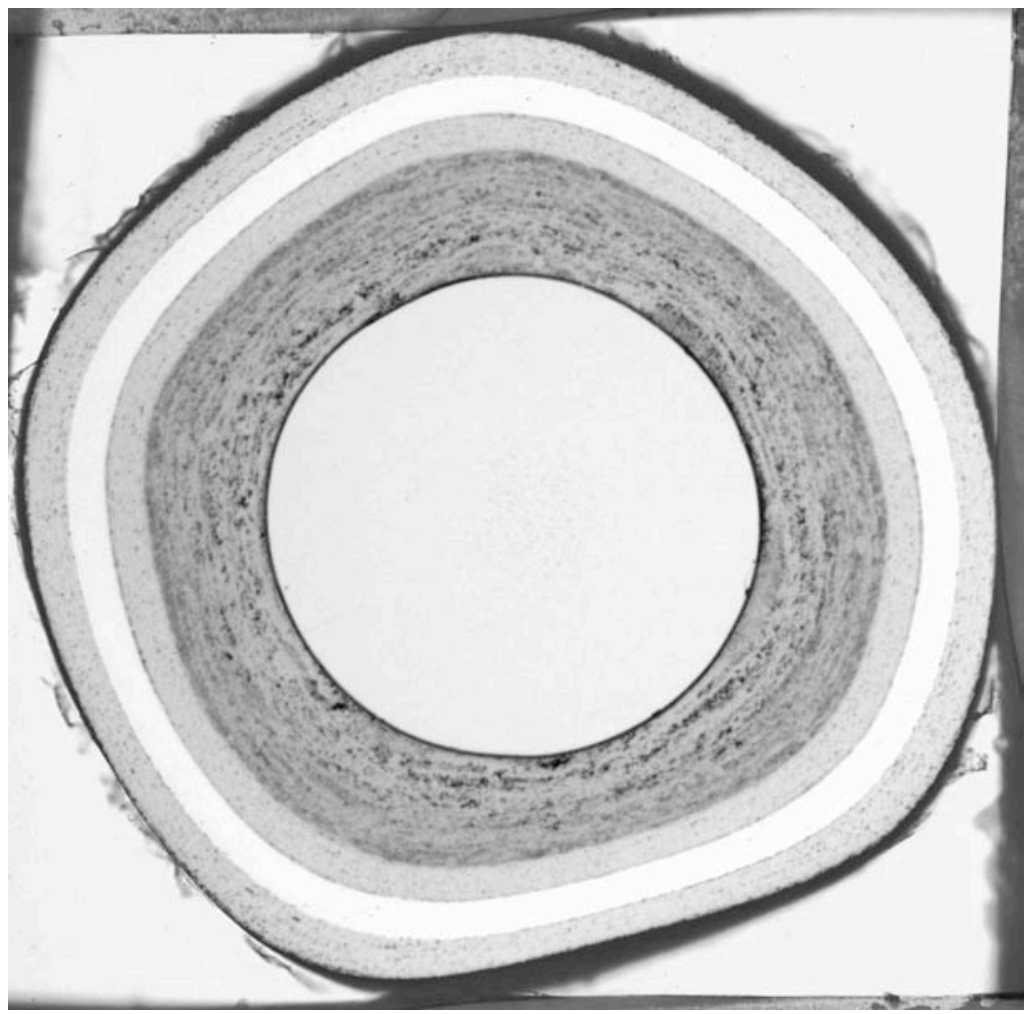

Figure 3-8: Particle showing thinnest local OPyC region. 


\subsection{Total particle radius}

The mean kernel radius and mean layer thickness data were summed for each particle as a comparison check against the data obtained from the whole particle measurements made in section 2.2. The average mean radius obtained by summing the data from the cross section measurements was $461 \mu \mathrm{m}$ with a standard deviation in the distribution of $10 \mu \mathrm{m}$. This agreed well with the data obtained by shadow imaging the whole particles summarized in Figure 2-2 (461 $\mu \mathrm{m}$ with a standard deviation in the distribution of $12 \mu \mathrm{m}$ ).

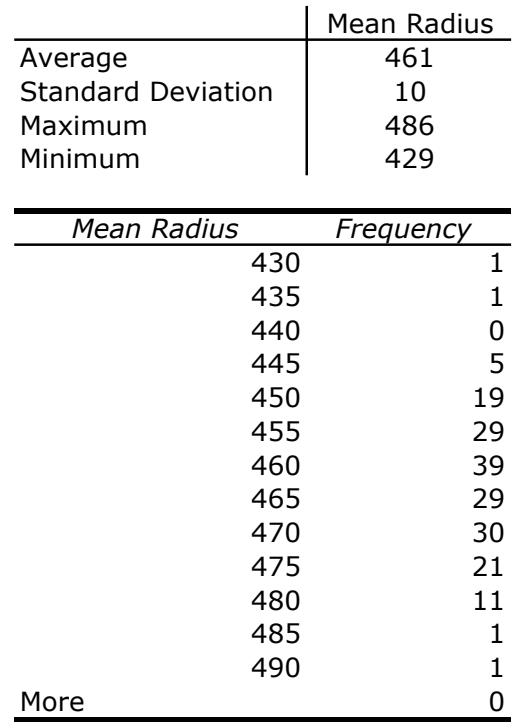

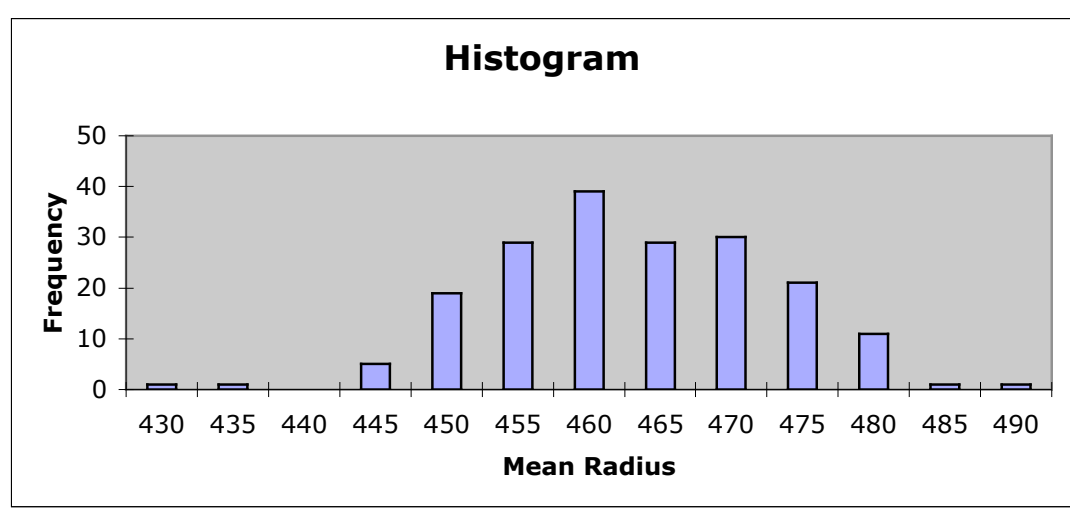

Figure 3-9: Data summary for total particle radius calculated from sum of kernel radius and layer thicknesses. Radii are in $\mu \mathrm{m}$. 


\title{
4 Density Measurement
}

\author{
P.J. Pappano and J.D. Hunn
}

\subsection{Kernel density}

Using the ASTM D3766 standard terminology, we define three different types of density: the theoretical density is based solely on the solid material volume, the skeletal density includes the closed pore volume, and the envelope density includes the open and closed pore volume. The theoretical density of $\mathrm{UO}_{2}$ is $10.96 \mathrm{~g} / \mathrm{cc}$.

Envelope density was measured with a $\mathrm{Hg}$ porosimeter on $7 \mathrm{~g}$ sample of kernels extracted from the coatings. The envelope density was measured by weighing the sample and measuring the volume of mercury displaced after sufficient pressure was applied to cause the mercury to envelop each individual kernel in the sample. Open porosity information was obtained by continuing to increase the pressure and measuring the amount of mercury penetrating into the pores. The envelope density was $10.6 \mathrm{~g} / \mathrm{cc}$ with less than $0.02 \%$ open porosity (below a measurable amount). This result is preliminary in that the uncertainty and repeatability of the porosimetry measurement has not yet been fully analyzed.

Skeletal density was measured with a helium pycnometer on the same $7 \mathrm{~g}$ sample. The skeletal density of the sample was $10.97 \pm 0.16 \mathrm{~g} / \mathrm{cc}$. The skeletal density was measured by weighing the sample and measuring the volume of helium displaced by the kernel. In this technique, the helium freely enters any open porosity in the kernels. Given the near zero open

porosity measured by the porosimeter, the envelope density appears to be low when compared to the skeletal density result.

\subsection{Buffer and IPyC density}

The buffer and IPyC layer could not be isolated from the coated particles. The density was not measured. 


\subsection{SiC density}

Coatings were broken off of the particles as described in section 1. Pieces of IPyC/SiC/OPyC fragments were removed and heated in air at $750^{\circ} \mathrm{C}$ for $90 \mathrm{~min}$ to remove the carbon layers. The separated $\mathrm{SiC}$ fragments were placed in a liquid gradient density column spanning a range of 3.15-3.21 g/cc. The column was created using an appropriate combination of methylene iodide and bromoform in such a way as to create a linear density gradient. Six calibration floats were used to generate a density versus position linear fit for the column and the density of the SiC fragments was calculated after measuring their equilibrium position in the column. Figure 4-1 shows the column calibration and measured values for the $\mathrm{SiC}$ fragments. The average density measured by this method was $3.201 \pm 0.002 \mathrm{~g} / \mathrm{cc}$. The $95 \%$ confidence interval for the SiC density by this method was 3.200-3.202. A rigorous uncertainty analysis has not yet been performed for the density column characterization of $\mathrm{SiC}$, but it is expected to be around $\pm 0.001-0.002 \mathrm{~g} / \mathrm{cc}$. The density measured by this technique is expected to have a value between the envelope density and the skeletal density, depending on the porosity of the material and how the liquid penetrates the open pores. The SiC had very little porosity, so there should be little difference between the envelope density and the skeletal density.

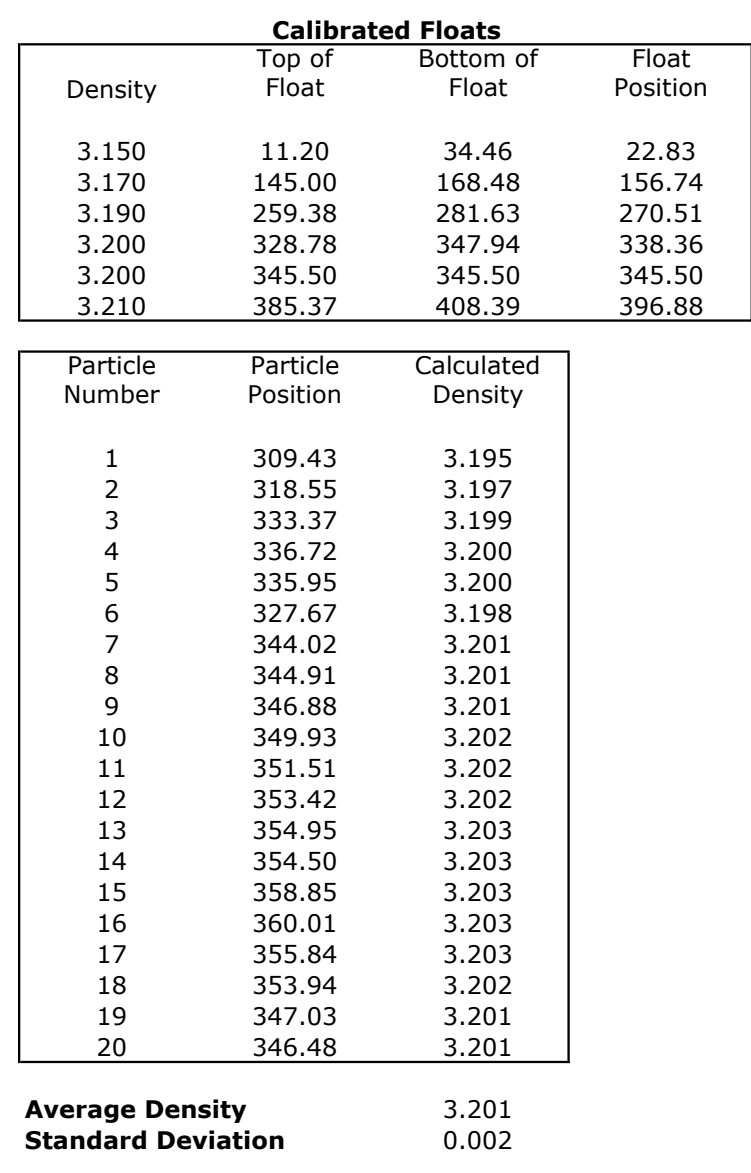

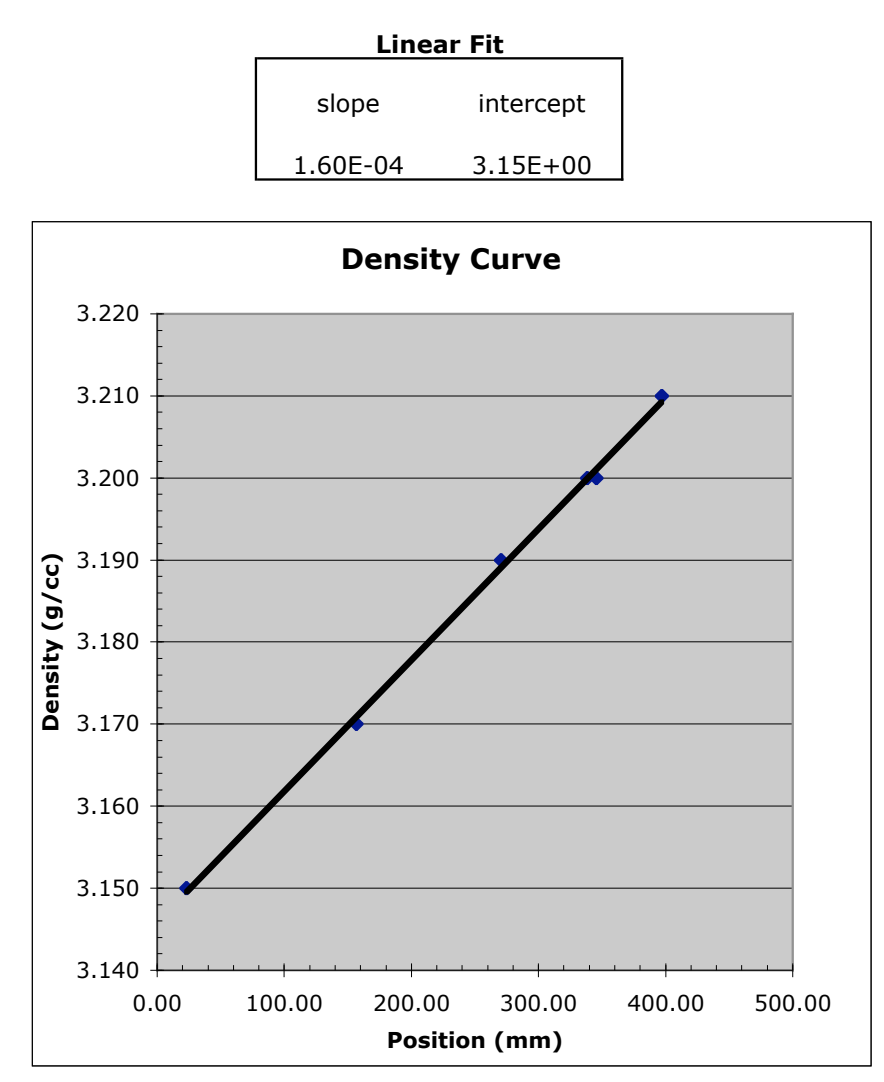

Figure 4-1: Density column data report for SiC. Densities are in $\mathrm{g} / \mathrm{cc}$. 


\subsection{OPyC density}

Coatings were broken off of the particles as described in section 1. Pieces of free OPyC fragments were removed. The separated $\mathrm{OPyC}$ fragments were placed in a liquid gradient density column spanning a range of $1.8-2.1 \mathrm{~g} / \mathrm{cc}$. The column was created using an appropriate combination of ethylene bromide and tetrachloroethylene in such a way as to create a linear density gradient. Four calibration floats were used to generate a density versus position linear fit for the column and the density of the $\mathrm{OPyC}$ fragments was calculated after measuring their equilibrium position in the column. Figure 4-2 shows the column calibration and measured values for the OPyC fragments. The average density measured by this method was $1.926 \pm 0.014$ $\mathrm{g} / \mathrm{cc}$. A rigorous uncertainty analysis has not yet been performed for the density column characterization of $\mathrm{OPyC}$, but it is expected to be around $\pm 0.005 \mathrm{~g} / \mathrm{cc}$.

\begin{tabular}{|c|c|c|}
\hline \multicolumn{2}{|c|}{ Calibrated Floats } & \\
\hline Density & $\begin{array}{c}\text { Float } \\
\text { Position }\end{array}$ & \\
\hline 1.800 & 216.01 & \\
\hline 1.906 & 376.42 & \\
\hline 2.000 & 488.48 & \\
\hline 2.100 & 607.97 & \\
\hline Particle & Particle & Calculated \\
\hline Number & Position & Density \\
\hline 1 & 350.72 & 1.897 \\
\hline 2 & 371.71 & 1.913 \\
\hline 3 & 372.79 & 1.914 \\
\hline 4 & 381.65 & 1.920 \\
\hline 5 & 386.75 & 1.924 \\
\hline 6 & 387.18 & 1.925 \\
\hline 7 & 387.89 & 1.925 \\
\hline 8 & 397.05 & 1.932 \\
\hline 9 & 401.41 & 1.936 \\
\hline 10 & 403.42 & 1.937 \\
\hline 11 & 425.42 & 1.954 \\
\hline 12 & 397.50 & 1.933 \\
\hline 13 & 385.61 & 1.923 \\
\hline o & & 1.926 \\
\hline ndard : & on & 0.014 \\
\hline
\end{tabular}
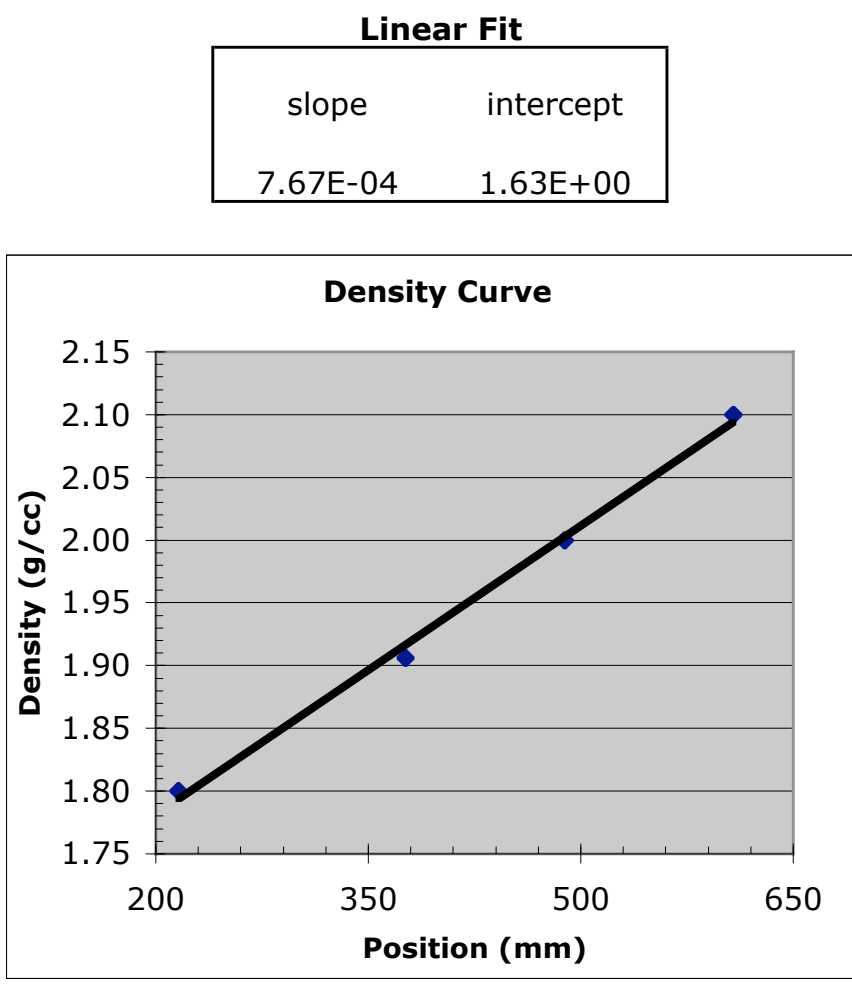

Figure 4-2: Density column data report for $\mathrm{SiC}$, second run. Densities are in $\mathrm{g} / \mathrm{cc}$.

The density measured by this technique is expected to have a value between the envelope density and the skeletal density, depending on the porosity of the material and how the liquid penetrates the open pores. Because the OPyC layers may be porous, it is not sufficient to simply measure the density using the liquid gradient density column. OPyC envelope density was measured using a $\mathrm{Hg}$ porosimeter. The average envelope density of the OPyC layer was 
measured by first measuring the mass and envelope volume of the fully coated particles. After this measurement, all the particles were recovered, cleaned, heated at low temperature to remove the residual mercury, and heated in air at $750^{\circ} \mathrm{C}$ to remove the OPyC layer. The mass and envelope volume of the particles with the OPyC removed was then measured and the mass and envelope volume of the OPyC calculated by subtraction. The accuracy of this measurement depended on not loosing any particles between measurements, fully removing the $\mathrm{Hg}$ between measurements, and low porosity in the $\mathrm{SiC}$ to prevent burnoff of the inner carbon layers. The measured buffer density of the OPyC layer by this method was $1.8 \mathrm{~g} / \mathrm{cc}$.

The porosimetry measurement also provided data on the porosity of the OPyC and SiC layers. The $\mathrm{OPyC}$ open porosity was around $1.1 \%$. The $\mathrm{SiC}$ open porosity was $<0.05 \%$. Figure 4-3 shows the low pressure curve ( 0 to $50 \mathrm{psi}$ ) for the fully coated particles. The steepest part of the curve corresponded to particle re-arrangement. The next region of the curve showed a decrease in slope which corresponded to interparticular volume being filled. The last region of the curve where there was little further volume change indicated that all of the interparticular volume had been filled. The low pressure curve was used to calculate the envelope volume used in the envelope density measurements described above.

Figure 4-4 shows the high pressure curve ( 0 to 60,000 psi) for fully coated particles. The red line is the intrusion curve, where mercury is being forced into any open porosity by increasing the pressure. The blue curve is the extrusion curve, where pressure on the mercury is being reduced and the mercury is coming back out of the pores. The regions of large volume increase as a function of pressure correspond to mercury filling the intraparticulate volume (the open porosity). The pressure at which the open porosity is intruded indicates the size of the pores. There were three distinct regions of intrusion observed in the high pressure curve. Note that the sharp changes in slope in the intrusion curve in Figure 4-4 are due to the scale, the transitions are actually more gradual than they appear. Figure 4-5 shows the pore size distribution versus normalized pore volume calculated from the intrusion curve in Figure 4-4. Three distinct regions of pore size were evident.

The high pressure curve for the particles after burn-off of the OPyC is shown in Figure 4-6. This curve is difficult to interpret. There is an initial intrusion into a very small volume at very low pressure. This could be due to a low density of large pores or cracks in the $\mathrm{SiC}$ layer or it could be due to a measurement artifact, such as an air bubble introduced during transfer to the high pressure station. At higher pressure the $\mathrm{SiC}$ showed negligible porosity. The abnormal blue extrusion curve should be ignored, it was caused by particles shifting into the cell stem during depressurization. Figure 4-7 shows the pore size distribution versus normalized pore volume calculated from the intrusion curve in Figure 4-6.

This $\mathrm{Hg}$ porosimeter results above are preliminary in that the uncertainty and repeatability of the porosimetry measurement has not yet been fully analyzed. 
ORNL/CF-04/06

Revision 0

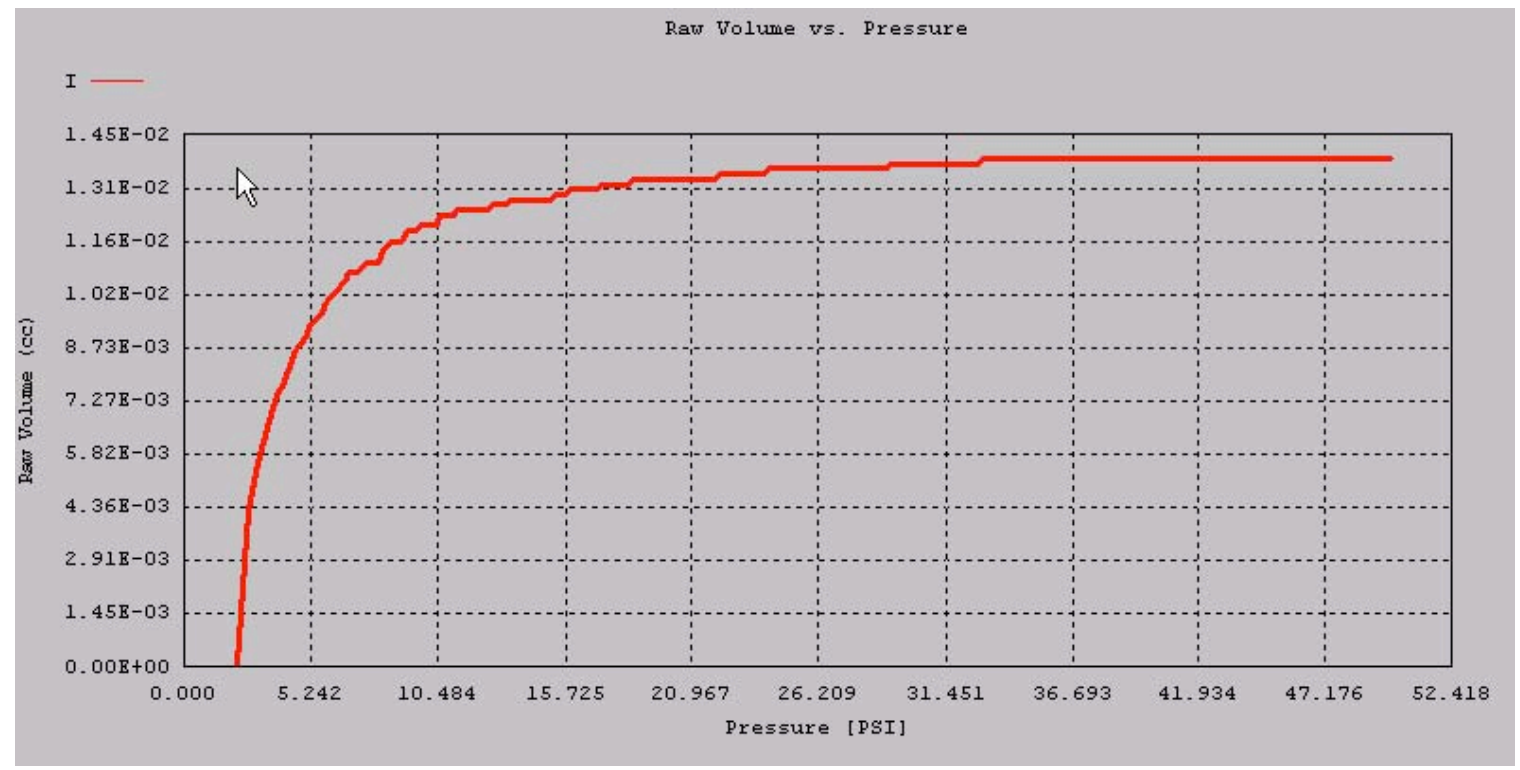

Figure 4-3: Low pressure curve for fully coated particles.

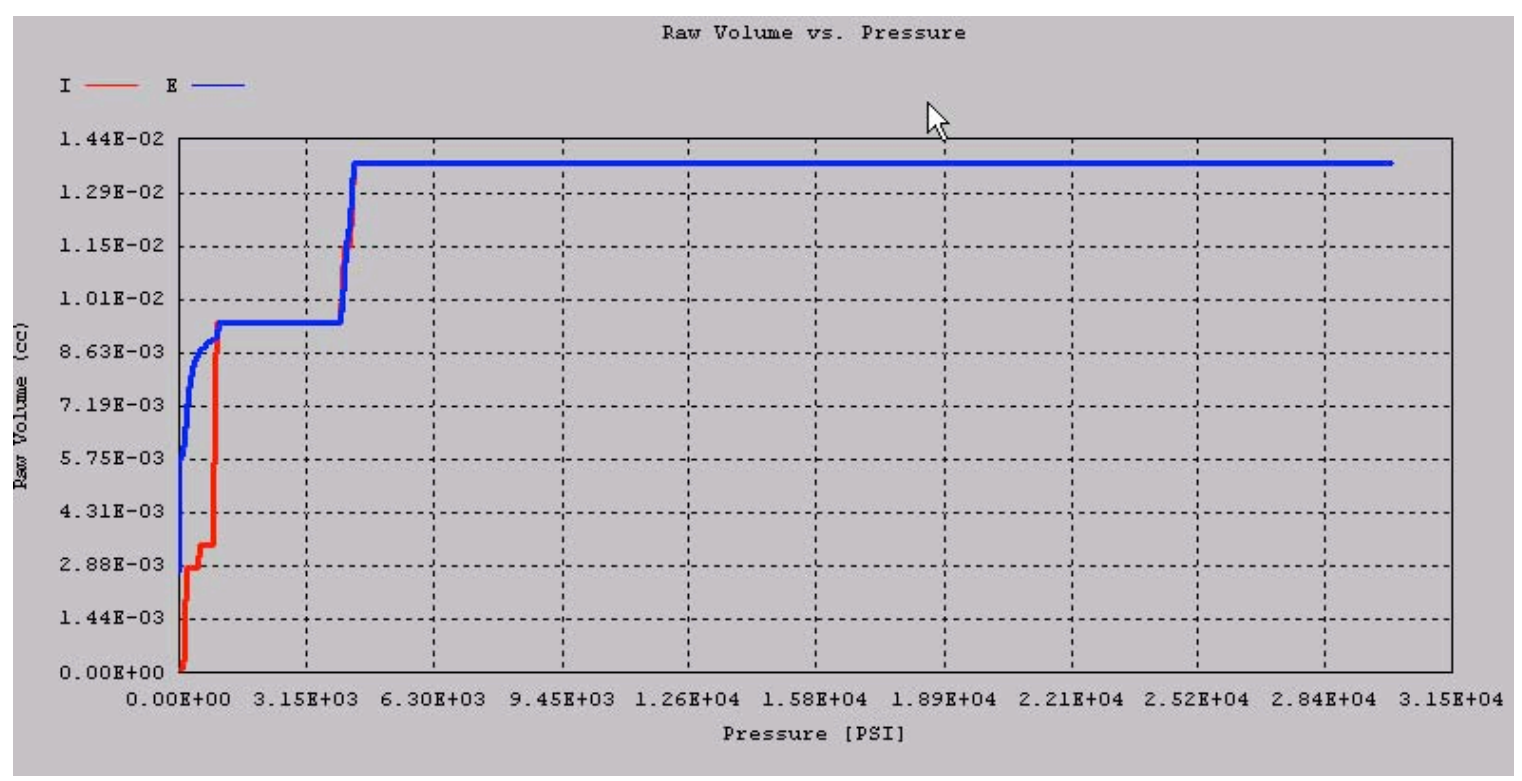

Figure 4-4: High pressure volume vs. pressure curve for fully coated particles. 
ORNL/CF-04/06

Revision 0

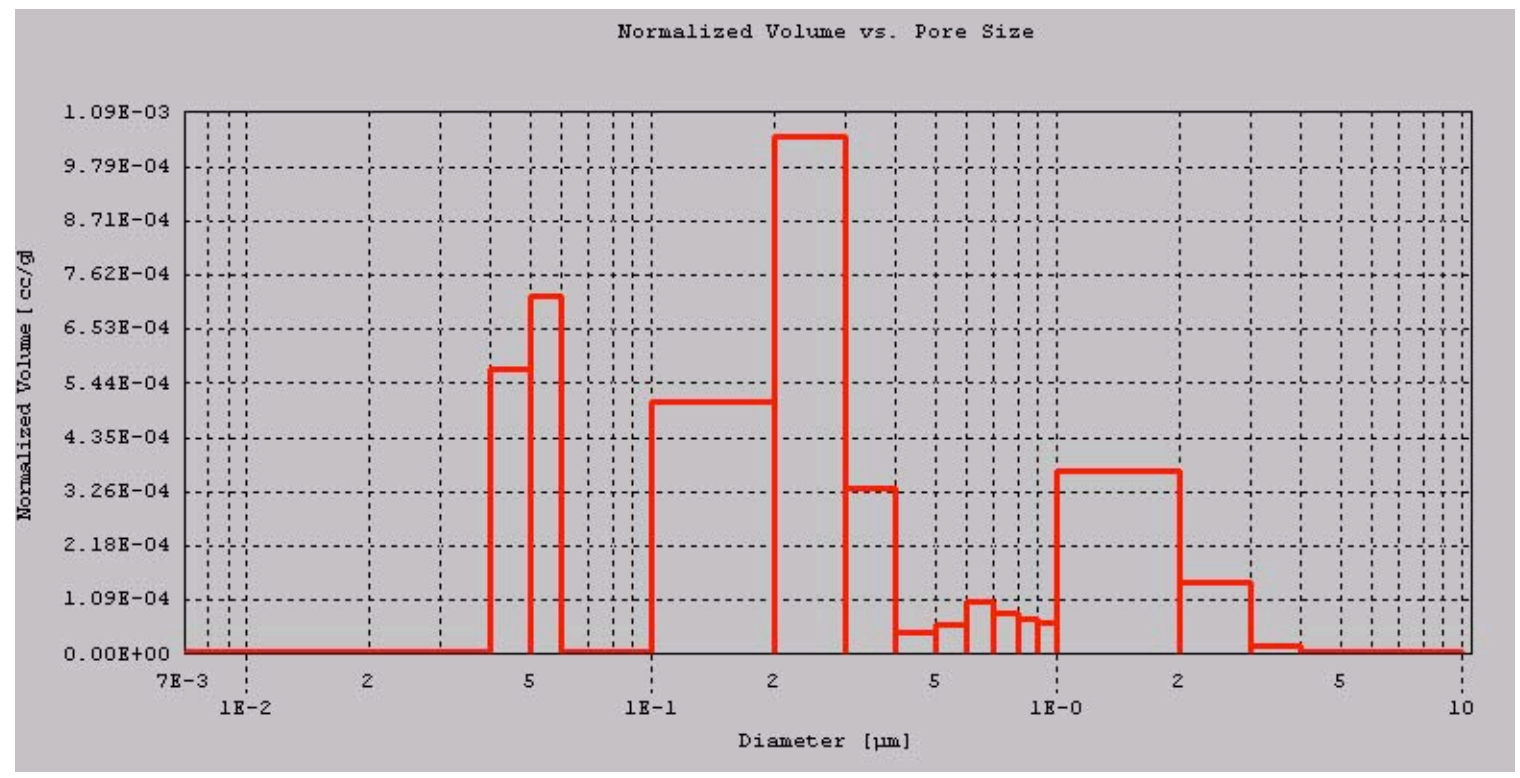

Figure 4-5: Pore size distribution for fully coated particles.

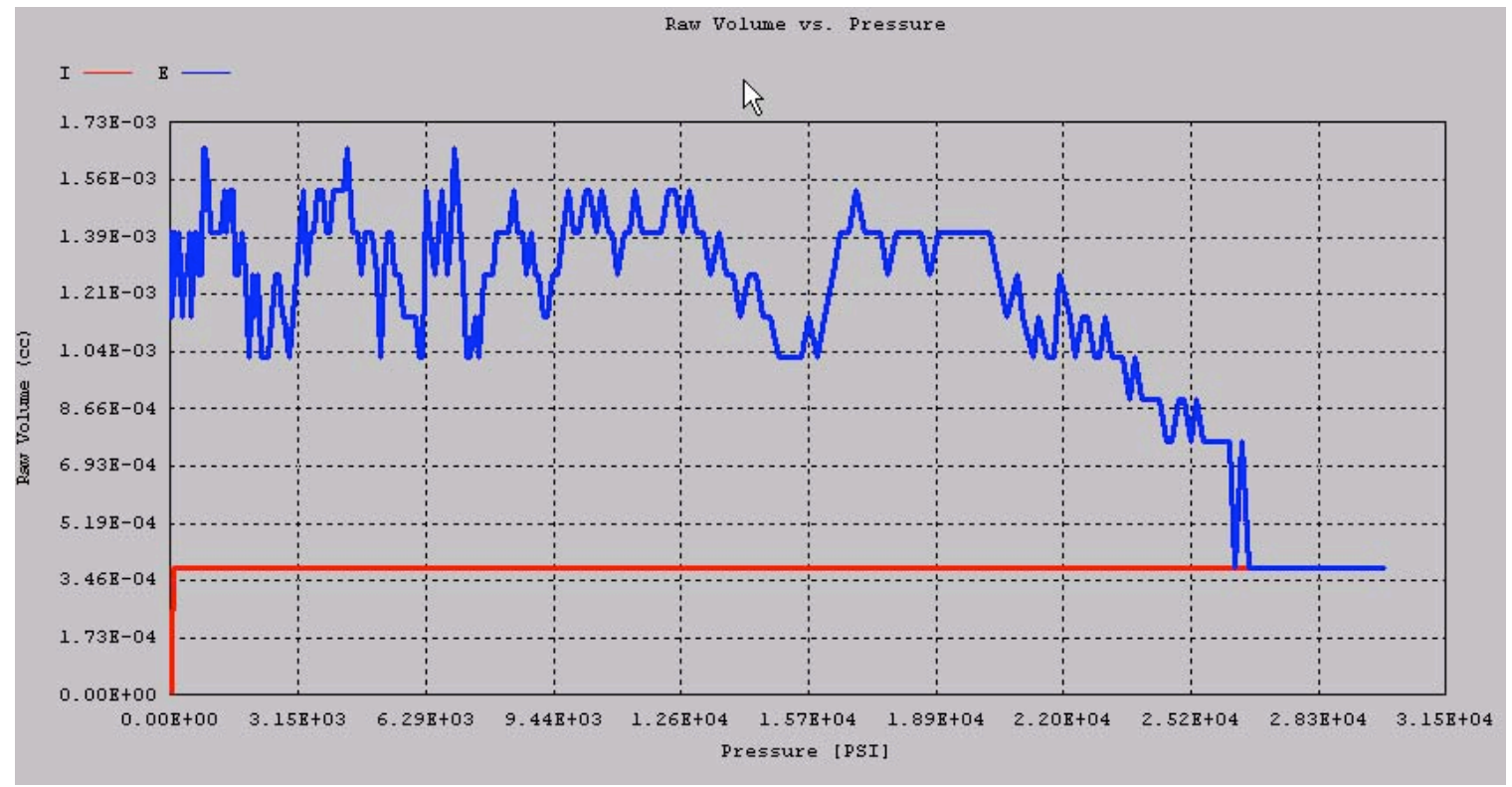

Figure 4-6: High pressure volume vs. pressure curve after removal of OPyC. 
ORNL/CF-04/06

Revision 0

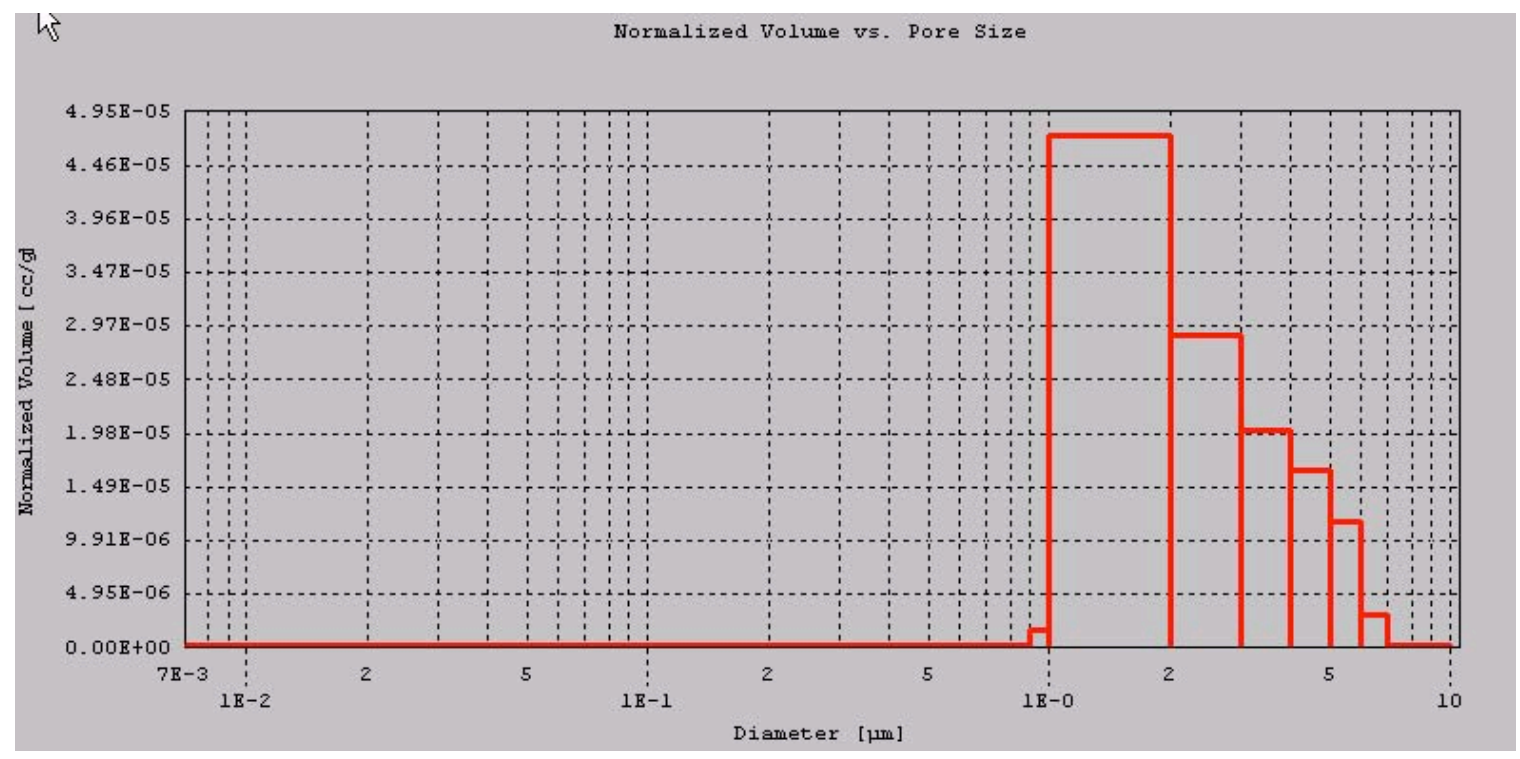

Figure 4-7: Pore size distribution for SiC after removal of OPyC.

\subsection{Particle Density}

A particle envelope density of $3.5 \mathrm{~g} / \mathrm{cc}$ was obtained from the first half of the OPyC density measurement using the porosimeter. This result is preliminary in that the uncertainty and repeatability of the porosimetry measurement has not yet been fully analyzed. 


\title{
5 Optical Anisotropy Measurements
}

\author{
G. E. Jellison, Jr. and J. D. Hunn
}

Nineteen particles were mounted and polished to reveal the individual coatings and a series of optical anisotropy measurements were made using the two-modulator generalized ellipsometry microscope (2-MGEM). The 2-MGEM measured the average Mueller matrix in a $10 \mu \mathrm{m}$ diameter spot which was scanned over the specimen surface in two dimensions with a 10 $\mu \mathrm{m}$ step size in each direction. With this data, various optical anisotropy parameters could be imaged with a $10 \times 10 \mu \mathrm{m}$ per pixel resolution. A data set containing 2-MGEM data for 8,000 to 10,000 spots was generated for each particle. An example of some of the images obtained for various parameters is shown in Figure 5-1, and will be described in more detail below.

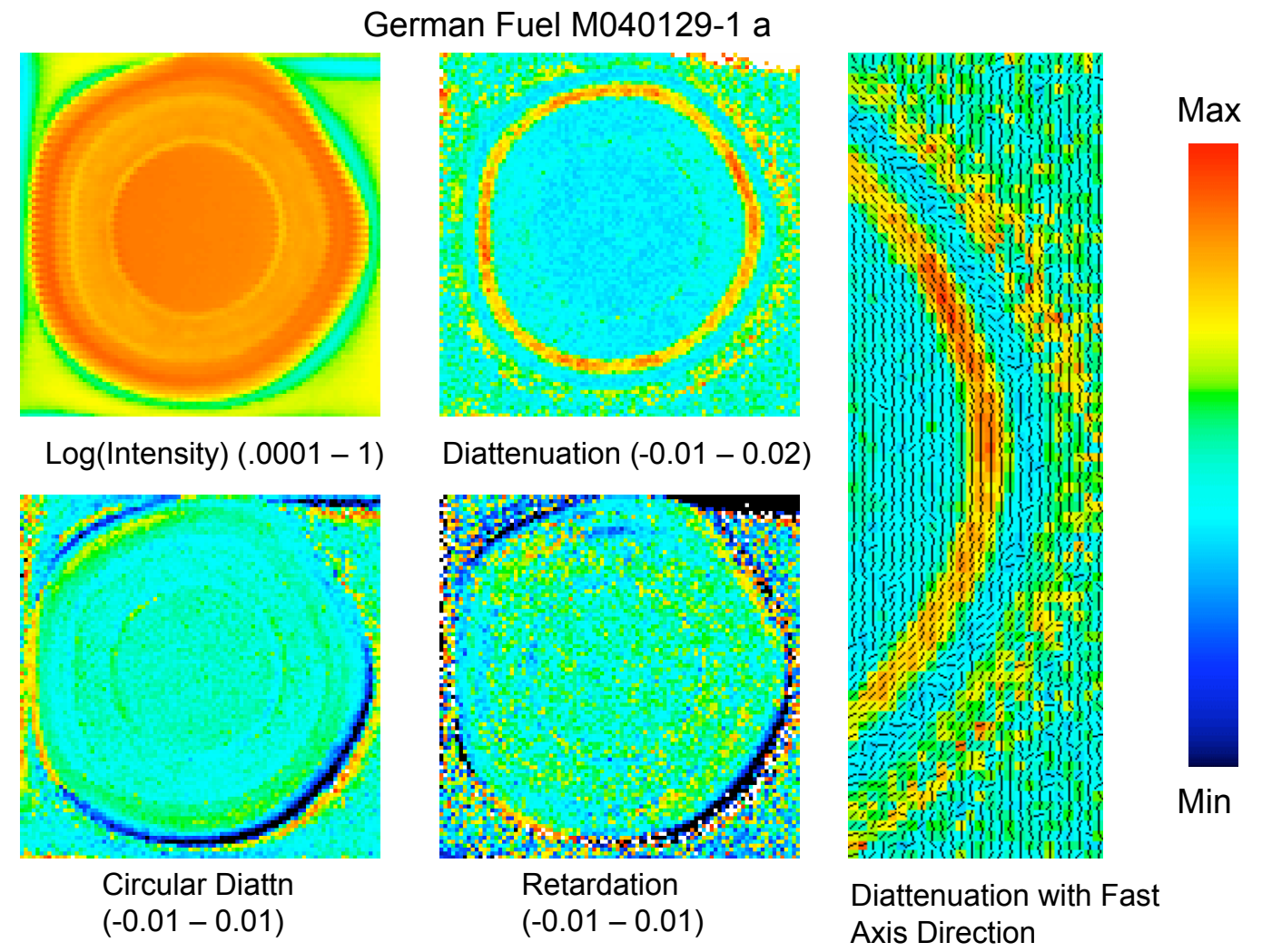

Figure 5-1: Images of various parameters obtained using the 2-MGEM. The intensity scale is logarithmic and the endpoints are parenthetical in the figure captions. The lines in the figure labeled "Diattenuation with Fast Axis Direction" indicate the direction of the fast axis (ab-plane) at that position. 
Images produced by the 2-MGEM were analyzed using a software tool developed for this project which allowed for individual pixels in the image to be selected and added to different lists. Using this tool, data was grouped together for the kernel (used for final data normalization), the IPyC layer, the $\mathrm{SiC}$ layer, and the OPyC layer. Relevant optical parameters for each list of data points was then output on a data sheet such as that in Appendix A.

Data points can be selected using any of the optical parameter images. The diattenuation is often used, as was the case for the data analysis shown in Appendix A. In some cases, such as when the diattenuation is near zero, it is more convenient to use the reflected intensity image in order to be able to identify the individual layers. Any one of the pictures can be displayed in the data sheet.

Several relevant parameters were selected for observation: the diattenuation, the retardation, the circular diattenuation, the direction of the fast axis, the polarization factor, and the relative intensity of light reflecting from the sample. It was assumed that the diattenuation was the primary quantity, and it was set to be positive definite and was used to determine the direction of the fast axis.

In the data sheet, the average and standard deviation (SD) of the data in each list was calculated. The average error (that is, the average of the error limits for each of the selected parameters measured at each point) was also calculated. If there is a significant variation of the observed quantity around the layer, then the SD will be on the order of or greater than the average error, but if the quantity is uniform at all the selected points in the list, then the SD will be less than the average error.

For the particle shown in Appendix A, the $\mathrm{SiC}$ layer (saved list A) was optically isotropic by all measures. The diattenuation was indistinguishable from 0 , as was the retardation and circular diattenuation. The direction of the fast axis was random, since it has little meaning for small values of optical anisotropy. Note, however, that for the $\mathrm{SiC}$ layer, the relationship (if any) between the optical anisotropy and anisotropy in the orientation of the crystallites is not yet well understood. In the PyC layers, the technique of characterizing crystalline anisotropy by measuring average optical anisotropy is based on that fact that the graphite structure possesses a high optical anisotropy. Certain polytypes of $\mathrm{SiC}$ (such as $\beta-\mathrm{SiC}$ ) are optically isotropic, while other polytypes are hexagonal or rhombohedral and therefore optically anisotropic. Without additional knowledge of the $\mathrm{SiC}$ microstructure, the observed optical isotropy of the $\mathrm{SiC}$ layer can not be related to the crystallographic orientation of the crystallites in the SiC layer.

The IPyC layer (saved list E) had a significant diattenuation with possibly a small measurable variation around the layer. A diattenuation of $0.013 \pm 0.003$ corresponds to an optical anisotropy factor of $1.026 \pm 0.006[\mathrm{OAF}=(1+\mathrm{N}) /(1-\mathrm{N}) \approx 1+2 \mathrm{~N}]$. There may have been some associated retardation in this layer, but it was not significantly different from 0 . The circular diattenuation was 0 as well, within the error of the measurement. The direction of the fast axis (from $-90^{\circ}$ to $+90^{\circ}$, corresponding to the direction of the a-b plane) was roughly perpendicular to the growth direction, and can be seen in the right part of Figure 5-1.

There was a smaller amount of optical anisotropy in the OPyC layer (saved list F), again with the direction of the fast axis perpendicular to the growth direction. The diattenuation was $0.008 \pm 0.002(\mathrm{OAF}=1.016 \pm .004)$. This was $57 \%$ of the diattenuation measured for the IPyC layer. The amount of signal collected for this layer was a factor of 3-10 less than that reflected from the IPyC layer. This was due to the polished surface not being perfectly planar. The failure 
of the 2-MGEM to collect all of the reflected light did not introduce an absolute error, as it would for the old optical polarimeter technique, but it did increase the stochastic error because of the reduction in signal. This caused the image to be "noisier" for the OPyC layer and the uncertainty of each data point to be higher. Improvements in sample preparation should solve this issue.

A total of 12 particles in M040129.1 were analyzed with the 2-MGEM. Table 5-1 summarizes the diattenuation measurements. For all the particles, the average $\mathrm{SiC}$ diattenuation was not different from zero with respect to the average error. The average of the average diattenuation for the IPyC layers was $0.014 \pm .002(\mathrm{OAF}=1.028 \pm 0.004)$. The average of the average diattenuation for the $\mathrm{OPyC}$ layers was $0.008 \pm 0.001(\mathrm{OAF}=1.016 \pm 0.002)$.

Please note that a formal and rigorous calibration and analysis of uncertainty for the measurements on the 2-MGEM is still in the process of completion. For this reason, the results presented in this section should be considered as preliminary. However, there exists strong evidence that the systematic errors are below the stated stochastic errors. Work is also being done to reduce both types of errors and more accurate measurements are anticipated in the near future.

Table 5-1 : Diattenuation of German Fuel

\begin{tabular}{|c|c|c|c|c|c|c|c|c|c|}
\hline & & IPyC & & & $\mathrm{SiC}$ & & & OPyC & \\
\hline & Ave. & S.D. & $\begin{array}{l}\text { Ave } \\
\text { Error }\end{array}$ & Ave. & S. D. & $\begin{array}{l}\text { Ave } \\
\text { Error }\end{array}$ & Ave. & S. D. & $\begin{array}{l}\text { Ave } \\
\text { Error }\end{array}$ \\
\hline & 0.0134 & 0.0025 & 0.0032 & 0.0015 & 0.0009 & 0.0026 & 0.0077 & 0.0019 & 0.0040 \\
\hline & 0.0140 & 0.0022 & 0.0029 & 0.0011 & 0.0006 & 0.0027 & 0.0077 & 0.0027 & 0.0040 \\
\hline & 0.0160 & 0.0022 & 0.0034 & 0.0015 & 0.0007 & 0.0030 & 0.0083 & 0.0029 & 0.0046 \\
\hline & 0.0127 & 0.0022 & 0.0037 & 0.0014 & 0.0008 & 0.0035 & 0.0078 & 0.0024 & 0.0040 \\
\hline & 0.0129 & 0.0023 & 0.0038 & 0.0017 & 0.0011 & 0.0035 & 0.0089 & 0.0023 & 0.0044 \\
\hline & 0.0174 & 0.0022 & 0.0031 & 0.0014 & 0.0008 & 0.0028 & 0.0097 & 0.0035 & 0.0036 \\
\hline & 0.0138 & 0.0019 & 0.0028 & 0.0024 & 0.0011 & 0.0023 & 0.0086 & 0.0028 & 0.0045 \\
\hline & 0.0122 & 0.0018 & 0.0028 & 0.0017 & 0.0006 & 0.0024 & 0.0071 & 0.0033 & 0.0036 \\
\hline & 0.0159 & 0.0022 & 0.0033 & 0.0016 & 0.0012 & 0.0031 & 0.0089 & 0.0051 & 0.0037 \\
\hline & 0.0133 & 0.0017 & 0.0028 & 0.0019 & 0.0009 & 0.0027 & 0.0074 & 0.0025 & 0.0046 \\
\hline & 0.0125 & 0.0015 & 0.0027 & 0.0014 & 0.0010 & 0.0027 & 0.0062 & 0.0021 & 0.0032 \\
\hline & 0.0137 & 0.0017 & 0.0028 & 0.0017 & 0.0009 & 0.0028 & 0.0074 & 0.0038 & 0.0039 \\
\hline & 0.0140 & 0.0020 & 0.0031 & 0.0016 & 0.0009 & 0.0029 & 0.0080 & 0.0030 & 0.0040 \\
\hline s & 0.0016 & 0.0003 & 0.0004 & 0.0003 & 0.0002 & 0.0004 & 0.0010 & 0.0009 & 0.0004 \\
\hline
\end{tabular}




\title{
6 TEM Analysis of PyC Layer
}

\author{
N. Hashimoto and J.D. Hunn
}

Coating fragments were obtained as described in Section 1. A TEM specimen was prepared using focused ion beam micromaching (FIB). The FIB used a focused ion beam for controlled removal of material by sputtering. The FIB preparation involved sputter-coating the sample with Pt then depositing a thick protective layer of Pt using the FIB. Machining of the TEM specimen was then performed using $30 \mathrm{keV} \mathrm{Ga}^{+}$ions.

Figure 6-1 shows a typical bright field image of the IPyC layer. 200-400 nm clumps were observed. Diffraction patterns from polycrystalline specimens can be viewed in much the same way as X-ray diffraction from powders. If the polycrystal is textured, there is usually one special plane nearly common to all the grains. The pattern produced by a random polycrystal can be distinguished from one produced by a textured specimen by a tilting technique. The diffraction patterns for this sample indicated a random polycrystal structure.

Using the diffraction pattern, the grain size could be estimated from the width of the rings to be less than $10 \mathrm{~nm}$, but it was more direct to observe the dark field image. Figure 6-2 shows a dark field image of the inner pyrocarbon layer. In the dark field image, diffracted spots selected by the objective lens aperture made white contrast on the image. From these spots, the size distribution of grains and average grain size could be estimated to be $1.2 \pm 0.2 \mathrm{~nm}$. Figure 6-3 shows a dark field image of the outer pyrocarbon layer. The estimated grain size was $1.1 \pm 0.2$ $\mathrm{nm}$. Figure 6-4 shows the distribution in grain size as measured by this technique. 


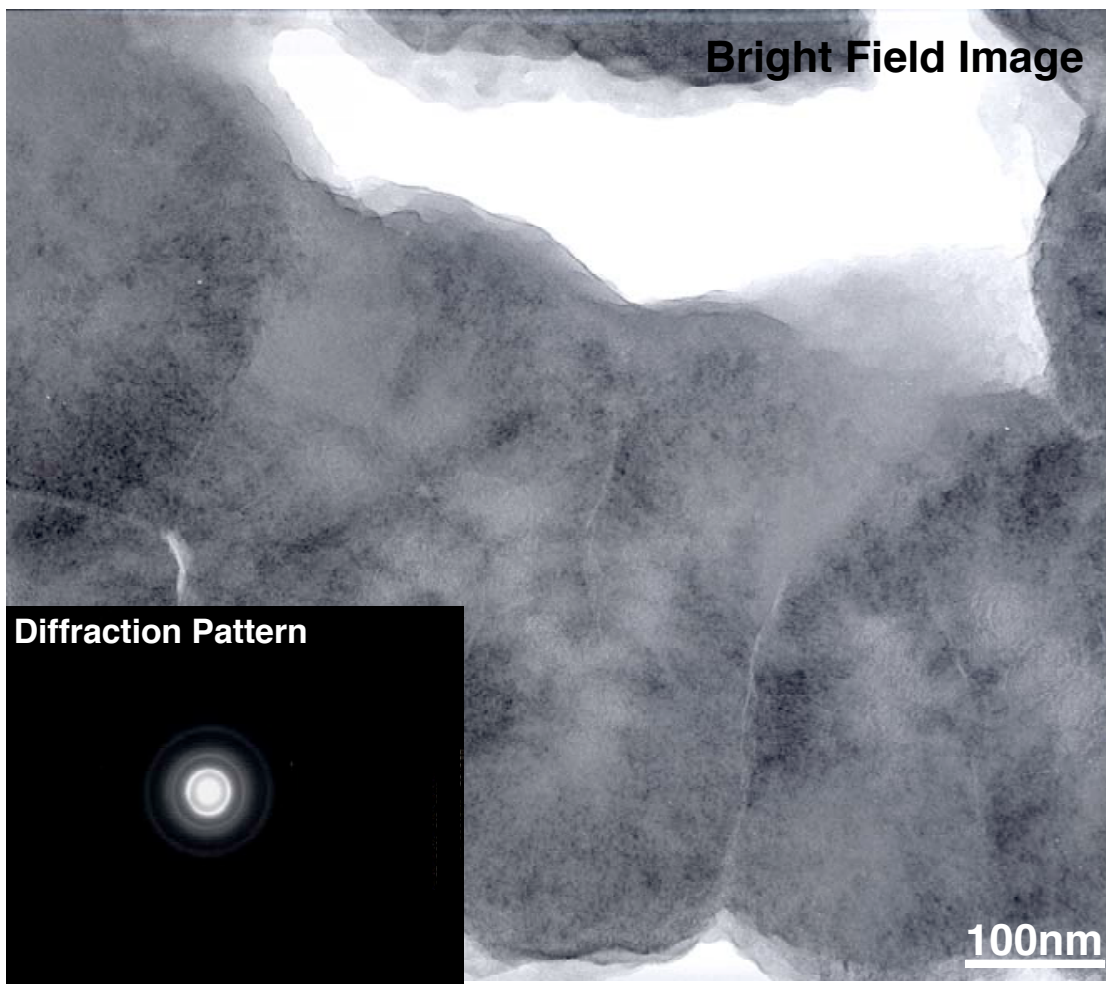

Figure 6-1: IPyC bright field image

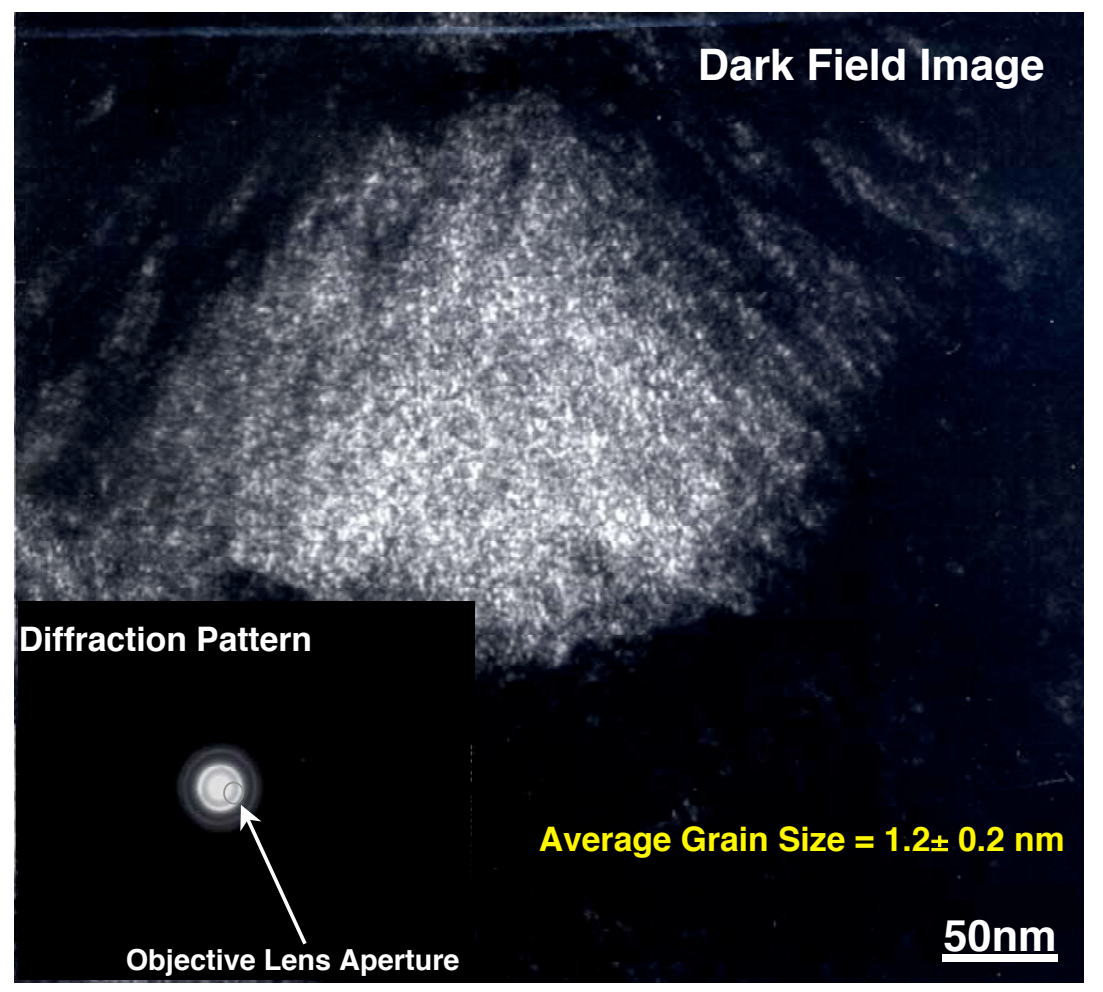

Figure 6-2: IPyC dark field image 
ORNL/CF-04/06

Revision 0

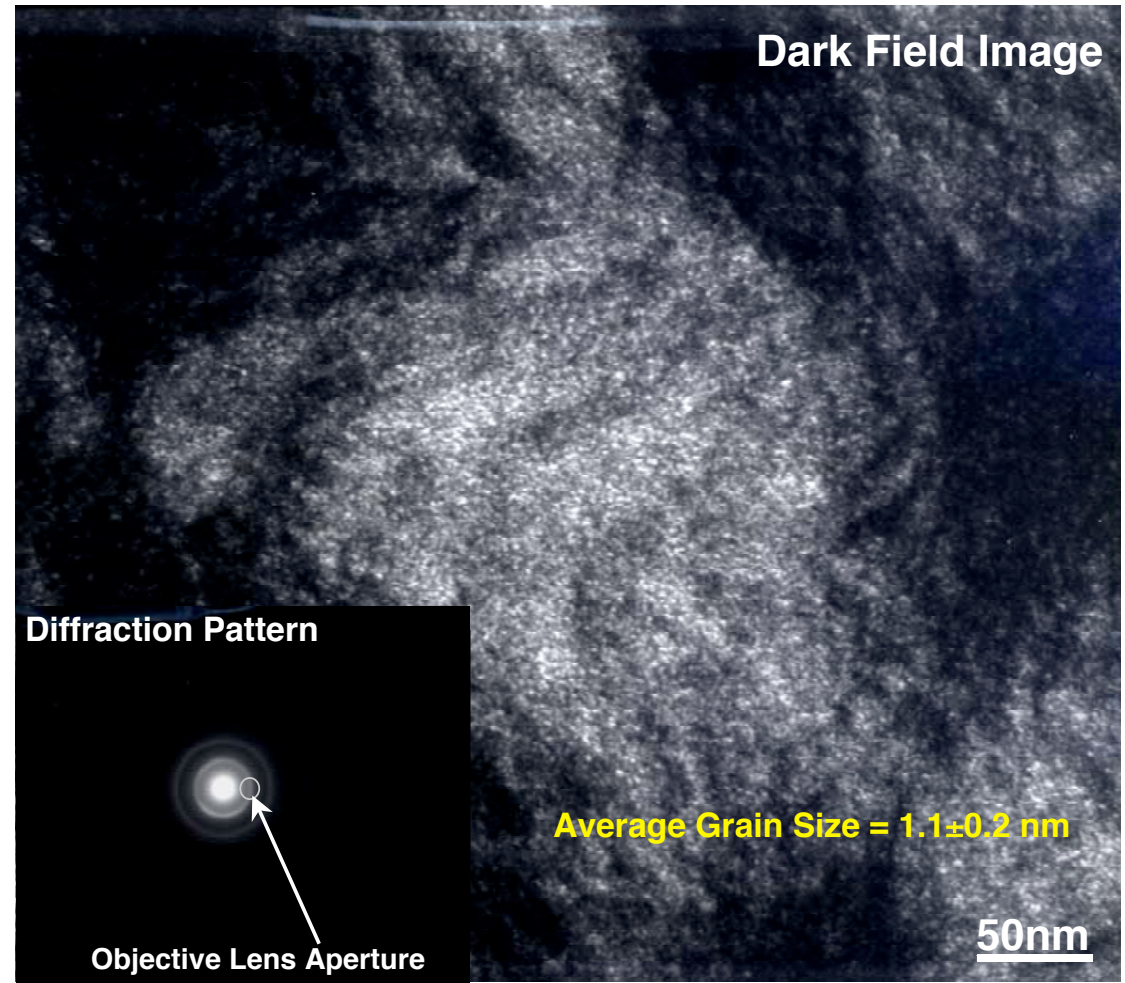

Figure 6-3: OPyC dark field image

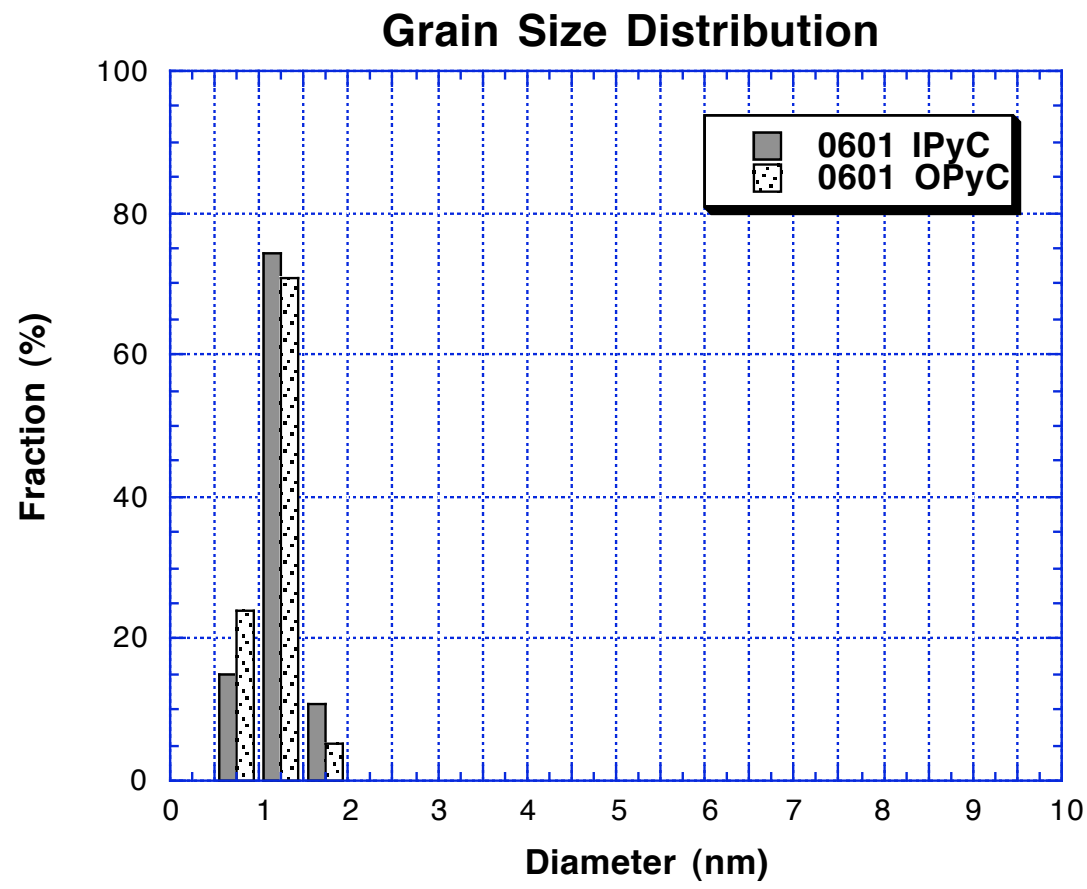

Figure 6-4: Grain size in PyC layers measured by TEM 


\title{
7 SEM Analysis
}

\author{
P.A. Menchhofer, J.D. Hunn, and W.E. Comings
}

\subsection{SEM of kernels}

Kernels were extracted from the German reference fuel as described in Section 1. A single kernel was selected at random and the surface was imaged by SEM. This was done to make a quick qualitative analysis and should not be considered a statistically adequate measure of the average microstructure. Figure 7-1 through Figure 7-4 show the surface of the German kernel. The surface was very smooth with well defined grain boundaries. The size of the grains at the surface was from $10-40 \mu \mathrm{m}$. Some open porosity was observed within the grains.

38 particles were mounted in a conducting epoxy and polished for imaging by SEM (mount ID\# M040127.1 and M040127.2). Again, no attempt was made to obtain sufficient images and measurements to produce statistically sound quantitative measurements of grain size for this qualitative analysis. However, it was observed that most of the polished particles had a similar microstructure.

Figure 7-5 through Figure 7-7 show a kernel in cross section. The scratches that were observed were due to a non-optimized polishing procedure. Grain structure was imaged by using backscattered electron imaging (BSE). This produced contrast between grains of different orientation due to channeling effects. The grain size in the plane of the cross section for the German kernels was larger at the surface $(30-50 \mu \mathrm{m})$ than in the interior of the kernel $(5-20$ $\mu \mathrm{m})$. The kernel also exhibited pits that were probably closed porosity exposed by the cross sectioning. Pit size was $0.5-1.5 \mu \mathrm{m}$. Figure 7-8 and Figure 7-9 show two of these pits at higher magnification.

Energy dispersive x-ray spectroscopy (EDS) in the kernel region showed uranium and oxygen, with some carbon from the carbon flash coating used to reduce charging during analysis. Some iron deposits were found around the edges of the kernel but these were most likely due to gaps at the kernel/buffer interface being filled with iron-bearing conductive epoxy. A sensitive search for iron can be done but would require using a different epoxy and clean polishing cloths. EDS comparison of grains which appeared light or dark in BSE imaging mode showed no difference. 
ORNL/CF-04/06

Revision 0

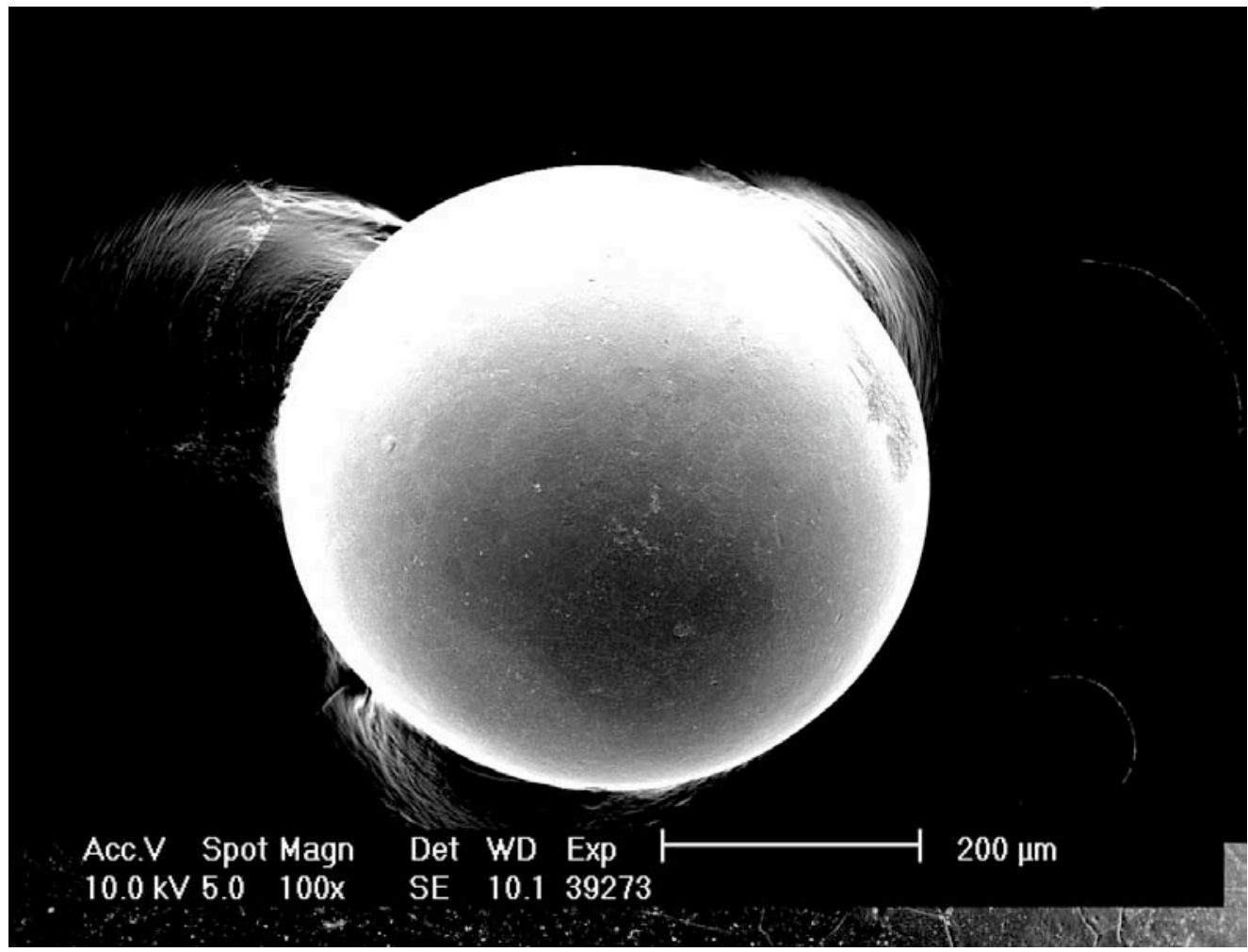

Figure 7-1: German kernel

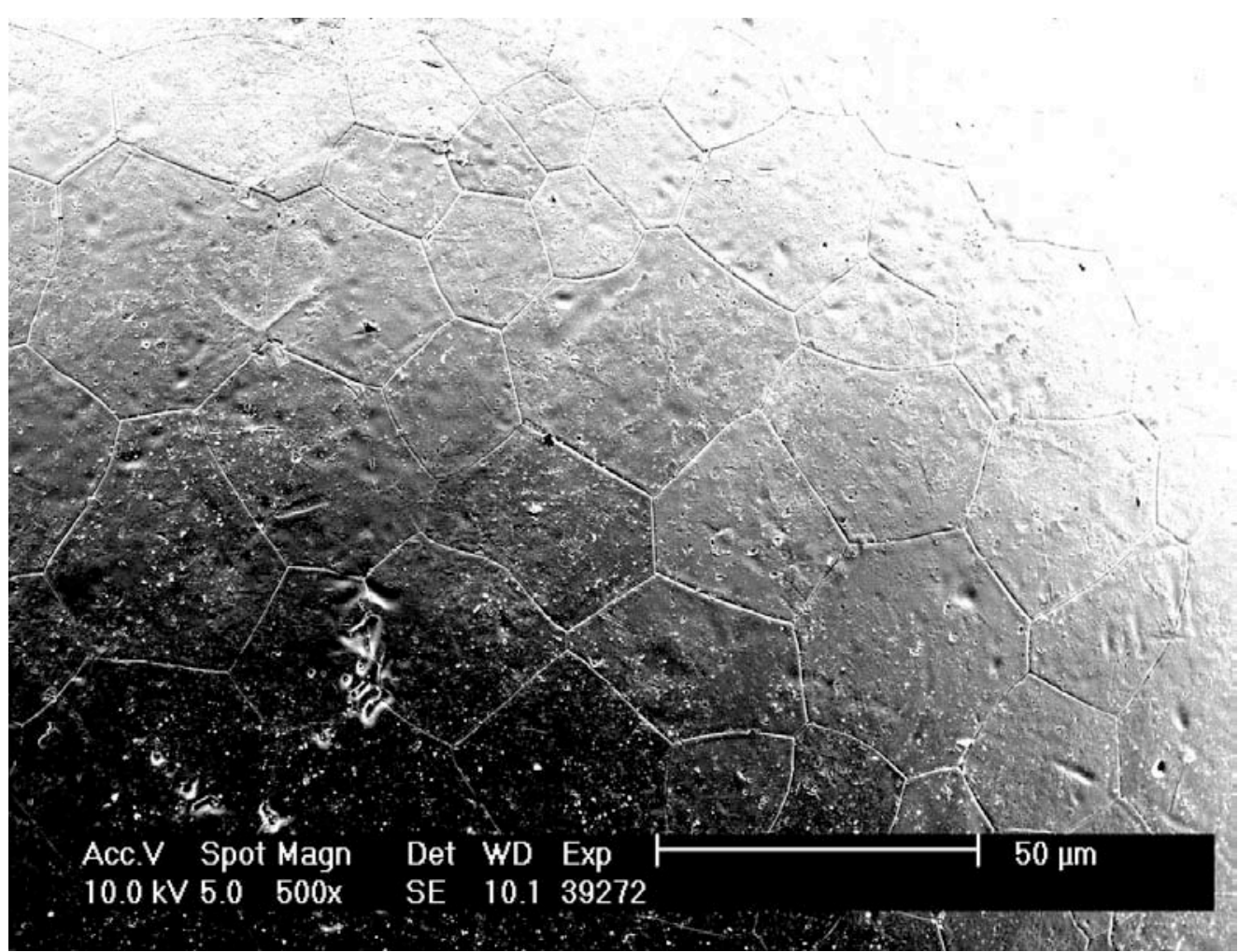

Figure 7-2: German kernel 
ORNL/CF-04/06

Revision 0

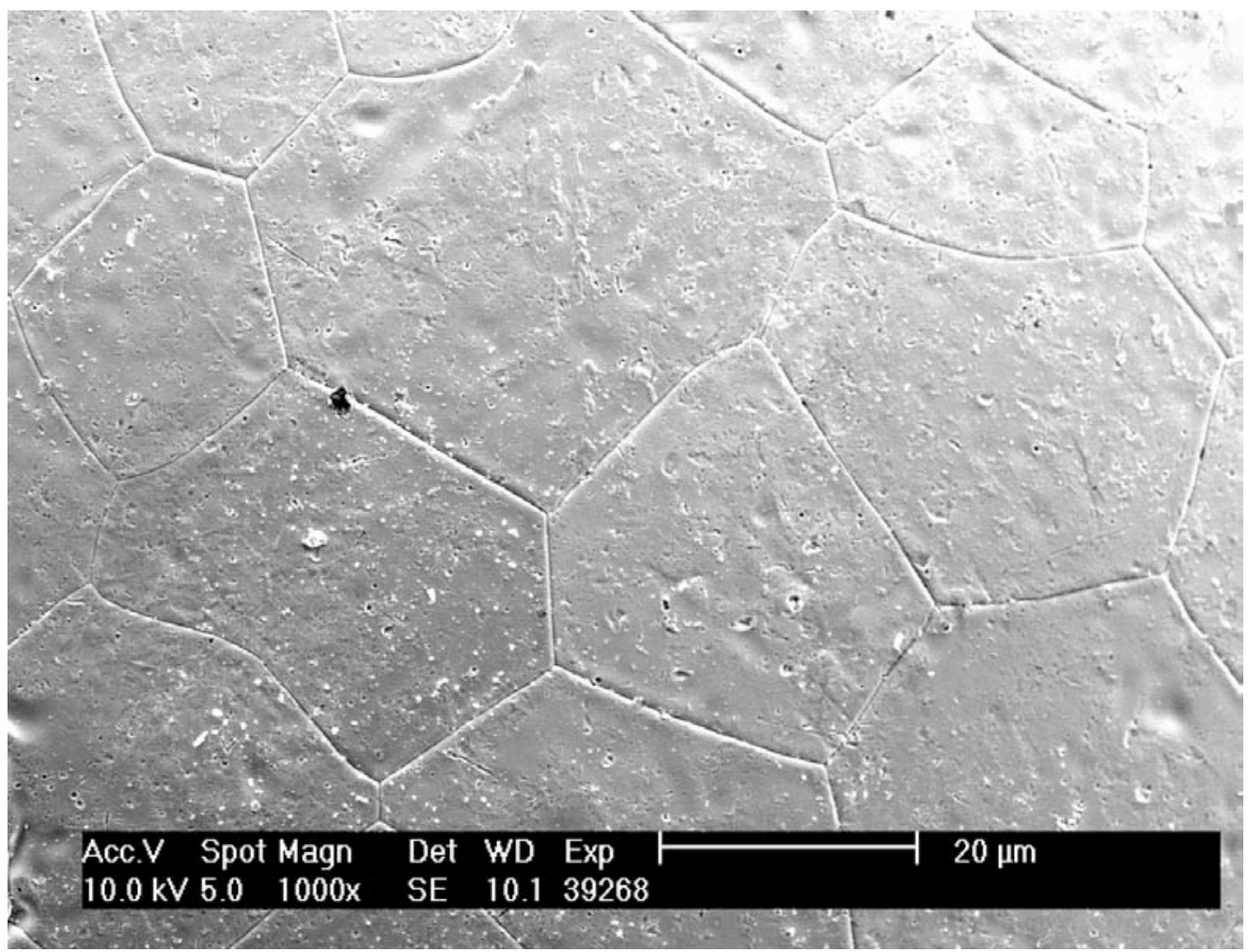

Figure 7-3: German kernel

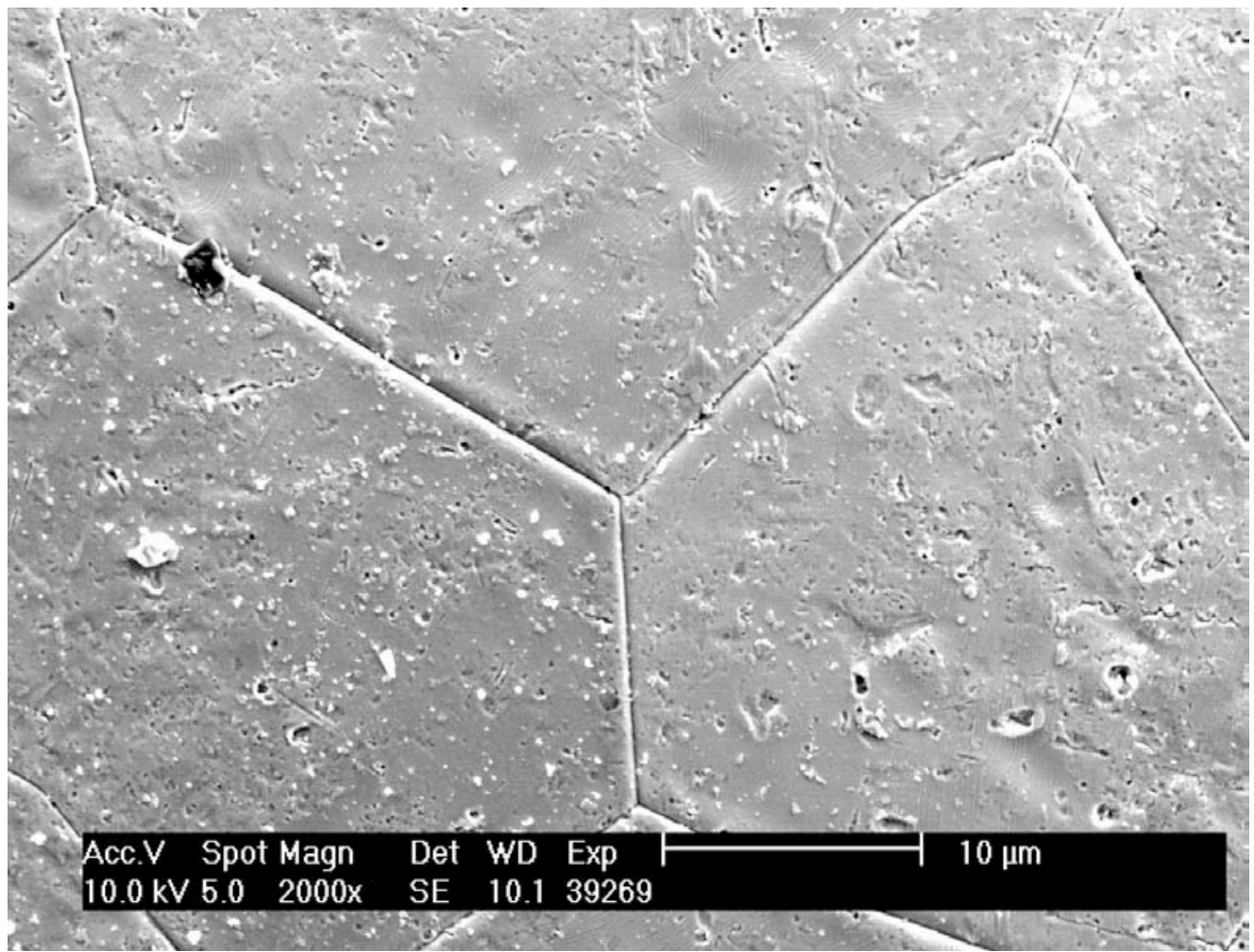

Figure 7-4: German kernel 
ORNL/CF-04/06

Revision 0

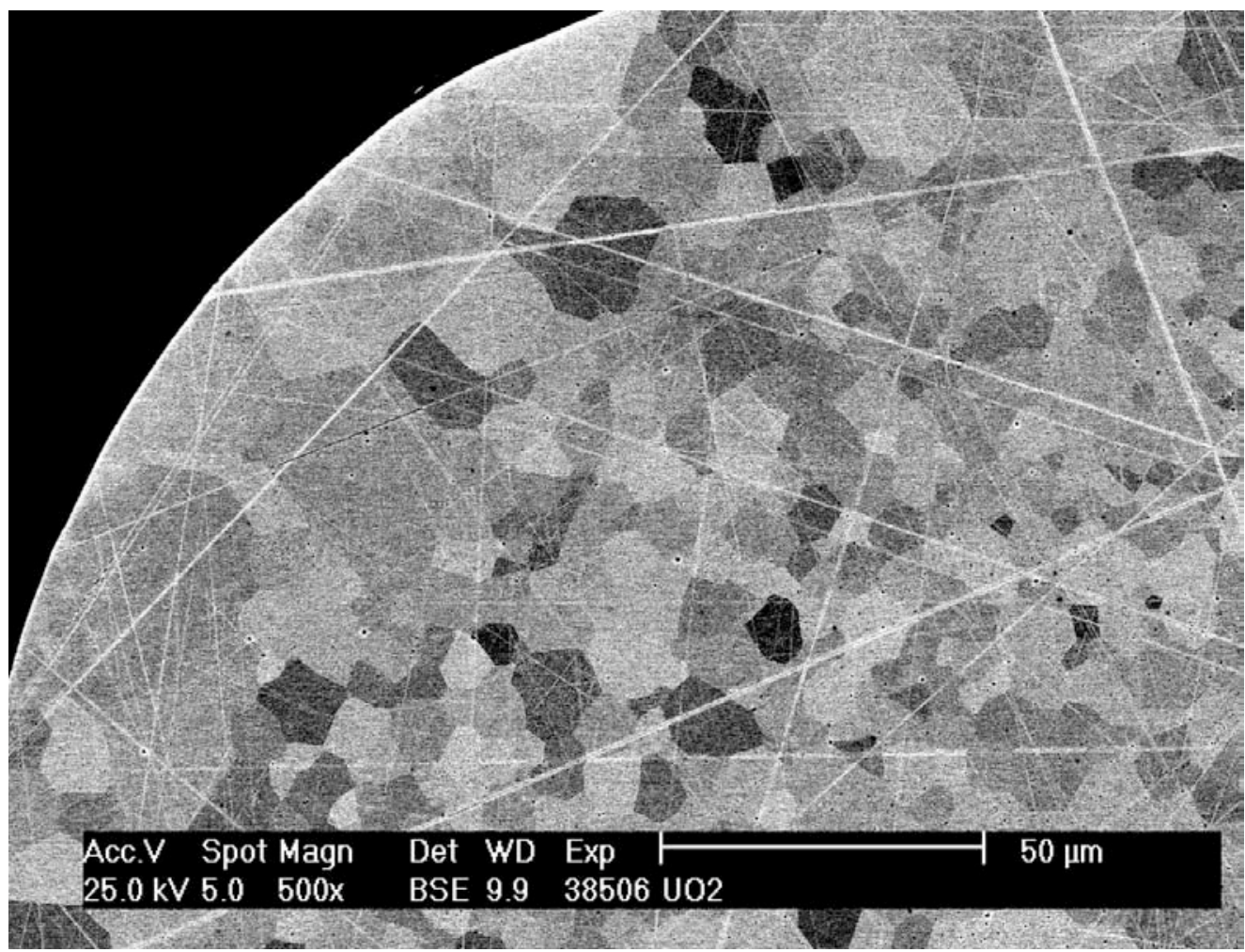

Figure 7-5: German kernel cross section

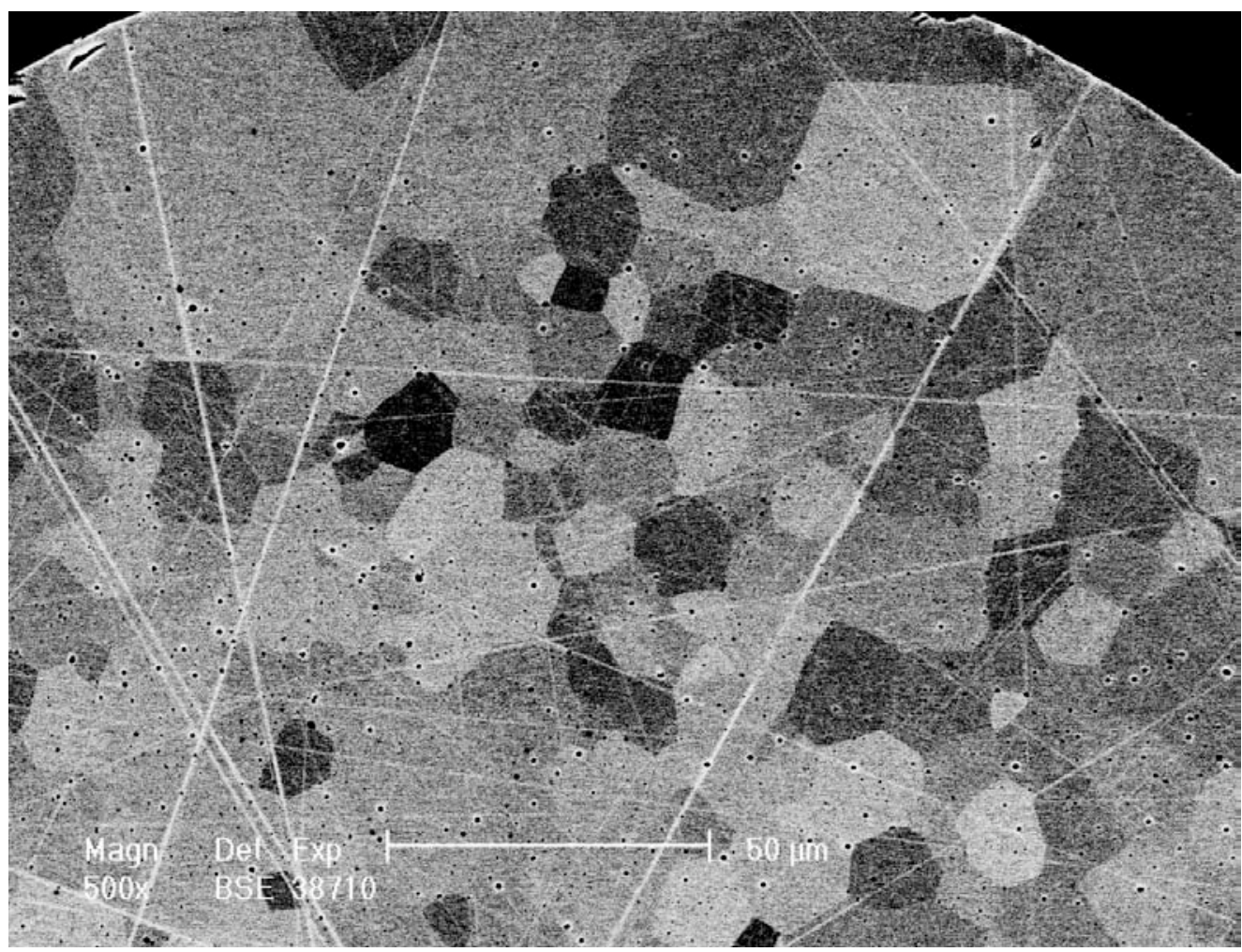

Figure 7-6: German kernel cross section 


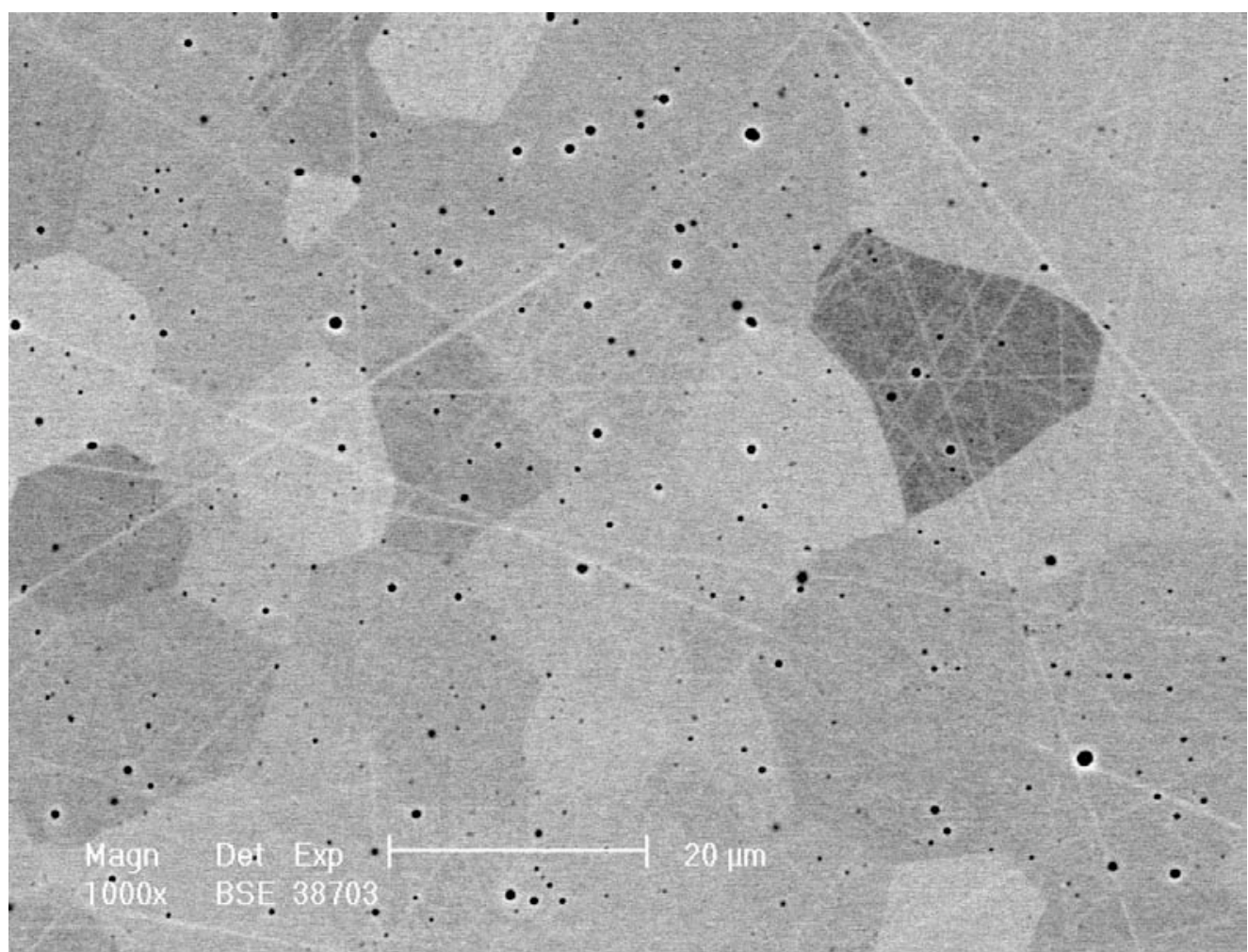

Figure 7-7: German kernel cross section

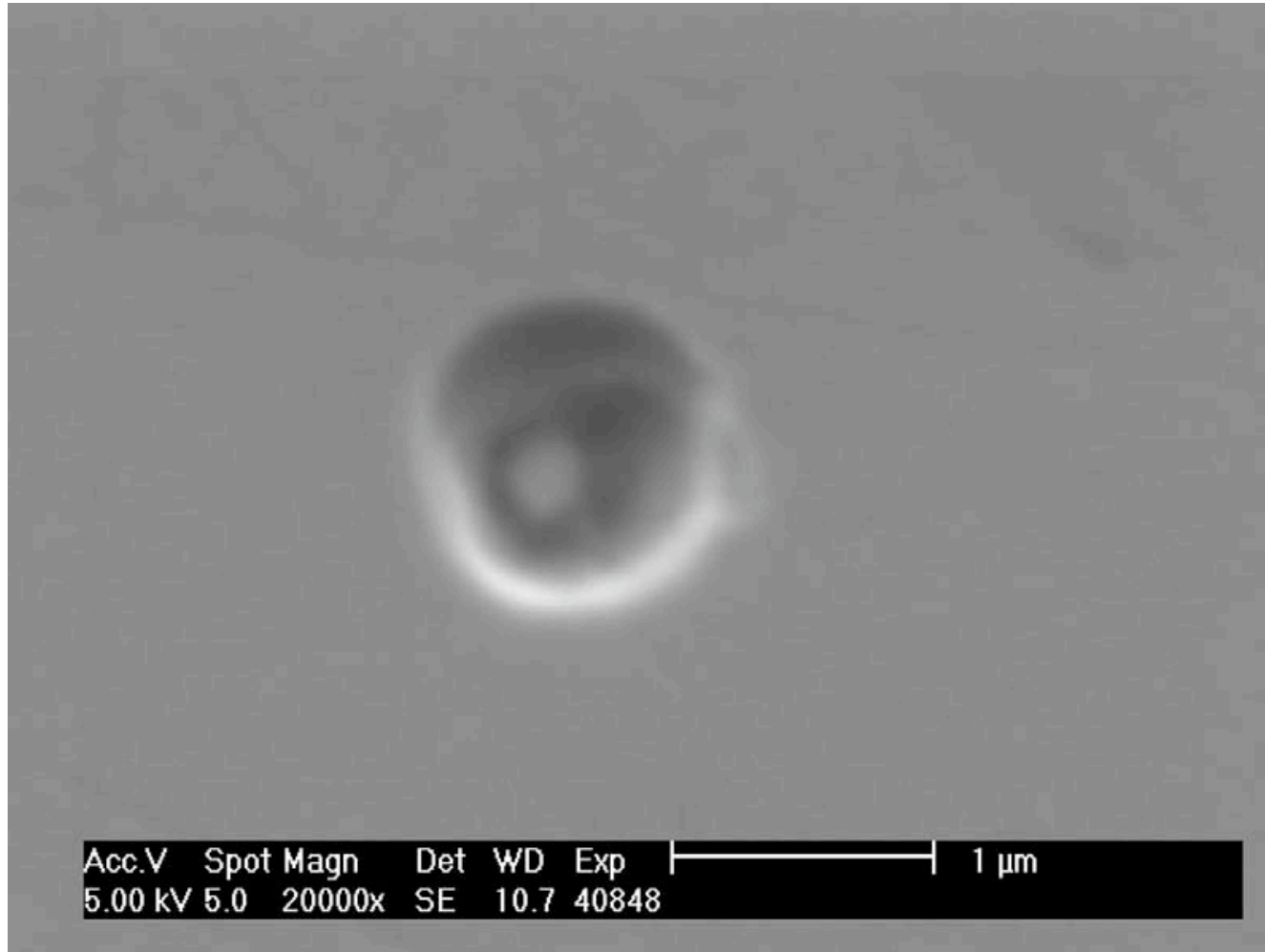

Figure 7-8: Small pit in kernel 
ORNL/CF-04/06

Revision 0

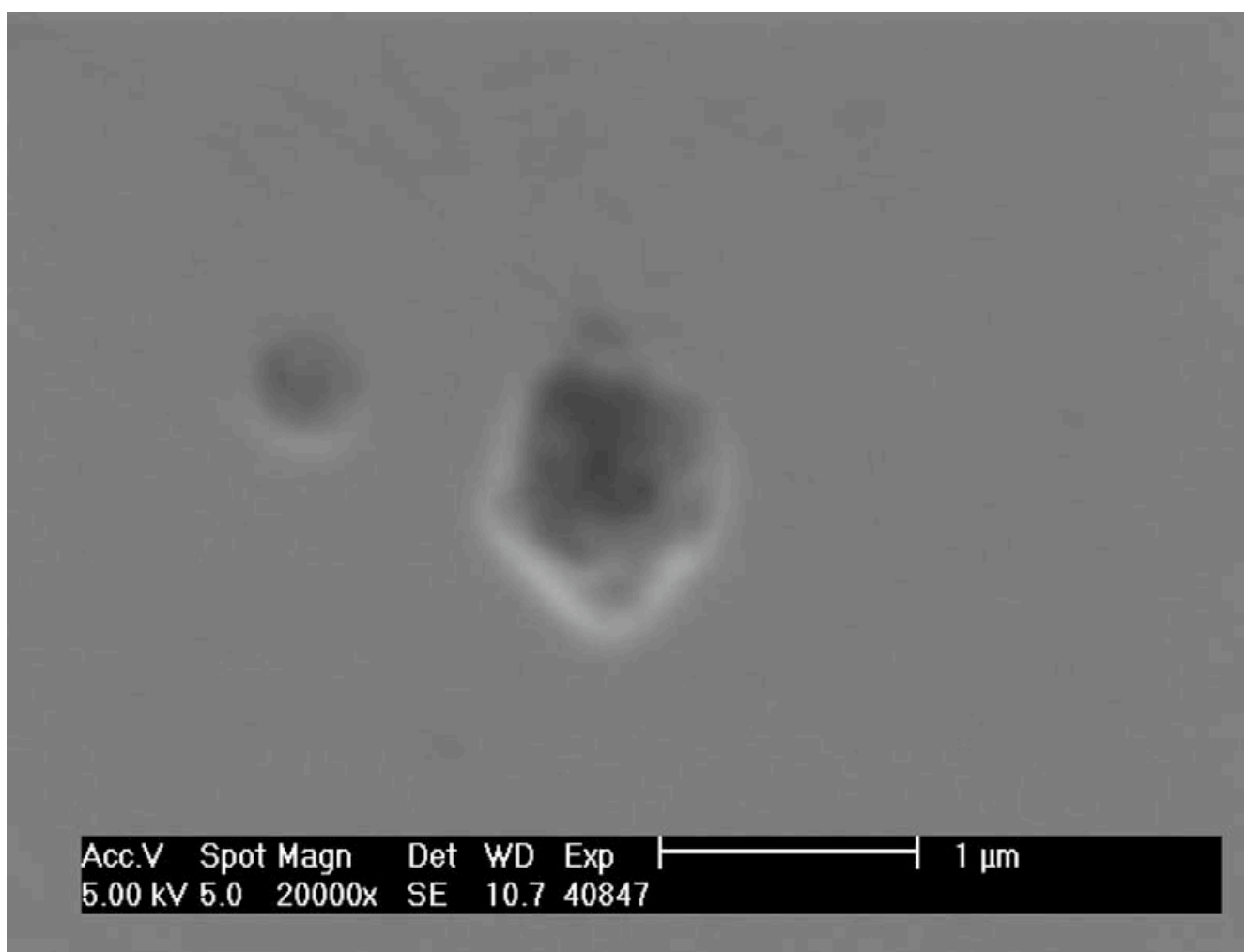

Figure 7-9: Small pit in kernel 


\subsection{SEM of coated particles}

Figure 7-10 shows a typical particle cross section with a bright kernel surrounded by a porous buffer surrounded by a dark IPyC layer, a bright $\mathrm{SiC}$ layer, and a dark OPyC layer. Figure 7-11 and Figure 7-12 show the coating layers at higher magnification. The buffer layer was clearly more porous than the IPyC and OPyC layers. A band structure of alternating higher and lower porosity was observed in the buffer and PyC layers. This was presumably caused by the fluidized particles cycling through zones with varying coating conditions. Counting these "growth rings" indicates how many times the particle cycled through the bed. The bands were observed to become thinner with increasing radius. This probably indicates that the gas concentrations were fairly constant during deposition of the layer and the deposition rate decreased in proportion to the increasing surface area.

Figure 7-13 shows a close up of the buffer/IPyC interface. There was a dark gray band at the edge of the buffer surrounded by light gray band. The contrast of the dark gray band was similar to that observed in the IPyC and the contrast of the light gray band was similar to that observed in the buffer. The light gray band looks like it may be slightly less porous than the IPyC layer. This interface layer is suspected of having caused the fracture behavior observed in the German coatings discussed in section 1 . These coatings were unique in that they showed a higher probability of separation at the buffer IPyC interface, compared to HRB-21 and early ORNL coatings.

Figure 7-14 shows a close up of the OPyC layer. Both PyC layers appeared to be composed of micron-size clumps of pyrocarbon with open space or filler between the clumps.

Figure 7-15 through Figure 7-18 show the difference between the IPyC/SiC interface and the $\mathrm{SiC} / \mathrm{OPyC}$ interface. When the $\mathrm{SiC}$ was deposited on the porous IPyC surface there was apparently significant penetration of $\mathrm{SiC}$ into the open pores. This resulted in a stitched interface as seen in Figure 7-16 and Figure 7-17. This stitching would not be expected when the OPyC was deposited on the non-porous SiC. Figure 7-18 shows a sharp boundary at the SiC/OPyC interface. However, it is apparent that the $\mathrm{SiC}$ surface was not smooth. This can be seen by the irregular interface in Figure 7-18.

By increasing the contrast in the SEM image it was possible to image some of the SiC grain structure due to electron channeling. Figure 7-19 and Figure 7-20 show the SiC layer at high contrast. Most of the grains were smaller than $2 \mu \mathrm{m}$ in the plane of the cross section. A few grain cross sections in the $2-3 \mu \mathrm{m}$ range were also visible. 
ORNL/CF-04/06

Revision 0

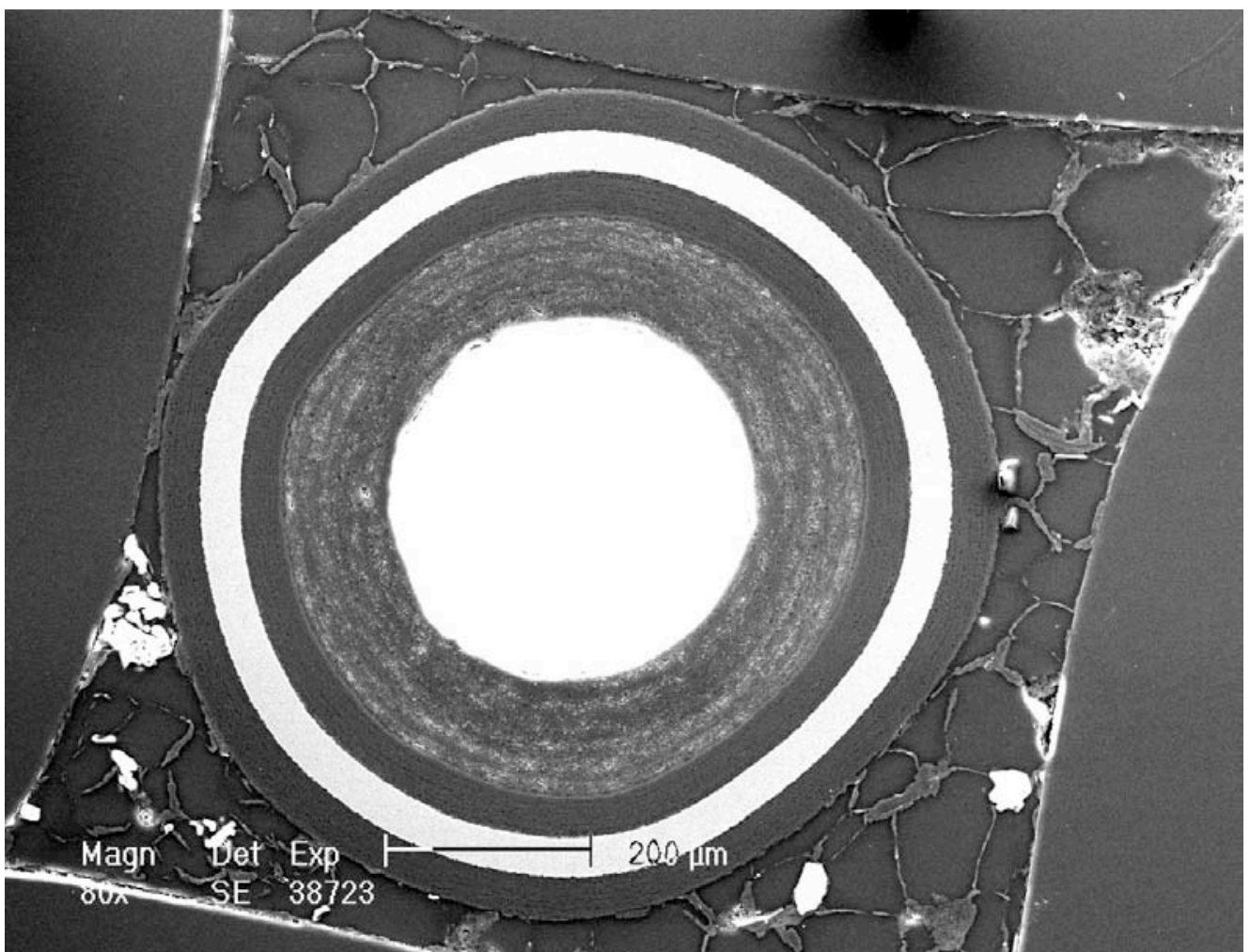

Figure 7-10: Typical particle cross section

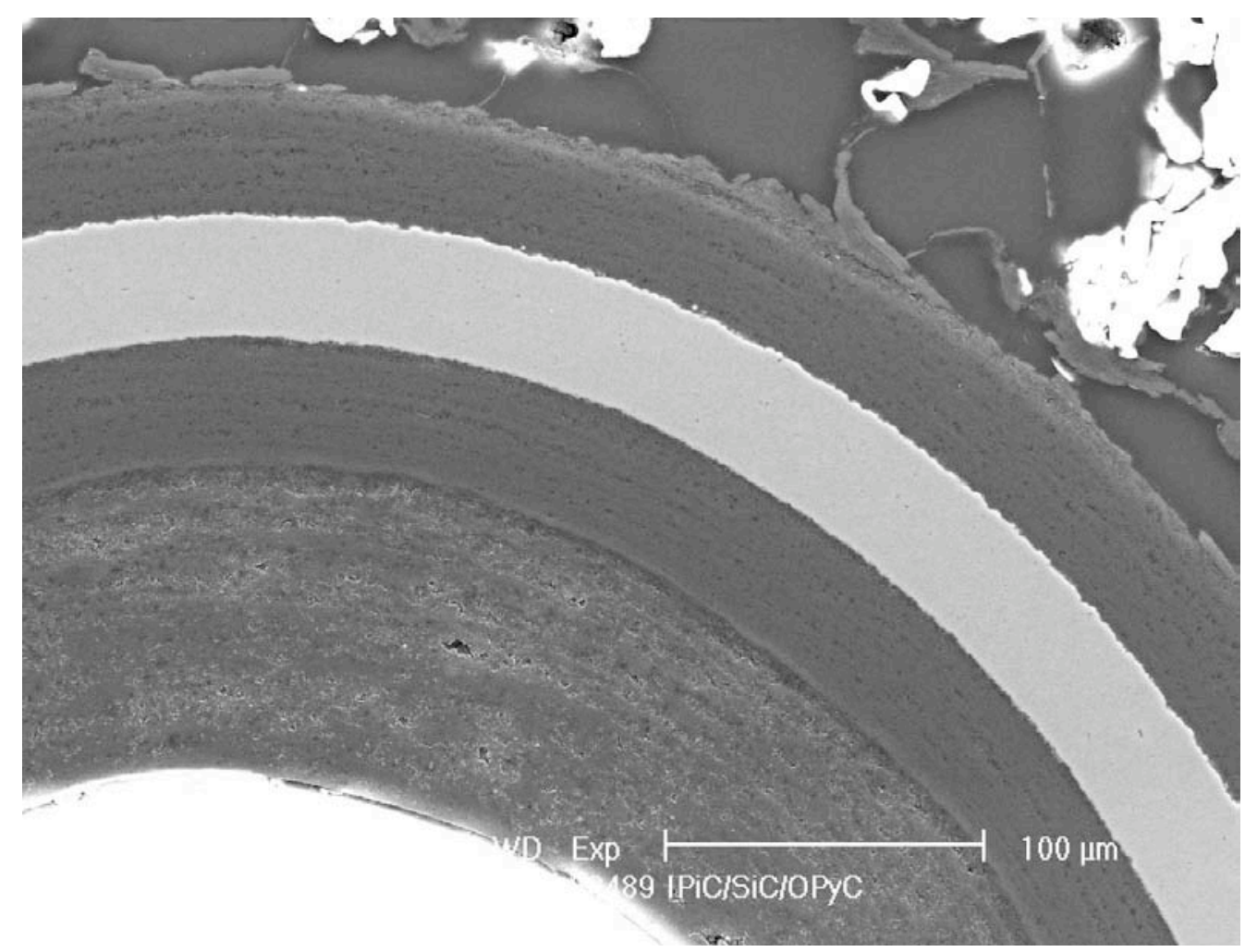

Figure 7-11: Typical coating layers 
ORNL/CF-04/06

Revision 0

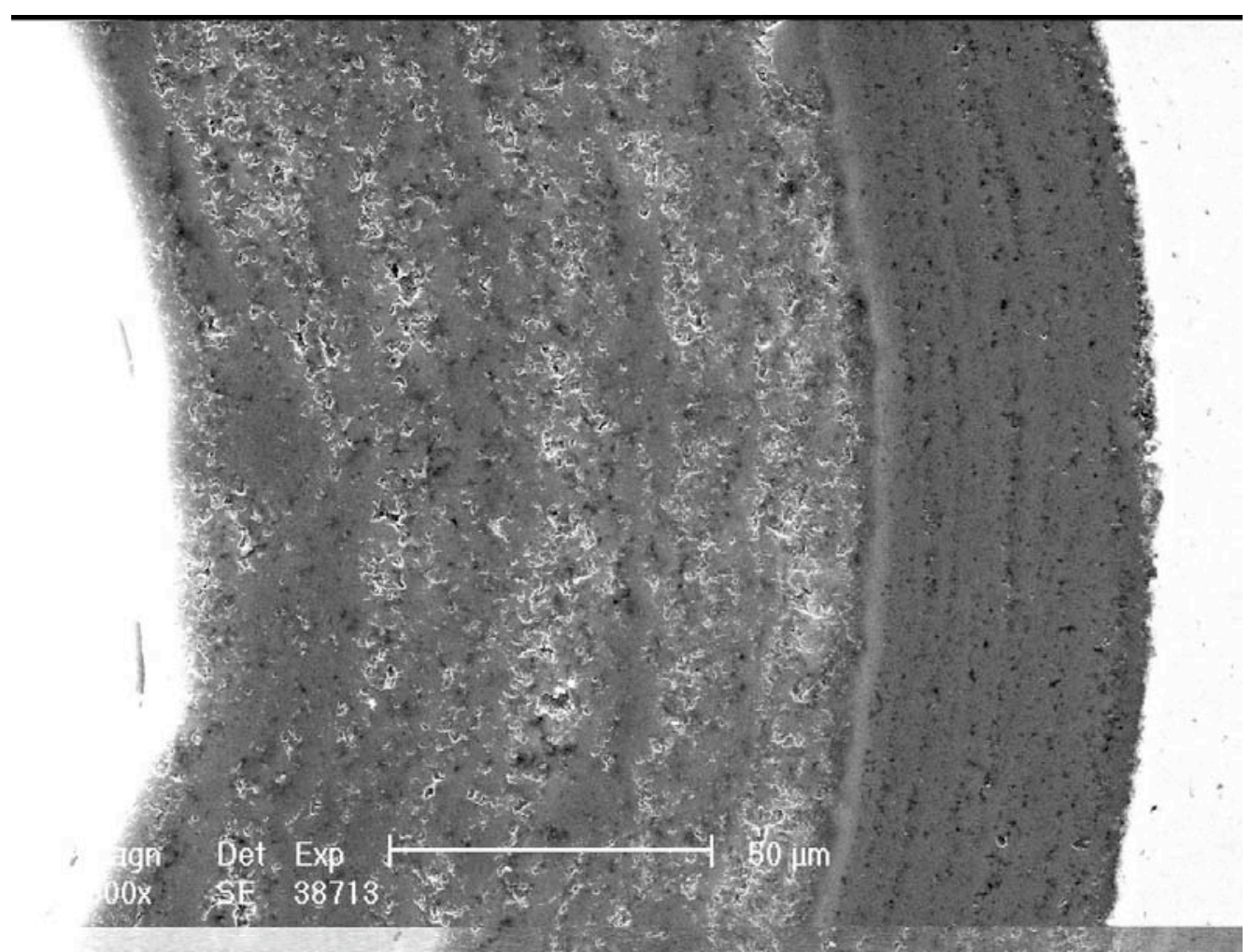

Figure 7-12: Buffer and IPyC

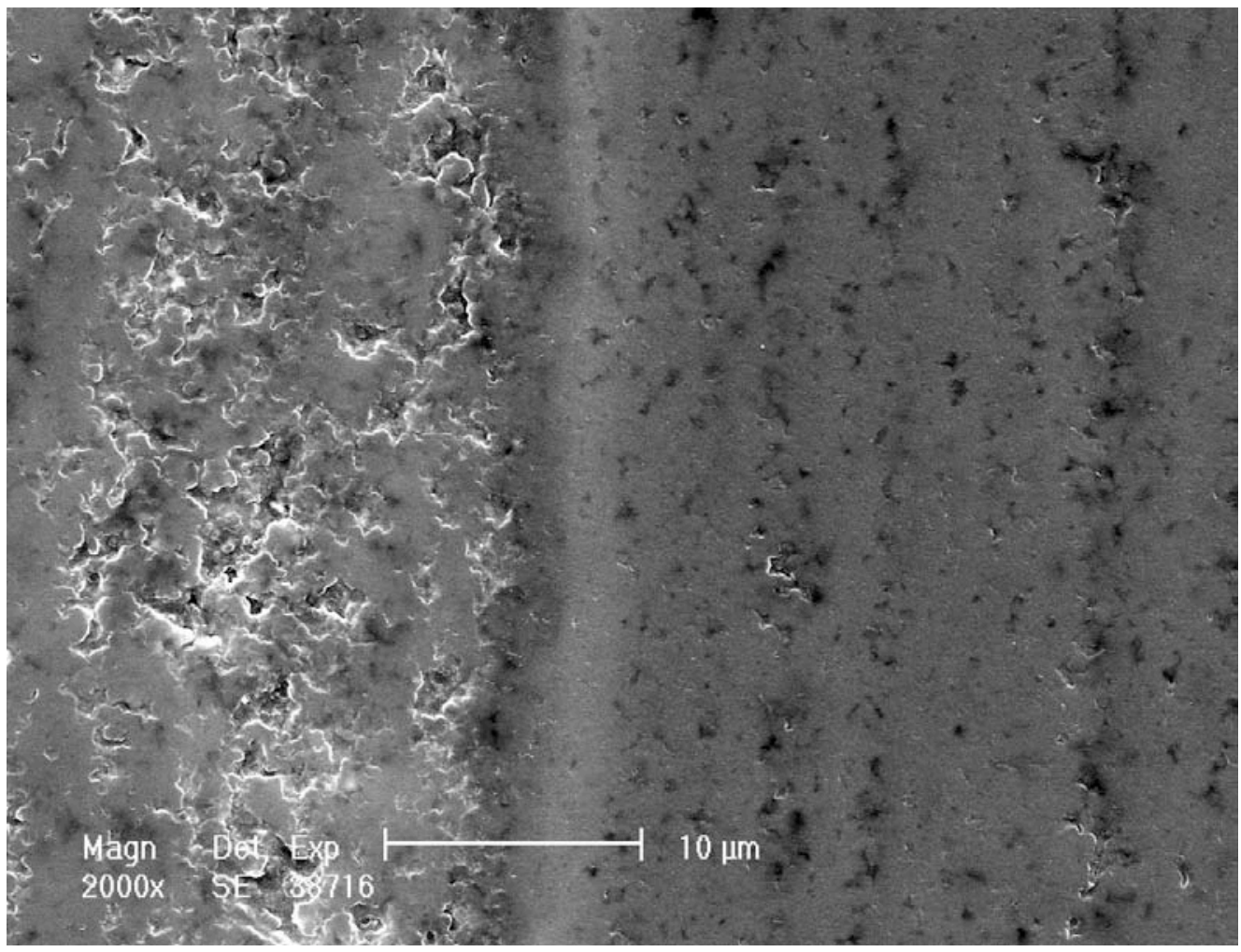

Figure 7-13: Buffer/IPyC interface 
ORNL/CF-04/06

Revision 0

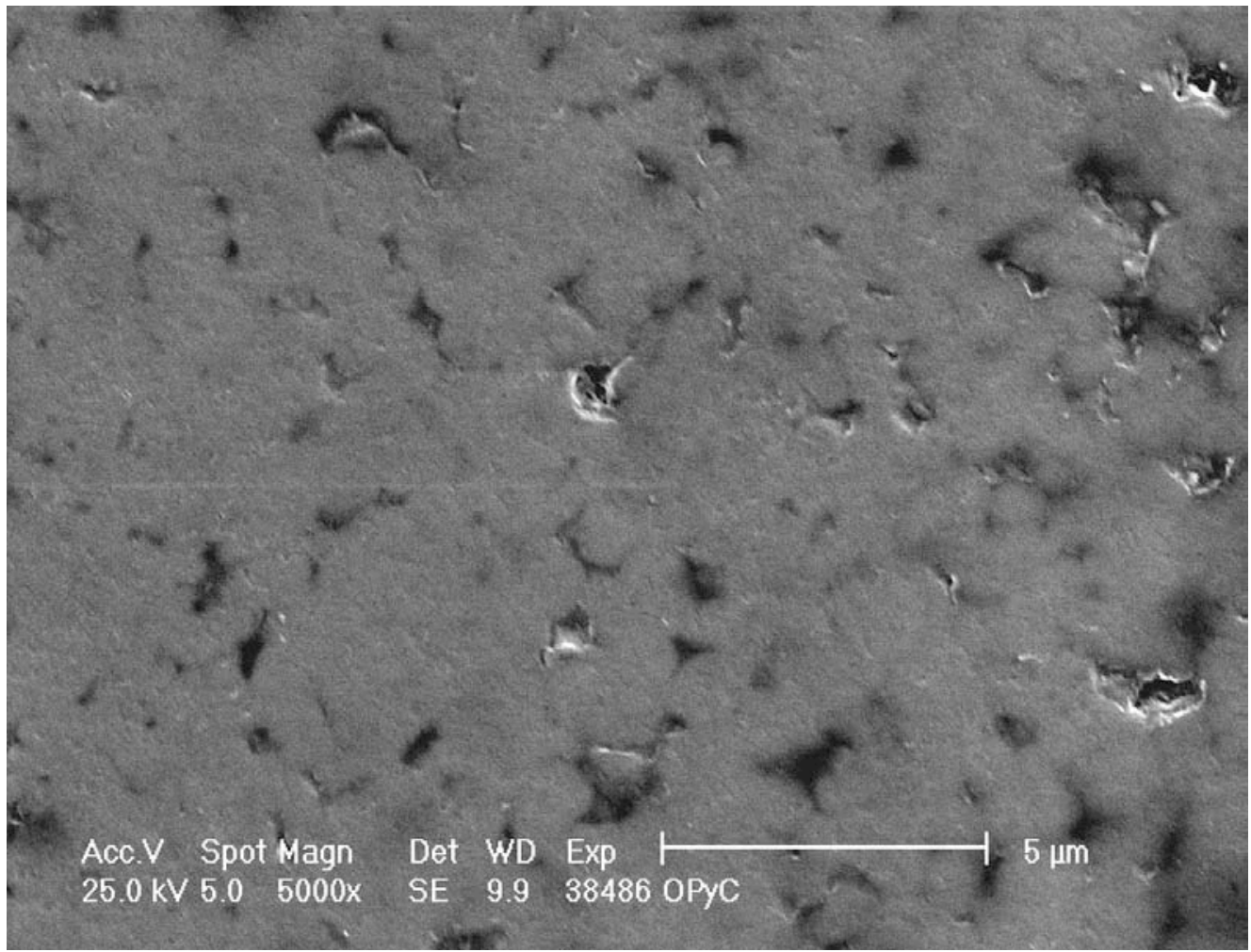

Figure 7-14: $\mathrm{OPyC}$

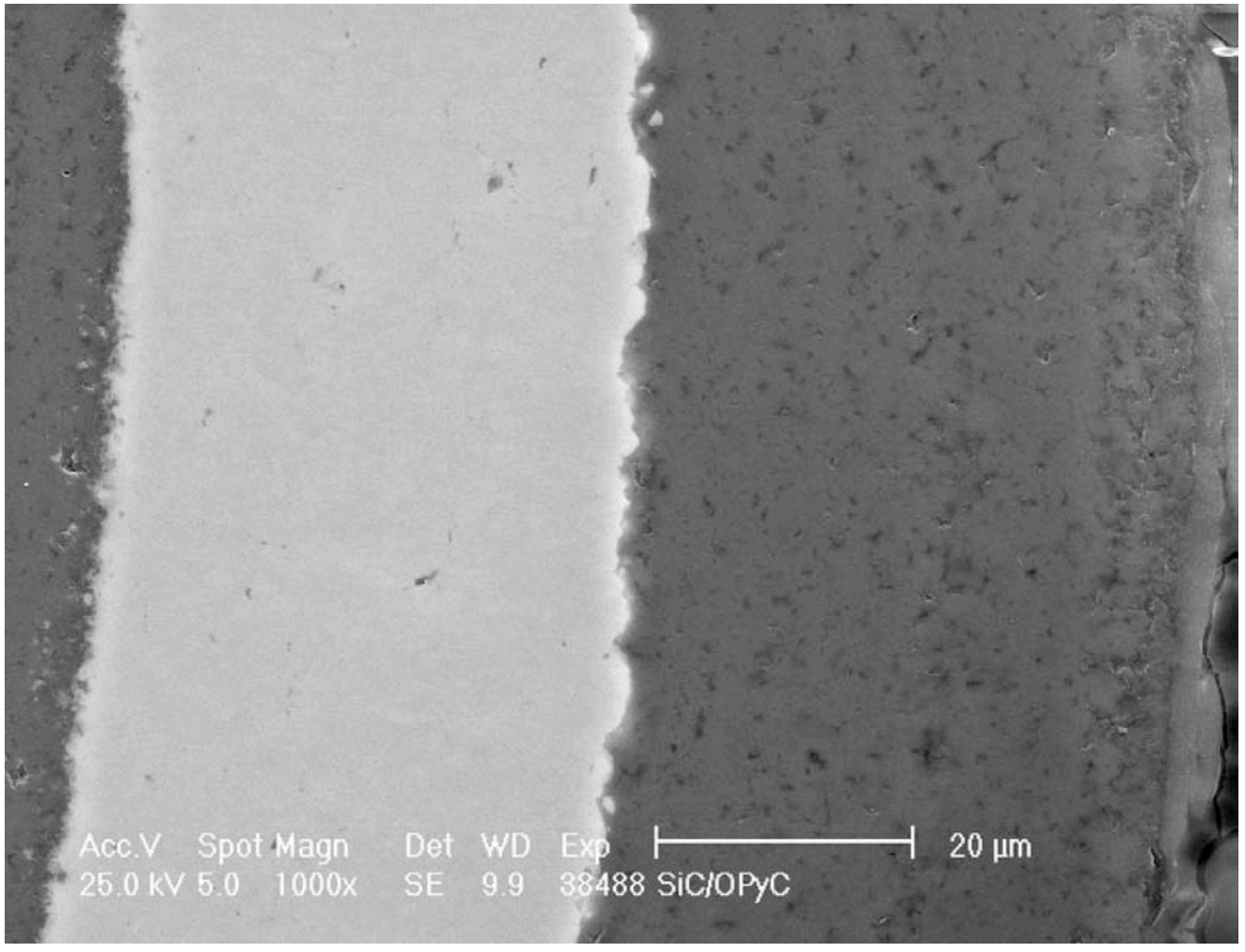

Figure 7-15: IPyC/SiC/OPyC layers (left to right) 
ORNL/CF-04/06

Revision 0

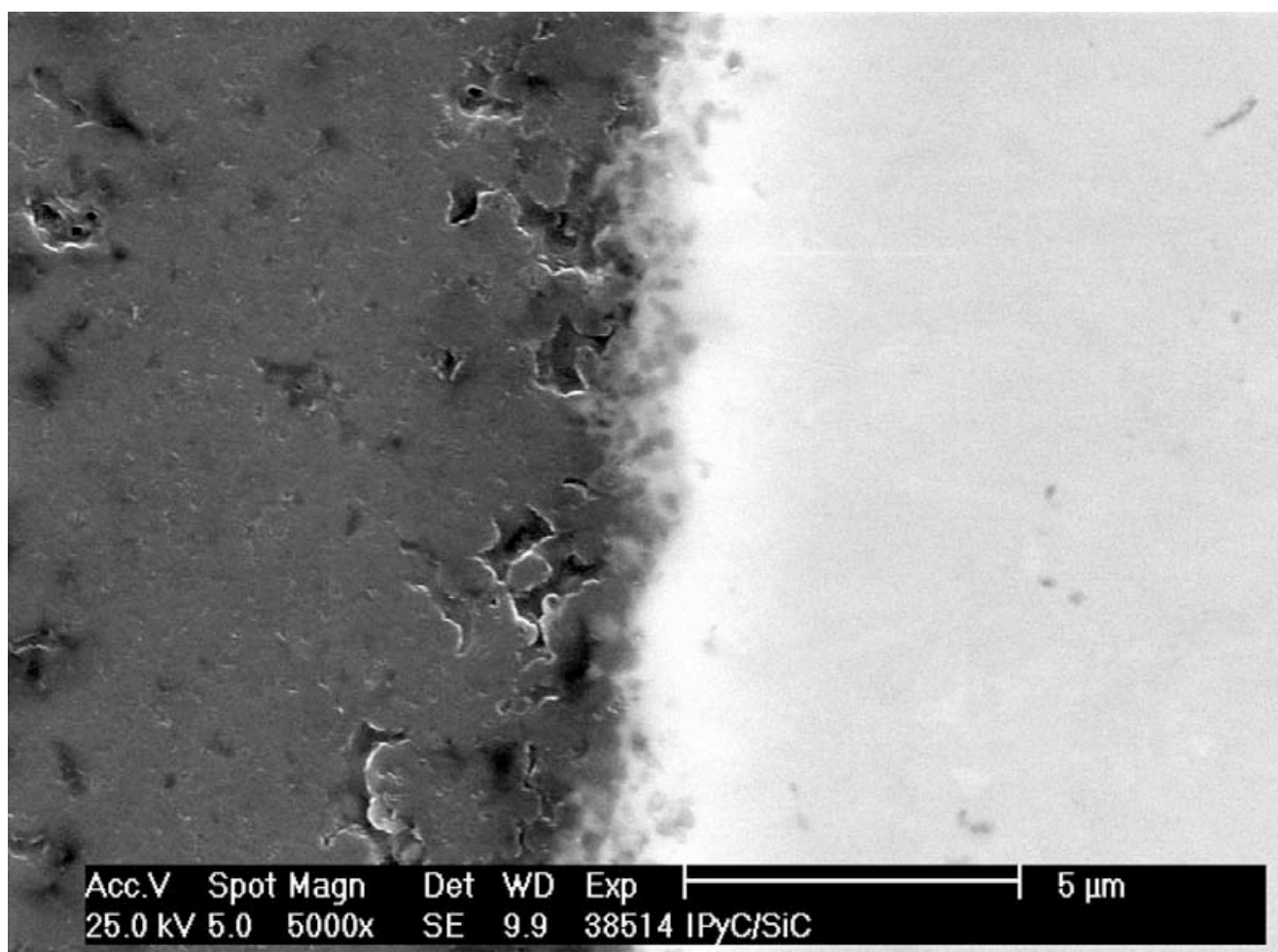

Figure 7-16: $\mathrm{IPyC} / \mathrm{SiC}$ interface (right to left)

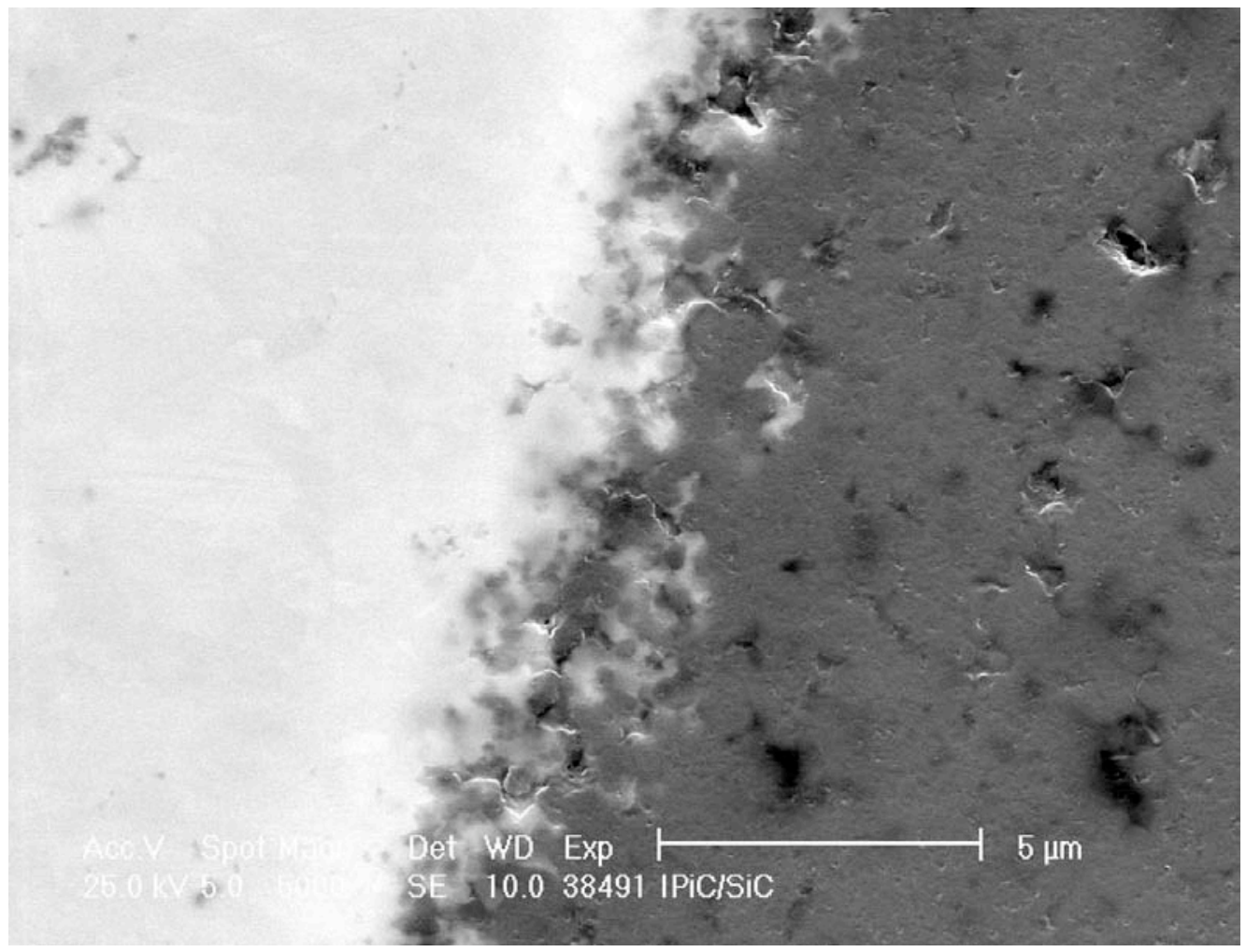

Figure 7-17: $\mathrm{IPyC} / \mathrm{SiC}$ interface (left to right) 
ORNL/CF-04/06

Revision 0

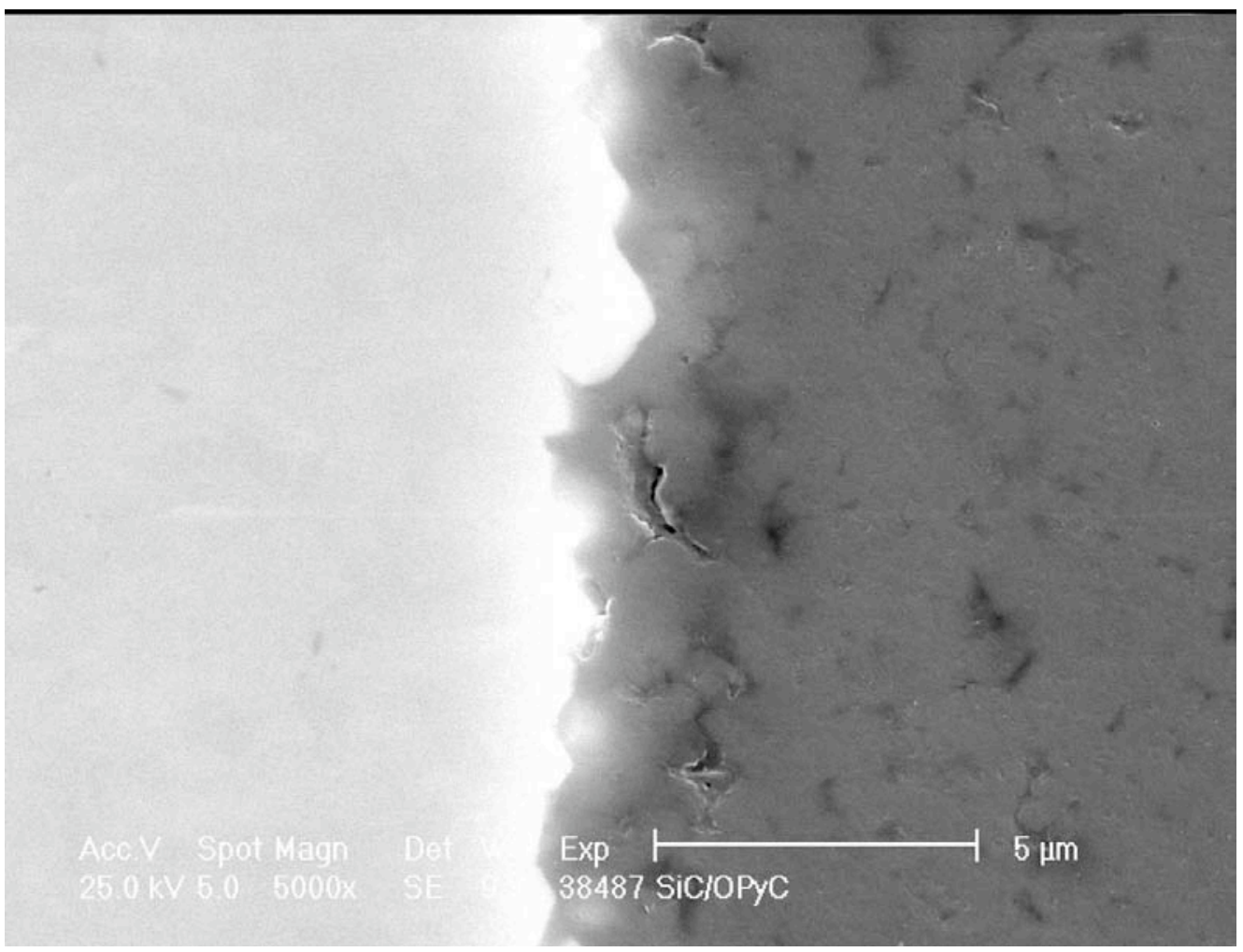

Figure 7-18: $\mathrm{SiC} / \mathrm{OPyC}$ interface (left to right)

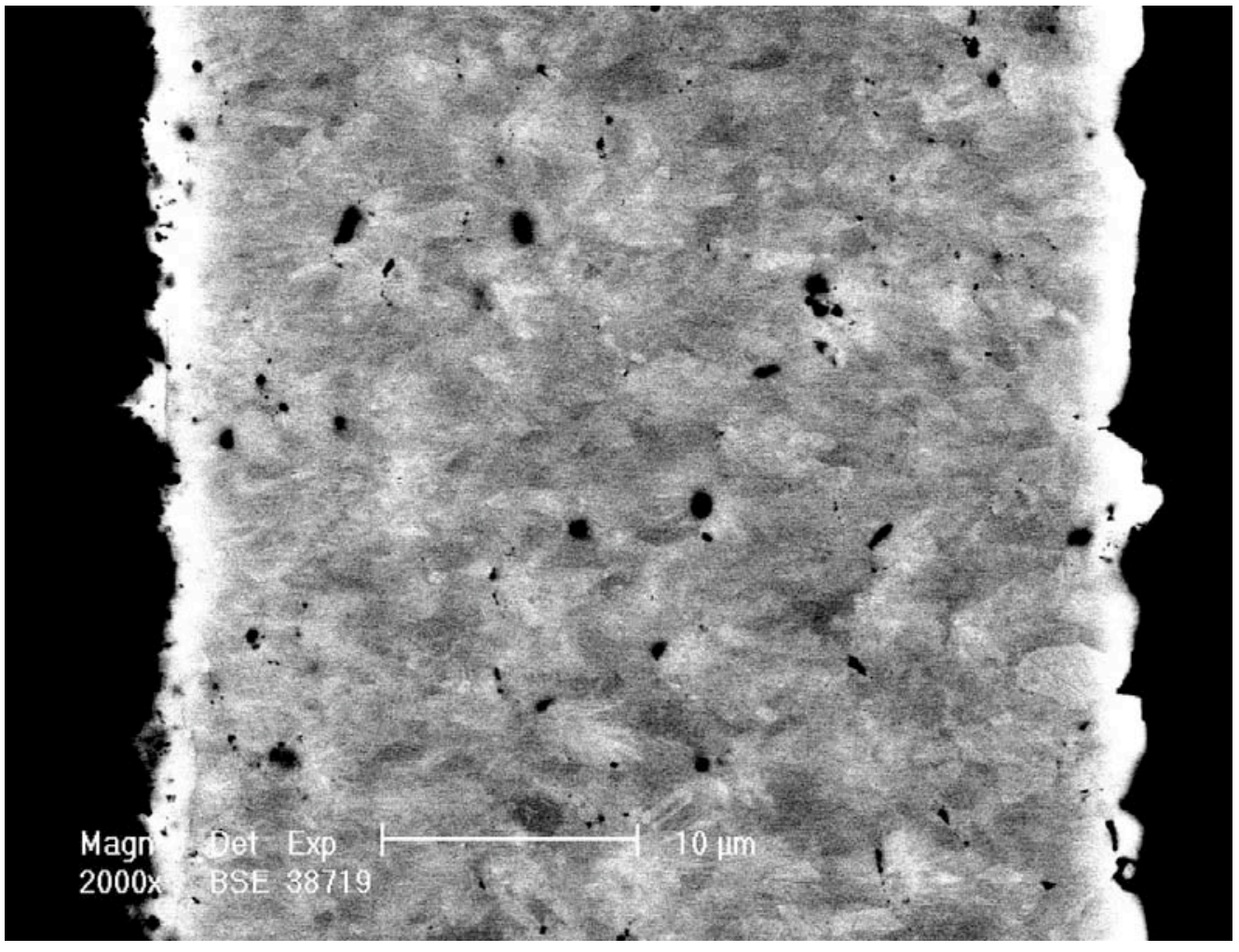

Figure 7-19: $\mathrm{SiC}$ at high contrast 
ORNL/CF-04/06

Revision 0

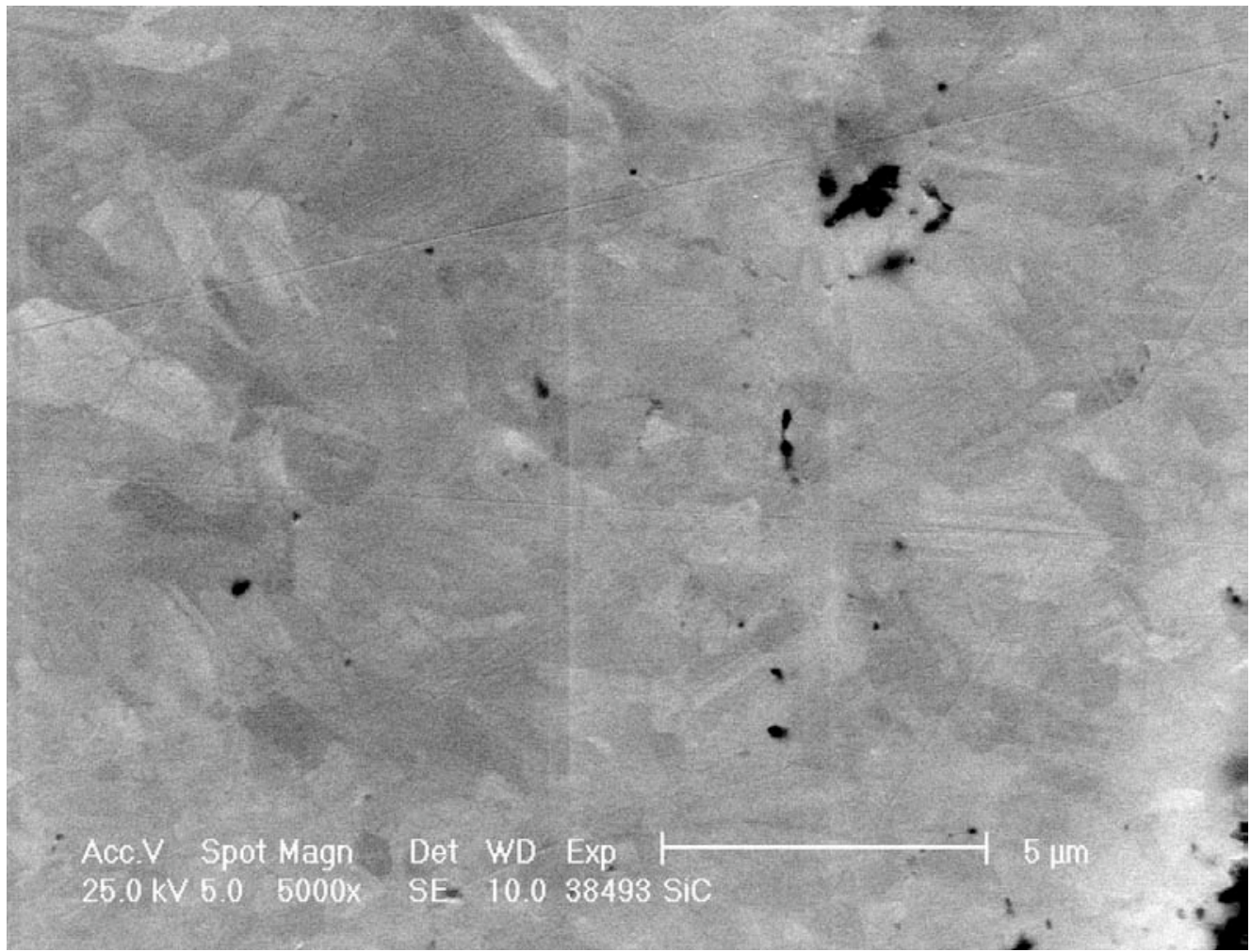

Figure 7-20: $\mathrm{SiC}$ at high contrast 


\section{Summary and Comparison to HOBEG and GA Data}

GA document \#910852 “Acceptance Test report for German Fuel Particles" contains characterization information pertaining to the EUO 2358-2365 composite. This data was obtained from HOBEG by GA or generated by GA. GA reported that some of the material they received had residual overcoating debris. ORNL was told by John Saurwein (GA) that the particles ORNL received came from can \#2 in the reference and do not include this debris. A coarse visual inspection of the particles confirmed that the GA observed debris was not obviously present.

Table 8-1 provides a summary of the ORNL data versus the GA and HOBEG data extracted from the report. All the values are in reasonable agreement but there was still some difference outside of the stochastic error of the measurements. The methods used to measure size and thickness were different for the three labs. GA used x-radiography and HOBEG used a particle size analyzer. It should be noted that the data available in the table only gives the mean values with a confidence interval calculated from the standard deviation. The experimental uncertainties in the measurements may not have been taken into account. In many cases, the experimental uncertainty in a measurement, which includes sources of systematic error, may be greater than the standard deviation in the data. In these cases, it is possible to calculate a $95 \%$ confidence statistical interval that is narrower than the uncertainty interval of the measurement. The small differences in diameter and thickness measurements in the table are most likely within the uncertainties of the various measurements.

It is not surprising that a difference was seen in the measurement of anisotropy. The 2MGEM uses a dramatically different method to measure the crystallographic anisotropy than the optical polarimeter technique used by GA and HOBEG. The 2-MGEM measures the entire Mueller matrix which fully describes the polarization effects on light reflected from the specimen surface. The measurement method used by GA and HOBEG, based on an optical polarimeter system, only measured a single element in this $4 \times 4$ matrix. The optical polarimeter technique was also very sensitive to the loss of light due to scattered reflections from the specimen surface. In contrast, loss of light due to non-specular reflection does not introduce systematic error into the 2-MGEM measurement. The GA report also mentioned a round-robin study done to compare GA and HOBEG results which identified the presence of a systematic discrepancy in measurements produced by the two facilities. In spite of the presence of systematic errors, it is worthy to note that the relative value of the diattenuation of the IPyC versus the OPyC for the three separate measurements is nearly the same. This suggests that, although all the measurements may not be accurate, they all appear to be measuring the same physical parameter to at least first order. 
ORNL/CF-04/06

Revision 0

Table 8-1: GA and HOBEG data from GA\#910852

\begin{tabular}{|c|c|c|c|c|c|c|}
\hline Property & \multicolumn{2}{|c|}{ ORNL } & \multicolumn{2}{c|}{ HOBEG } & \multicolumn{2}{c|}{ GA } \\
\hline & Mean & $95 \%$ Conf & Mean & 95\% Conf & Mean & $95 \%$ Conf \\
\hline Particle diameter $(\mu \mathrm{m})$ & 922 & $920-924$ & 915 & ND & 926.8 & $923.5-930.1$ \\
\hline Av. Particle sphericity $(\mu \mathrm{m})$ & 1.09 & & & & & \\
\hline Kernel diameter $(\mu \mathrm{m})$ & 506 & $504-508$ & 508 & ND & 510.3 & $508.9-511.7$ \\
\hline Av. Kernel sphericity $(\mu \mathrm{m})$ & 1.05 & & & & & \\
\hline Buffer thickness $(\mu \mathrm{m})$ & 94 & $92-96$ & & & & \\
\hline Buffer/IPyC thickness $(\mu \mathrm{m})$ & 133 & $130-136$ & 141 & $137-145$ & 130.6 & $129.0-132.2$ \\
\hline IPyC thickness $(\mu \mathrm{m})$ & 39 & $38-40$ & & & & 37.8 \\
\hline SiC thickness $(\mu \mathrm{m})$ & 34 & $33-35$ & 36 & $35-37$ & $37.2-38.4$ \\
\hline OPyC thickness $(\mu \mathrm{m})$ & 36 & $35-37$ & 38 & 37.39 & 37.9 & $36.4-39.4$ \\
\hline SiC density $(\mathrm{g} / \mathrm{cc})$ & 3.201 & $3.200-3.202$ & 3.2 & ND & 3.206 & $3.203-3.209$ \\
\hline OPyC density $(\mathrm{g} / \mathrm{cc})$ & 1.8 & N.D. & 1.92 & ND & 1.926 & $1.920-1.932$ \\
\hline Particle density $(\mathrm{g} / \mathrm{cc})$ & 3.5 & N.D. & 3.46 & ND & 3.42 & $3.41-3.44$ \\
\hline IPyC BAFo & $1.028 \pm .004$ & ND & 1.04 & ND & 1.061 & $1.057-1.065$ \\
\hline OPyC BAFo & $1.016 \pm .002$ & ND & 1.02 & ND & 1.033 & $1.030-1.036$ \\
\hline SiC defect fraction & ND & ND & $7.00 \mathrm{E}-06$ & ND & $6.00 \mathrm{E}-06$ & ND \\
\hline
\end{tabular}

$\mathrm{ND}=$ Not Determined 
ORNL/CF-04/06

Revision 0

\section{Appendix A: 2-MGEM Data Report}

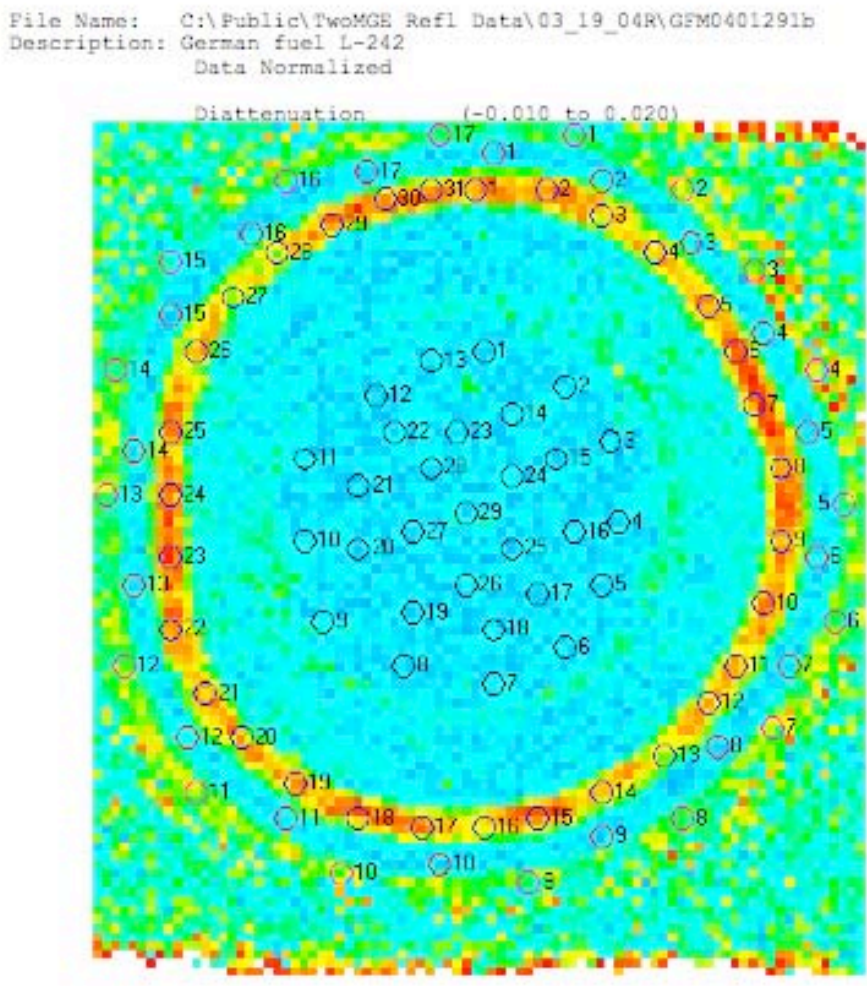

$\begin{array}{ll}\text { Date: } & 4 / 1 / 2004 \\ \text { Tire: } & 4: 21: 03 \mathrm{FN}\end{array}$

Selected Data

\begin{tabular}{|c|c|c|c|c|c|c|c|c|c|c|}
\hline$\xi$ & $\begin{array}{l}\text { Pi } \\
i\end{array}$ & $\operatorname{cel}$ & \multicolumn{2}{|c|}{ Position } & $\begin{array}{l}\text { Diattenuation } \\
\text { (N) }\end{array}$ & $\begin{array}{l}\text { Retardation } \\
\text { (rad) }\end{array}$ & \multirow[t]{2}{*}{$\begin{array}{l}\text { Fast Mxis } \\
\text { Angle }\left({ }^{\circ}\right)\end{array}$} & $\begin{array}{l}\text { Circular } \\
\text { Diattn }\end{array}$ & \multicolumn{2}{|c|}{ Polar. Intensity } \\
\hline \multicolumn{10}{|c|}{ Saved list } & \\
\hline 5 & 45 & 92 & 0.44 & 0.91 & $0.0014 \pm 0.0028$ & $-0.0007 \pm 0.0037$ & $-87.7 \pm 55.9$ & $0.0013 \pm 0.0023$ & 1.0024 & 3.5796 \\
\hline 2 & 57 & 89 & 0.56 & 0.88 & $0.0023 \pm 0.0025$ & $-0.0028 \div 0.0040$ & $-44,1 \pm 40,7$ & $0.0004 \pm 0.0015$ & 1.0012 & 3,4334 \\
\hline & 67 & 32 & 0.66 & 0.81 & $0.0036 \pm 0.0022$ & 0.001520 .0033 & -30.3420 .3 & -0.000720 .0021 & 1.0033 & 3.5942 \\
\hline 4 & 75 & 72 & 0.74 & 0,71 & $0,0012 \pm 0.0029$ & $0.0031+0.0047$ & $-47,0 \pm 73,6$ & $=0.0006 \pm 0.0017$ & 1.0048 & 3.1637 \\
\hline & 30 & 61 & 0.79 & 0.60 & $0.0014 \pm 0.0023$ & $-0.0047 \pm 0.0043$ & $-47.4 \pm 56.3$ & $0.0000 \pm 0.0024$ & 0.9941 & 3.7263 \\
\hline & 81 & 47 & 0.80 & 0,46 & $0.0016 \pm 0.0030$ & $0.0013 \pm 0.0033$ & $3,6 \pm 44,0$ & $0.0007 \pm 0.0021$ & 0,9807 & 3.8283 \\
\hline & 78 & 35 & 0.77 & 0.34 & 0.001010 .0027 & $-0.0012 \pm 0.0044$ & 18.0276 .0 & $-0.0008 \pm 0.0025$ & 0.9994 & 2.2559 \\
\hline 8 & 70 & 26 & 0.69 & 0.25 & $0.0010 \pm 0.0027$ & -0.002540 .0043 & 57.1480 .7 & 0.001840 .0018 & 0.9572 & \\
\hline & 57 & 16 & 0.56 & 0.15 & .0 & $0.0070 \pm 0.0043$ & $31.6 \pm 29$ & $0.0019+0.08$ & & 53 \\
\hline 10 & 39 & 13 & 0.39 & 0.12 & $0.0007 \pm 0.0024$ & -0.001110 .0035 & $-47.5 \pm 160.9$ & 0.000940 .0019 & 0.9785 & 3.5910 \\
\hline 11 & 22 & 18 & 0.21 & 0.17 & $0.0015 \pm 0.0023$ & $-0.0027 \pm 0.0028$ & $-57.8 \pm 52.1$ & $0.0006 * 0.0019$ & 1.0041 & 038 \\
\hline 2 & 11 & 27 & 0.10 & 0.26 & 0.003410 .0027 & 0.002440 .0037 & $-26.4 \pm 21$. & $0.0007 \pm 0.0019$ & 0.9 & 67 \\
\hline 13 & 5 & 44 & 0.04 & 0.43 & $0.0009 \pm 0.0023$ & $=0.0017 \pm 0.0033$ & $5.2 \pm 67,3$ & $0.0010 \pm 0.0024$ & 0.9986 & 4,3024 \\
\hline 14 & 5 & 59 & 0.04 & 0.58 & $0.0007 \pm 0.0031$ & $-0.0004 \pm 0.0031$ & $-19,8 \pm 133,9$ & $0.0003 \pm 0.0027$ & 0.9881 & 4.1838 \\
\hline 15 & 9 & 74 & $0.0 \mathrm{~B}$ & 0.73 & 4007 & -0.0029 & -6.9 & & & \\
\hline 16 & 16 & 83 & 0.17 & 0.82 & $.0022 \pm 0.0021$ & $0.0021 \pm 0.0036$ & $60,7 \pm 27,4$ & $0.0020 \pm 0.0019$ & 0.9929 & 3.6339 \\
\hline 7 & 31 & 90 & 0.30 & 0.89 & $0.0011 \pm 0.0027$ & 0.000920 .0043 & -75.8477 .6 & 0.001810 .0020 & 0.9900 & 975 \\
\hline \multirow{2}{*}{\multicolumn{5}{|c|}{ verage }} & $.0015 \pm 0.0009$ & -0.0002 & -17.3 & .0005 & & \\
\hline & & & & & 0.0025 & 0.0038 & 95.7 & 0.0021 & & \\
\hline \multicolumn{5}{|c|}{ ved 1 ist } & & & & & & \\
\hline 1 & 43 & 88 & 0.42 & 0.87 & $0.0133 \pm 0.00$ & $-0.0054 \div 0.0040$ & $80.4=$ & $0.0000 \pm 0.0$ & 1.0086 & 2,4749 \\
\hline & 51 & 38 & 0.50 & 0.67 & $.0143 \pm 0.00$ & -0.003640 .00 & $-73.2=6$ & -0.000120 .0 & 1. & 2. 6811 \\
\hline 3 & 57 & 85 & 0.56 & 0.84 & $0.0100 \pm 0.00$ & $=0.0002 \pm 0.00$ & $-60.4=\theta$ & $=0.0008 \pm 0.08$ & & 2.6307 \\
\hline 4 & 53 & 31 & 0.62 & 0.80 & 0.012140 .0045 & -0.003640 .0033 & $-45.8=9$ & 0.000640 .0017 & 1.0044 & 3.3392 \\
\hline 5 & 69 & 75 & 0.68 & 0.74 & $0.0131 \pm 0.0022$ & $0.0025+0.0037$ & $-32,7 \pm 6,7$ & $0.0007 \pm 0.0016$ & 1.0057 & 3,3708 \\
\hline
\end{tabular}


ORNL/CF-04/06

Revision 0

File Name: C:\Publicl TwoMGE Refl Datal03_19_04RYGrMo401291b Description: German fuel L-242
Data Normalized

5
5
6
7
8
9
10
11
12
13
14
15
16
17
16
19
20
21
22
23
24
25
26
27
28
29
30
31

\begin{tabular}{cc}
\multicolumn{2}{c}{ PixeI } \\
i & $j$ \\
72 & 70 \\
74 & 64 \\
77 & 57 \\
77 & 49 \\
75 & 42 \\
72 & 35 \\
59 & 31 \\
64 & 25 \\
57 & 21 \\
50 & 18 \\
44 & 17 \\
37 & 17 \\
30 & 16 \\
23 & 22 \\
17 & 27 \\
13 & 32 \\
9 & 39 \\
9 & 47 \\
9 & 54 \\
9 & 61 \\
12 & 70 \\
16 & 76 \\
21 & 81 \\
27 & 84 \\
33 & 87 \\
38 & 88 \\
\hline & 4
\end{tabular}

Position

। Di

(N)

$0.0163 \pm 0.0025$

$0.0141 \pm 0.0039$

$0.0129 \pm 0.0036$

$0.0153 \pm 0.0032$

$0.0138 \pm 0.0034$

$0.0143 \pm 0.0028$

$0.0085 \pm 0.0023$

$0.0130 \pm 0.0033$

$0.0149 \pm 0.0027$
$0.0105 \pm 0.0027$

$0.0163 \pm 0.0030$

$0.0123 \pm 0.0025$

0.012340 .0025
0.014910 .0040
0.015010 .0039

$0.0150 \pm 0.0039$

$0.0137 \pm 0.0033$

$0.0188 \pm 0.0051$

$0.0155 \pm 0.0045$

$0.0133 \pm 0.0035$

$0.0089 \pm 0.0026$

$0.0070 \pm 0.0035$

$0.0141 \pm 0.0029$

$0.0152 \pm 0.0023$

0.014240.002

$0,0134+0.0025$

0.0032 (rad)

0.002840 .0037

$0.0028 \pm 0.0037$

$0.0045+0.0040$

0.003440 .0042

$0.0047 \pm 0.0037$

0.002440 .003

$0.0049 \pm 0.0047$

$0.0058 \pm 0.0047$

$-0.006840 .0042$

$0.0067 \pm 0.0029$

$0.0002 \div 0.0037$

$0.0038 \div 0.003$ ?

$0.0017 \pm 0.0041$

0.002040 .0031

$0.0035+0.0048$

0.005590 .0035

$-0.004640 .0940$

$0.0022+0.0048$

$0.0091+0.0050$

$0.0076+0.0043$

$-0.0067 \pm 0.0042$

0.000840 .0043

0.0040

Saved 1ist E-- (17)

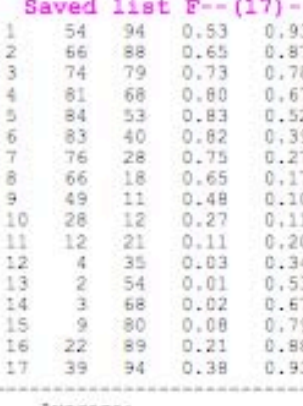

$0.0056 \pm 0.0035$

$.0110 \pm 0.0033$

0.009540 .0052

6.010370.005?

$0.0060+0.0040$

$0.0096 \pm 0.0062$

$0.0072+0.0063$

$0.0058 \pm 0.0039$

$0.0080 \pm 0.0046$

$0.0100 \pm 0.0042$

$0.0084 \pm 0.0038$

$0.0060 \pm 0.0025$

$0.0050 \pm 0.0018$

$0.0055+0.0029$

0.008710 .0039

Average:

$0.0077 \pm 0.0019$

$-0.0014 \div 0.0044$

0.006220 .0062

$0.0057 \pm 0.0200$

$2.0057 \pm 0.0100$

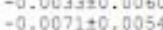

$-0.001540 .005$

$-0.0063+0.0070$

$-0.0052 \pm 0.0050$

0.004040 .0043

$-0.0047 \pm 0.0039$

$0.0046 \pm 0.0038$

$-0.0019 \pm 0.005$

$-0.000340 .0040$

0.0040

-0.000840 .0053
0.0054

Fant Nxis

Angle $\left(1^{\circ}\right)$

$-20.2 \pm 5.1$
$-23.0 \pm 6.5$

$-7.8=7.1$

$6.2 \pm 4,4$

$19 \cdot 5 \pm 6.6$

$25,9 \geq 7$,

$50,1+11,5$

$60.1 \pm 8.2$

$81.8 \div 7.0$

$88,1+10.1$

$-80.4 \pm 5.7$

$-75.0=6.1$

$-53.4 \leq 6$.

$-33,4=8.8$

$-19.4 \pm 6.7$

$-1.2 \pm 4.9$
$-10.3 \pm 6$

$12,3 \pm 6,5$

$30,3 \geq 7,3$

$40.0 \pm 10.2$

70.545 .9

$76.2+5,9$

$89,1 \leq 7.7$

6. $3+53,1$

7.3

Date: $4 / 1 / 2004$

Tite: 4:21:03 FM

Circular Polar. Intensity

Diattr Factor (Rrb. Unita)

$\begin{array}{lll}0.0007 \pm 0.0023 & 0.9837 & 3.2376 \\ 0.001240 .0029 & 1.0051 & 2.5323\end{array}$

$0.0006 \pm 0.0019 \quad 0.9949 \quad 3.535$

$\begin{array}{lll}0.0015 \pm 0.0018 & 0.9945 & 3.1268\end{array}$

$\begin{array}{lll}0.001020 .0023 & 0.9937 & 2.9257\end{array}$

$0.00000+0.0020 \quad 1.0005 \quad 3.4673$

$\begin{array}{lll}0.0019510 .0032 & 0.9953 & 3.2739\end{array}$

$0.001120 .0022 \quad 0.9973 \quad 3.1157$

$\begin{array}{lll}0.001100 .0022 & 0.9973 & 3.1157 \\ 0.00090 .0026 & 0.9983 & 2.9519\end{array}$

$0.0010620 .0023 \quad 0.9963 \quad 2.979$

$0.001240 .0021 \quad 0.9959522 .013$

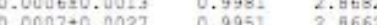

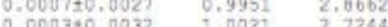

0.004320 .0032

0.000320 .0022

$0.0005+0.0026$

0.001210 .4028

$0.0004+0.002$

0.000440 .0021

$0.0006+0.0020$

0.000540 .0021

0.000440 .0019

$0,0005+0,0009$

1.0021

$0.9929 \quad 2.5666$

$\begin{array}{ll}1.0082 & 2.4525 \\ 0.9876 & 2.5797\end{array}$

$\begin{array}{ll}1.0082 & 2.4525 \\ 0.9045 & 2.5797\end{array}$

2.2463
0.0028
0.9090

$\begin{array}{ll}1.0041 & 2.1864 \\ 0.9890 & 2.2710\end{array}$

$0.9979 \quad 2.2710$

0.1648
1.0047

$1.0007 \quad 2.3701$

$0.9909 \quad 2.651$

1.0017 2.6118

0.0023

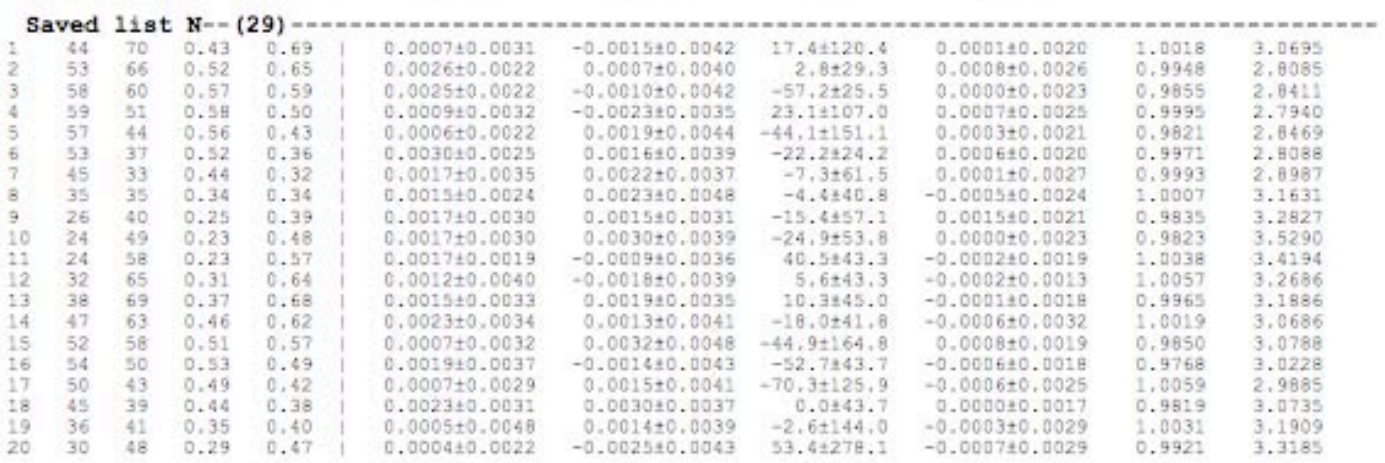


ORNL/CF-04/06

Revision 0

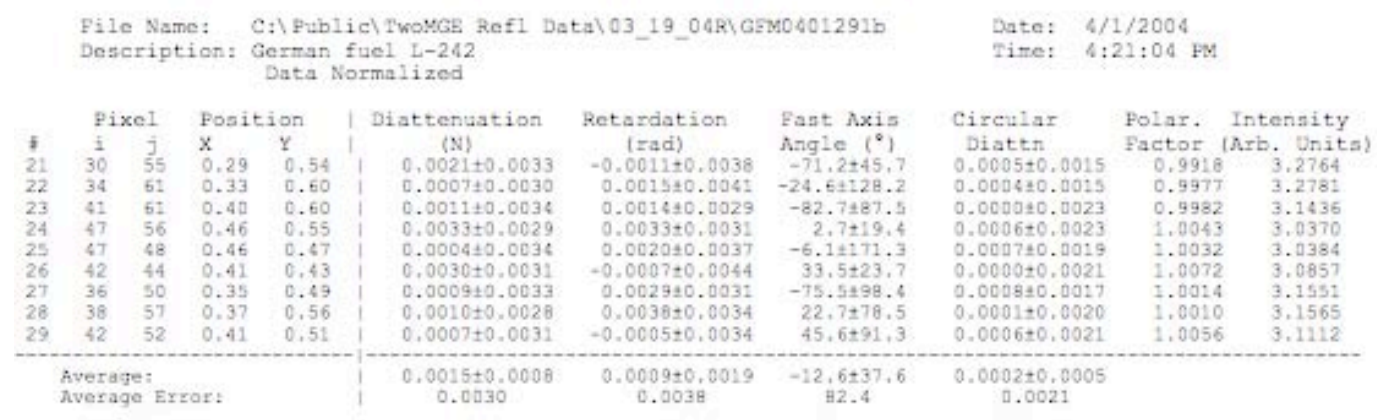




\section{ADVANCED GAS REACTOR PROGRAM OAK RIDGE NATIONAL LABORATORY}

\section{ORNL DOCUMENT CLEARANCE I REGISTRATION FORM}

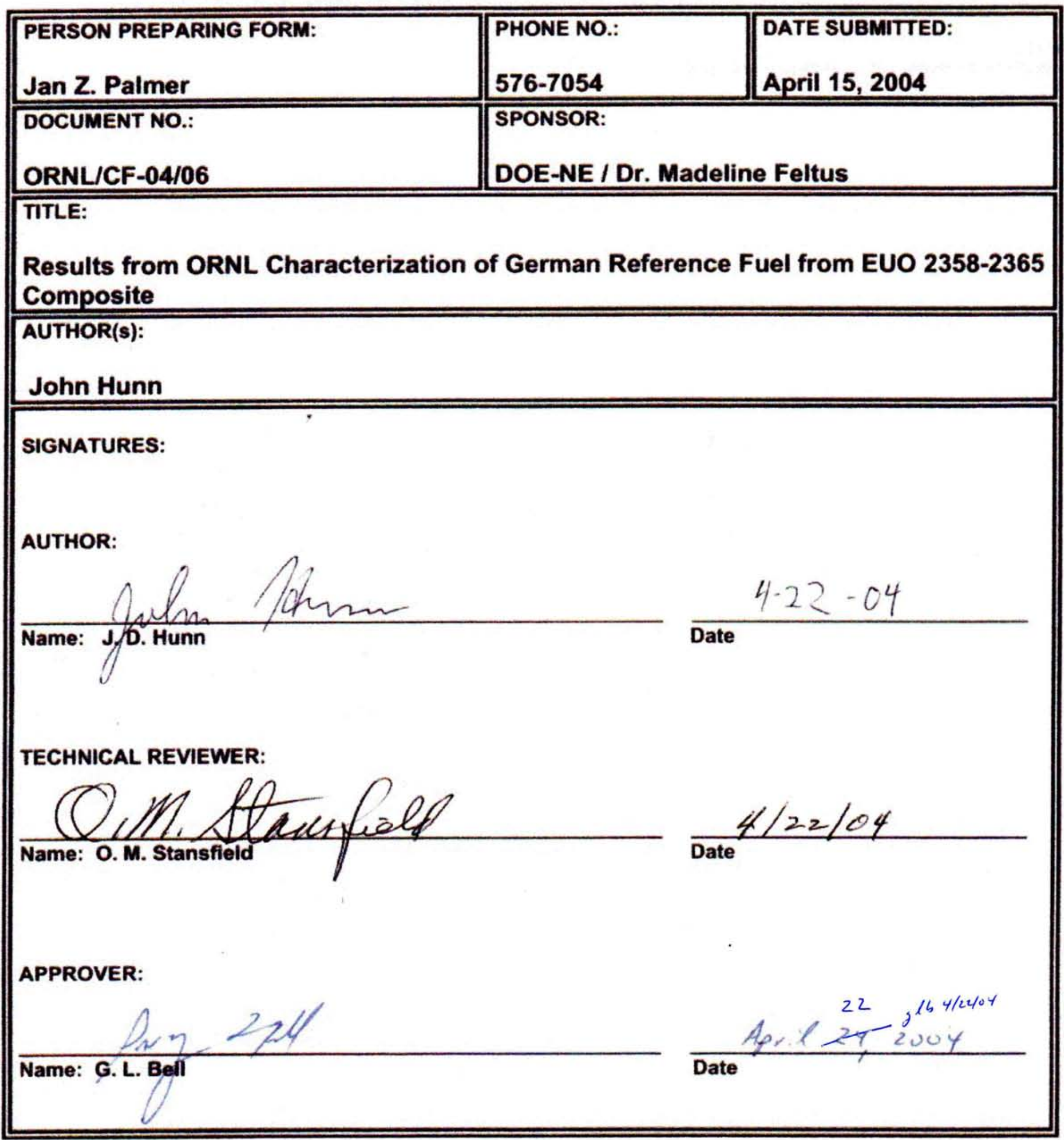

